NUREG/CR-6442

INEL-95/0654

NEA/CSNI/R(95) 9

\title{
Evidence of Aging Effects on Certain Safety-Related Components
}

Prepared by

H. L. Magleby, C. L. Atwood, P. E. MacDonald,

J. L. Edson, D. L. Bramwell

Idaho National Engineering Laboratory

Lockheed Idaho Technologies Company

0908898

OSTI

Prepared for

U.S. Nuclear Regulatory Commission 


\section{AVAILABILITY NOTICE}

Availability of Reference Materials Cited in NRC Publications

Most documents cited in NRC publications will be avallable from one of the following sources:

1. The NRC Public Document Room, 2120 L Street, NW., Lower Level, Washington, DC 20555-0001

2. The Superintendent of Documents, U.S. Government Printing Office, P. O. Box 37082 , Washington. DC 20402-9328

3. The National Technical Information Service, Springfield, VA 22161-0002

Although the llsting that follows represents the majority of documents cited in NRC publications, it is not intended to be exhaustive.

Referenced documents available for inspection and copying for a fee from the NRC Public Document Room include NRC correspondence and internal NRC memoranda; NRC bulletins, circulars, information notices, inspection and investigation notices; licensee event reports; vendor reports and correspondence; Commission papers; and applicant and licensee documents and correspondence.

The following documents in the NUREG series are available for purchase from the Government Printing Office: formal NRC staff and contractor reports, NRC-sponsored conference proceedings, international agreement reports, grantee reports, and NRC booklets and brochures. Also available are regulatory guldes, NRC regulations In the Code of Federal Regulations, and Nuclear Regulatory Commission Issuances.

Documents avallable from the National Technical Information Service include NUREG-series reports and technical reports prepared by other Federal agencies and reports prepared by the Atomic Energy Commission, forerunner agency to the Nuclear Regulatory Commission.

Documents available from public and special technical libraries include all open literature items, such as books. journal articles, and transactions. Federal Register notices. Federal and State legislation, and congressional reports can usually be obtained from these libraries.

Documents such as theses, dissertations, foreign reports and translations, and non-NRC conference proceedings are available for purchase from the organization sponsoring the publication cited.

Single copies of NRC draft reports are available free, to the extent of supply, upon written request to the Office of Administration, DIstribution and Mail Services Section, U.S. Nuclear Regulatory Commission, Washington, DC 20555-0001.

Coples of industry codes and standards used in a substantive manner in the NRC regulatory process are maintained at the NRC Library. Two White Flint North, 11545 Rockville Pike, Rockville, MD 20852-2738, for use by the public. Codes and standards are usually copyrighted and may be purchased from the originating organizatlon or, if they are American National Standards, from the American National Standards Institute, 1430 Broadway, New York, NY 10018-3308.

\section{DISCLAIMER NOTICE}

This report was prepared as an account of work sponsored by an agency of the United States Government. Neither the United States Government norany agency thereof, nor any of their employees, makes any warranty, expressed or implied, or assumes any legal liability or responsibility for any third party's use, or the results of such use, of any information, apparatus, product, or process disclosed in this report, or represents that its use by such third party would not infringe privately owned rights. 
NUREG/CR-6442

INEL-95/0654

NEA/CSNI/R(95) 9

\section{Evidence of Aging Effects on Certain Safety-Related Components}

Manuscript Completed: January 1996

Date Published: January 1996

Prepared by

H. L. Magleby, C. L. Atwood, P. E. MacDonald,

J. L. Edson, D. L. Bramwell

Idaho National Engineering Laboratory

Lockheed Idaho Technologies Company

Idaho Falls, ID 84315

Prepared for

Safety Programs Division

Office for Analysis and Evaluation of Operational Data

U.S. Nuclear Regulatory Commission

Washington, DC 20555-0001

NRC Job Code E8238 


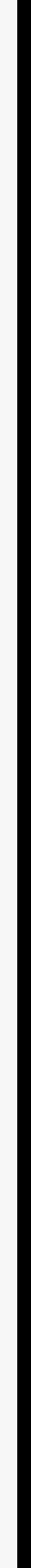




\begin{abstract}
In response to interest shown by the Nuclear Energy Agency (NEA), Principal Working Group 1 (PWG-1) of the Committee on the Safety of Nuclear Installations (CSNI) conducted a generic study on the effects of aging of active components in nuclear power plants. (This focus on active components is consistent with PWG-1's mandate; passive components are primarily within the mandate of PWG-3.) Representatives from France, Sweden, Finland, Japan, the United States, and the United Kingdom participated in the study by submitting reports documenting aging studies performed in their countries. This report consists of summaries of those reports, along with a comparison of the various statistical analysis methods used in the studies. The studies indicate that with some exceptions, active components generally do not present a significant aging problem in nuclear power plants. Design criteria and effective preventative maintenance programs, including timely replacement of components, are effective in mitigating potential aging problems. However, aging studies (such as qualitative and statistical analyses of failure modes and maintenance data) are an important part of efforts to identify and solve potential aging problems. Solving these problems typically includes such strategies as replacing suspect components with improved components, and implementing improved maintenance programs.
\end{abstract}

Job Code: E8238—Specialized Technical Assistance 


\section{CONTENTS}

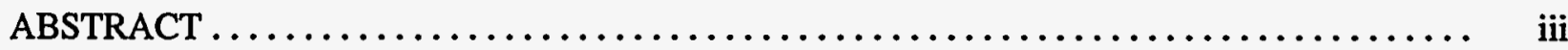

LIST OF FIGURES $\ldots \ldots \ldots \ldots \ldots \ldots \ldots \ldots \ldots \ldots \ldots \ldots \ldots \ldots \ldots \ldots \ldots \ldots \ldots$, vii

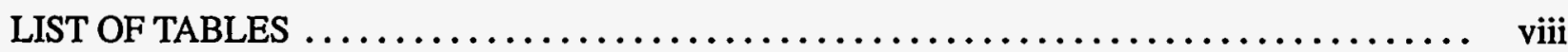

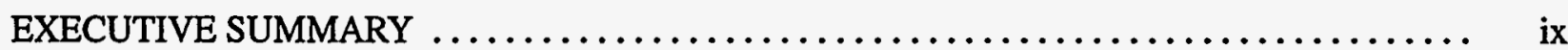

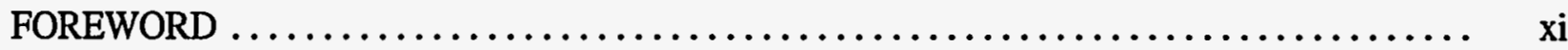

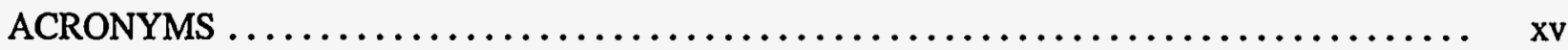

1. INTRODUCTION $\ldots \ldots \ldots \ldots \ldots \ldots \ldots \ldots \ldots \ldots \ldots \ldots \ldots \ldots \ldots \ldots \ldots \ldots \ldots, 1$

$1.1 \quad$ Progress of the Study $\ldots \ldots \ldots \ldots \ldots \ldots \ldots \ldots \ldots \ldots \ldots \ldots \ldots \ldots \ldots \ldots \ldots \ldots, 1$

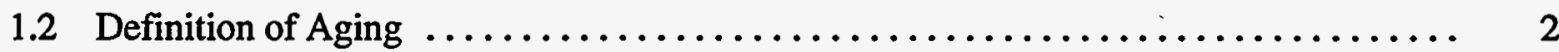

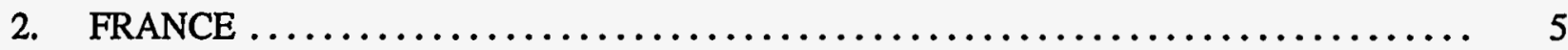

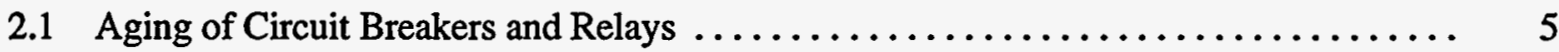

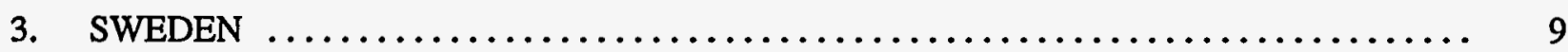

3.1 Description and Status of an Ongoing Aging Study $\ldots \ldots \ldots \ldots \ldots \ldots \ldots \ldots . \quad 9$

3.2 Development of a Trendmodel for Aging Analysis .................... 10

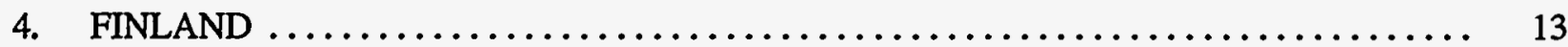

4.1 Experience Based Reliability Centered Maintenance $\ldots \ldots \ldots \ldots \ldots \ldots \ldots \ldots .13$

4.2 Probabilistic Methods in Nuclear Power Plant Component Ageing Analysis ......... 14

4.3 Analysis of Failure and Maintenance Experiences of Motor Operated Valves in a

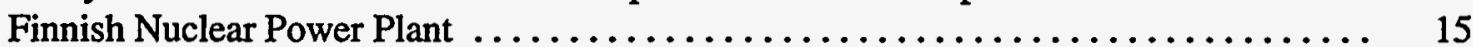

4.4 Probabilistic Safety and Aging Assessment of Structural Components $\ldots \ldots \ldots \ldots \ldots 19$

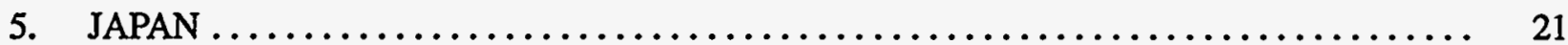

$5.1 \quad$ Evaluation of Aging Events $\ldots \ldots \ldots \ldots \ldots \ldots \ldots \ldots \ldots \ldots \ldots \ldots \ldots, 21$

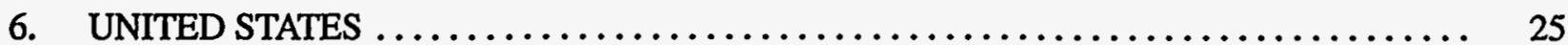

6.1 Performance Measures for Aging of Nuclear Power Plants $\ldots \ldots \ldots \ldots \ldots \ldots \ldots .26$

6.2 Evaluation of High Pressure Coolant Injection (HPC) System Performance ....... 29

6.3 A Reliability Study of Safety-Related Steam-Turbine-Driven Pumps $\ldots \ldots \ldots \ldots \ldots .33$ 


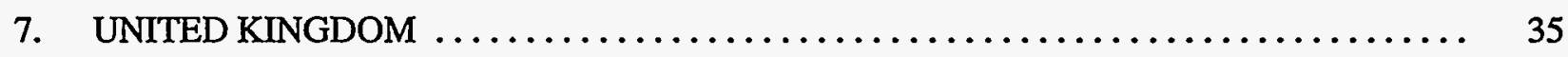

7.1 Review of Aging Studies $\ldots \ldots \ldots \ldots \ldots \ldots \ldots \ldots \ldots \ldots \ldots \ldots \ldots \ldots \ldots \ldots \ldots \ldots \ldots \ldots \ldots$

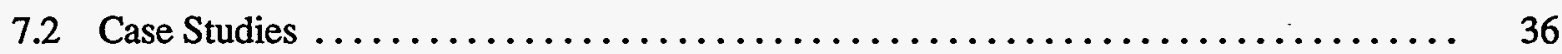

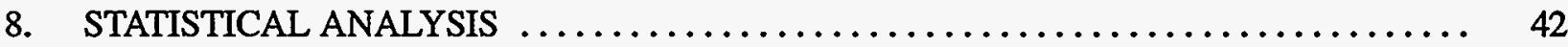

8.1 Examination of Failure Causes $\ldots \ldots \ldots \ldots \ldots \ldots \ldots \ldots \ldots \ldots \ldots \ldots \ldots \ldots \ldots \ldots \ldots \ldots \ldots$

8.2 Direct Estimates from Binned Failure Data $\ldots \ldots \ldots \ldots \ldots \ldots \ldots \ldots \ldots \ldots \ldots \ldots \ldots \ldots \ldots \ldots$

8.3 Modeling Trends in Failure Rates or Probabilities $\ldots \ldots \ldots \ldots \ldots \ldots \ldots \ldots \ldots$

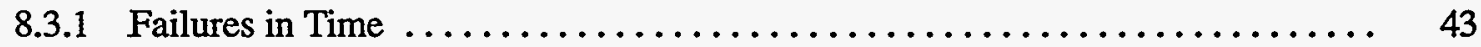

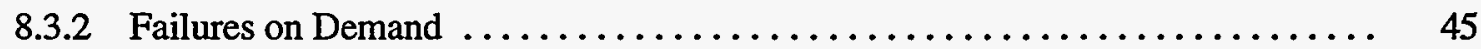

8.4 Passive Components ..................................... 45

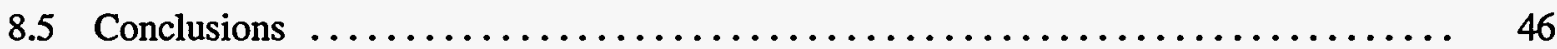

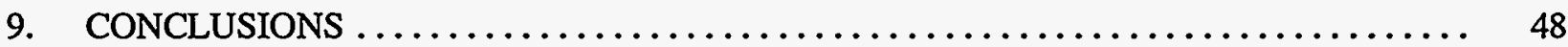

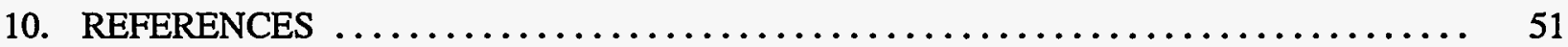

11. OTHER DOCUMENTS MENTIONED $\ldots \ldots \ldots \ldots \ldots \ldots \ldots \ldots \ldots \ldots \ldots \ldots \ldots \ldots$

ADDENDUM 1: A Critique of the Generic Study of PWG1 - June $1995 \ldots \ldots \ldots \ldots \ldots \ldots$ A-1 


\section{LIST OF FIGURES}

1-1. Classic bathtub curve, showing a high initial failure rate, a low, constant failure rate in mid-life, and an increasing failure rate late in life as the components age $\ldots \ldots \ldots \ldots \ldots$

1-2. Three sets of failure occurrence times, giving evidence for decreasing, increasing,

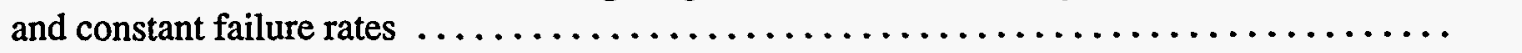

2-1. Failure history of $6.6-\mathrm{kV}$ breakers for Bugey plant $\ldots \ldots \ldots \ldots \ldots \ldots \ldots \ldots \ldots \ldots$

2-2. Failure rates of $6.6-\mathrm{kV}$ breakers at the Bugey site $\ldots \ldots \ldots \ldots \ldots \ldots \ldots \ldots \ldots \ldots$

3-1. Results of trend analysis for failures of centrifugal pumps in containment spray system

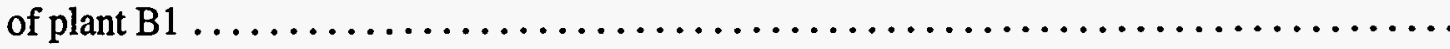

3-2. Results of trend analysis for spurious stops of centrifugal pumps in containment spray

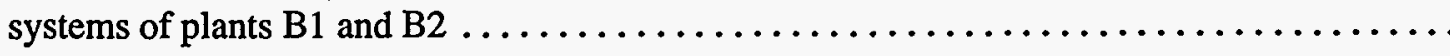

4-1. Failure trend of electromechanical subcomponents (TVO I and TVO 2) $\ldots \ldots \ldots \ldots$

4-2. Observed number of internal leakages and predicted distribution of number of failures in TVO I and TVO 2 MOVs

4-3. Cumulative probability distributions of MOV unavailability times caused by repairs during plant operating period

4-4. A proposed model for optimization of residual operation time and inspection strategies of a gradually failing structure (Pulkkinen 1994$) \ldots \ldots \ldots \ldots \ldots \ldots \ldots \ldots \ldots \ldots \ldots \ldots \ldots \ldots \ldots$

5-1. Summary of failure modes for failures caused by aging

5-2. Percent of events for each component $\ldots \ldots \ldots \ldots \ldots \ldots \ldots \ldots \ldots \ldots \ldots \ldots \ldots \ldots \ldots \ldots \ldots$

5-3. Percent of events for each failure mode $\ldots \ldots \ldots \ldots \ldots \ldots \ldots \ldots \ldots \ldots \ldots \ldots \ldots \ldots \ldots$

$5-4$. Number of events due to aging by fiscal year $\ldots \ldots \ldots \ldots \ldots \ldots \ldots \ldots \ldots \ldots \ldots \ldots \ldots$

5-5. Number of events caused by aging versus years of operation $\ldots \ldots \ldots \ldots \ldots \ldots \ldots \ldots$

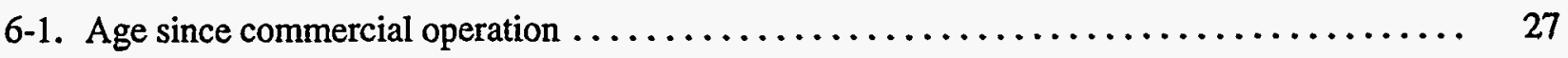

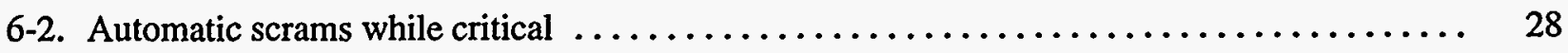

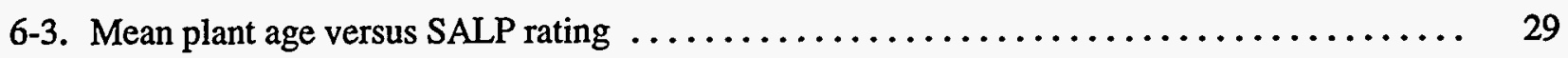

6-4. Plots of plant-specific HPCI system unreliabilities and failures per operating year plotted against plant-specific low power license date. (Failures per year are all failures divided by the equivalent operating years for the plant $) \ldots \ldots \ldots \ldots \ldots \ldots \ldots \ldots \ldots \ldots$

6-5. HPCI system unplanned demand rate, failure rate, and unreliability, per calendar year ..... 32

7-1. Failure rates for AGR and Magnox valves 
7-2. Trend charts for safety circuit data (monthly event rate)

8-1. Fitted trend lines for the failure probability and simultaneous confidence bands on the fitted lines at the two Finnish plants

\section{LIST OF TABLES}

7-1. Summary of findings in studies surveyed . 


\section{EXECUTIVE SUMMARY}

Principal Working Group Number 1 (PWG-1) of the Nuclear Energy Agency's Committee on the Safety of Nuclear Installations (CSNI) decided in 1993 to do a generic study on aging effects in nuclear power plants: As is the usual practice, representatives from several countries participated, on a voluntary basis. These were France, Sweden, Finland, Japan, the United States, and the United Kingdom. The U.S. representative volunteered to coordinate the work.

The participants from each country provided information on aging effects for different portions of nuclear power plants. The scope of the work does not include the materials under the domain of PWG-3, which addresses the reactor vessel and the primary system. In general, the studies are limited to active components in nuclear power plants. Some of the studies address a single component group (for example, motor-operated valves). Some of the individual studies address several components, and other studies address aging in general as it affects plant reliability. Taken altogether, the studies provided by the participating countries do not constitute a comprehensive examination of aging of active components; instead, they constitute a collection of representative examples of studies conducted in the respective countries.

The general theory of aging of active components is discussed in this report. It includes three regimes: (a) early failures, (b) relatively constant failure rate, (c) increasing failure rate over time. One of the objectives of the PWG-1 effort is to determine if there is evidence that components are in the third regime, with increasing failures with the passing of time. Information relative to each regime follows.

Early failures. A UK study found that static contactors in control rod and control and interlock systems showed a tendency for early failures.

Constant failure rate. A Swedish study of containment spray pumps showed a decreasing trend or, in some instances, no particular trend, in the failure rate. A Finnish study of motor-operated valves showed decreasing or constant trends for most subcomponents and failure modes, including those failure modes that were at least partly aging related. (An exception was the annual number of internal leakages, which showed an increasing trend.) U.S. studies of the high-pressure coolant injection system and of turbine-driven pumps showed no increase in failure rate, indicating no aging effect. A UK study examining one plant's corrective maintenance records of safety circuits showed a constant trend.

In addition, the Japanese study, a comprehensive study of many components at all the Japanese plants, indicated no aging effects. Similarly, a U.S. study using overall plant performance as a measure of aging effects found that where trends were evident, they showed improvement with age.

Increasing failure rate with time. The individual contributions were analyzed for age-related increases in the failure parameters. Using standard statistical techniques, it was seen that for some active components, age effects can be inferred. The French study found that $6.6-\mathrm{kV}$ circuit breakers at one of the subject sites (the Bugey site) showed an increasing failure rate until repairs were made to the subcomponents that had degraded after several years of service. After the repairs, the failure rate returned to the earlier low value. These circuit breakers were all of a particular manufacturer. Circuit breakers at other sites and of other manufacture showed a constant failure rate. Also, relays at the Bugey site showed a fivefold increase in the failure rate in ten years. Relays at other sites showed no increase with time.

In addition, a UK study of valve failure data for two plants showed a possible correlation between age and failure rate, but it was not possible, from the available data, to establish a quantitative relationship for predicting the failure rate with age.

Conclusion. This report demonstrates a tentative consensus that with some individual excep- 
tions, active components generally do not present an aging problem in nuclear power plants where the maintenance and modification strategies are effective. A summary of UK studies concluded that no major phenomena of degradation due to aging have been observed at the UK nuclear power plants studied, and that degradation phenomena, when present, are of a minor nature and do not appear to affect the reliability performance of plant systems. The Japanese study concluded that their preventative maintenance programs are effective in mitigating potential aging problems, resulting in a lower failure rate at older plants than at newer plants. A U.S. study of overall plant per- formance found no deleterious age effect; the study concluded that maintenance strategies are effective in managing the effects of aging and that design and licensing criteria produce an inherently rugged plant.

In addition to the summaries of the studies submitted by the participating countries, this report includes an examination and comparison of analysis methods. Statistical analysis of failure and maintenance data is an important part of efforts to identify potential aging problems and to focus maintenance activities to mitigate those problems. 


\section{FOREWORD}

This report, as presently published by the U.S. Nuclear Regulatory Commission (NRC), was originally published in September 1995 by the Committee on the Safety of Nuclear Installations (CSNI). The report was the product of an international effort consisting of a generic study performed by CSNI's Principal Working Group 1 (PWG-1). Representatives from several countries participated in the study by submitting reports on some of the aging studies being conducted in their respective countries. In accordance with the mandate of PWG-1, the study focused mostly on the effects of aging on active components in nuclear power plants. (Passive components are primarily within the mandate of PWG-3.) The CSNI's parent organization is the Nuclear Energy Agency (NEA) of the Organisation for Economic Co-operation and Development (OECD). A description of the missions of the CSNI, the NEA, and the OECD is presented later in this foreword.

The original CSNI report was published under the same title, Evidence of Aging Effects on Certain Safety-Related Components, with the report number NEA/CSNI/R(95) 9. The original report consists of two volumes. Volume 1 presents a summary of the 17 reports submitted by the six participating countries and includes a comparison of the various analysis methods used. Volume 2, consisting of three books (Volumes 2A, 2B, and $2 C)$, contains the full text of the 17 reports.

Some of the reports submitted for publication in Volume 2 were proprietary reports. For this reason, Volume 2 was published as a restricted foreign proprietary report. However the participants in the working group (PWG-1) agreed to publish Volume 1 as a public report. This NRC report is a republication of Volume 1. Except for differences in format, a few changes in the handling of references, and a few minor editorial changes, this NRC report is identical to Volume 1 of the original CSNI report.

The opinions expressed and the arguments employed in this document are the responsibility of the authors and do not necessarily represent those of the NRC or the OECD. Information regarding copies of the original CSNI report may be requested from:

Nuclear Safety Division

OECD Nuclear Energy Agency

Le Seine St-Germain

12 bd. des Iles

92130 Issy-les-Moulineaux

France

The copyright to the original CSNI report is held by the OECD (OOECD 1995). This NRC republication of the CSNI report is authorized by written permission from OECD. Applications for permission to reproduce or translate all or part of this publication should be made to:

Head of Publications Service, OECD

2, rue André-Pascal,

75775 PARIS CEDEX 16, France

The following discussion presents descriptions of the CSNI, the NEA, and the OECD. These descriptions are derived mostly from CSNI publications.

The Committee on the Safety of Nuclear Installations (CSNI) of the OECD Nuclear Energy Agency (NEA) is an international committee made up of senior scientists and engineers. It was set up in 1973 to develop, and co-ordinate the activities of the Nuclear Energy Agency concerning the technical aspects of the design, construction and operation of nuclear installations insofar as they affect the safety of such installations. The Committee's purpose is to foster international co-operation in nuclear safety among the OECD Member countries.

The CSNI constitutes a forum for the exchange of technical information and for collaboration between organizations which can contribute, from their respective backgrounds in research, development, engineering or regulation, to these activities and to the definition of the program of 
work. It also reviews the state of knowledge on selected topics on nuclear safety technology and safety assessment, including operating experience. It initiates and conducts program identified by these reviews and assessments in order to overcome discrepancies, develop improvements and reach international consensus on technical issues of common interest. It promotes the co-ordination of work in different Member countries including the establishment of co-operative research projects and assists in the feedback of the results to participating organizations. Full use is also made of traditional methods of co-operation, such as information exchanges, establishment of working groups, and organization of conferences and specialist meetings.

The greater part of the CSNI's current program is concerned with the technology of water reactors. The principal areas covered are operating experience and the human factor, reactor coolant system behavior, various aspects of reactor component integrity, the phenomenology of radioactive releases in reactor accidents and their confinement, containment performance, risk assessment, and severe accidents. The Committee also studies the safety of the nuclear fuel cycle, conducts periodic surveys of the reactor safety research programs and operates an international mechanism for exchanging reports on safety related nuclear power plant accidents.

In implementing its program, the CSNI established co-operative mechanisms with NEA's Committee on Nuclear Regulatory Activities (CNRA), responsible for the activities of the Agency concerning the regulation, licensing and inspection of nuclear installations with regard to safety. It also cooperates with NEA's Committee on Radiation Protection and Public Health and NEA's Radioactive Waste Management Committee on matters of common interest.

The OECD Nuclear Energy Agency (NEA) was established on 1st February 1958 under the name of the OEEC European Nuclear Energy Agency. It received its present designation on 20th April 1972, when Japan became its first nonEuropean full Member. NEA membership today consists of all European Member countries of OECD as well as Australia, Canada, Japan, Republic of Korea, Mexico and the United States. The Commission of the European Communities takes part in the work of the Agency.

The primary objective of NEA is to promote co-operation among the governments of its participating countries in furthering the development of nuclear power as a safe, environmentally acceptable and economic energy source.

This is achieved by:

- Encouraging harmonization of national regulatory policies and practices, with particular reference to the safety of nuclear installations, protection of man against ionising radiation and preservation of the environment, radioactive waste management, and nuclear third party liability and insurance

- Assessing the contribution of nuclear power to the overall energy supply by keeping under review the technical and economic aspects of nuclear power growth and forecasting demand and supply for the different phases of the nuclear fuel cycle

- Developing exchanges of scientific and technical information particularly through participation in common services

- Setting up international research and development programs and joint undertakings.

In these and related tasks, NEA works in close collaboration with the International Atomic Energy Agency in Vienna, with which it has concluded a Co-operation Agreement, as well as with other international organizations in the nuclear field.

The Organisation for Economic Co-operation and Development (OECD) was originally set up as the Organisation for European Economic Cooperation (OEEC) in 1948. The OECD took its present form in 1961. 
Pursuant to Article 1 of the Convention signed in Paris on 14th December 1960, and which came into force on 30th September 1961, the OECD promotes policies designed:

- To achieve the highest sustainable economic growth and employment and a rising standard of living in Member countries, while maintaining financial stability, and thus to contribute to the development of the world economy

- To contribute to sound economic expansion in Member as well as non-member countries in the process of economic development

- To contribute to the expansion of world trade on a multilateral, non-discriminatory basis in accordance with international obligations.

The original Member countries of the OECD are Austria, Belgium, Canada, Denmark, France, Germany, Greece, Iceland, Ireland, Italy, Luxembourg, the Netherlands, Norway, Portugal, Spain, Sweden, Switzerland, Turkey, the United Kingdom and the United States. The following countries became Members subsequently through accession at the dates indicated hereafter: Japan (28th April 1964), Finland (28th January 1969), Australia (7th June 1971), New Zealand (29th May 1973) and Mexico (18th May 1994). The Commission of the European Communities takes part in the work of the OECD (Article 13 of the OECD Convention). 


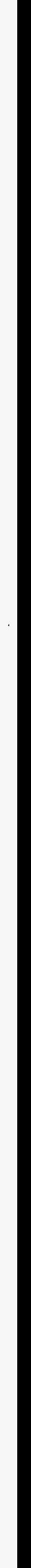




\section{ACRONYMS}

\begin{tabular}{|c|c|c|c|}
\hline $\mathrm{AEA}$ & $\begin{array}{l}\text { AEA Technology Consultancy } \\
\text { Services }\end{array}$ & MITI & $\begin{array}{l}\text { Ministry for International Trade } \\
\text { and Industry (Japan) }\end{array}$ \\
\hline AFW & auxiliary feedwater & MLE & maximum likelihood estimates \\
\hline AGR & advanced gas reactor & MOV & motor-operated valve \\
\hline ATWS & anticipated transient without scram & NDT & non-destructive testing \\
\hline BNFL & British Nuclear Fuels Ltd. (UK) & $\mathrm{NE}$ & Nuclear Electric (UK) \\
\hline BWR & boiling water reactor & NEA & Nuclear Energy Agency \\
\hline CSNI & $\begin{array}{l}\text { Committee on the Safety of } \\
\text { Nuclear Installations }\end{array}$ & NPAR & $\begin{array}{l}\text { Nuclear Plant Aging Research } \\
\text { (U.S.) }\end{array}$ \\
\hline CUSUM & cumulative sum & NPRDS & $\begin{array}{l}\text { Nuclear Plant Reliability Data } \\
\text { System (U.S.) }\end{array}$ \\
\hline DES & $\begin{array}{l}\text { Safety Assessment Department } \\
\text { (France) }\end{array}$ & NRC & $\begin{array}{l}\text { Nuclear Regulatory Commission } \\
\text { (U.S.) }\end{array}$ \\
\hline $\begin{array}{l}\text { DOE } \\
\text { EDF }\end{array}$ & $\begin{array}{l}\text { Department of Energy (U.S.) } \\
\text { Electricité de France }\end{array}$ & NUMARC & $\begin{array}{l}\text { Nuclear Management and } \\
\text { Resource Committee (U.S.) }\end{array}$ \\
\hline EPRI & $\begin{array}{l}\text { Electric Power Research Inștitute } \\
\text { (U.S.) }\end{array}$ & NUPEC & $\begin{array}{l}\text { Nuclear Power Engineering } \\
\text { Corporation (Japan) }\end{array}$ \\
\hline FMEA & failure modes and effects analysis & OECD & $\begin{array}{l}\text { Organisation for Economic } \\
\text { Co-operation and Development }\end{array}$ \\
\hline GALL & Generic Aging Lessons Learned & PRA & probabilistic risk assessment \\
\hline GNSR & $\begin{array}{l}\text { General Nuclear Safety Research } \\
\text { (UK) }\end{array}$ & PWG-1 & Principal Working Group No. 1 \\
\hline HPCI & high pressure coolant injection & PWR & pressurized water reactor \\
\hline IAEA & $\begin{array}{l}\text { International Atomic Energy } \\
\text { Agency }\end{array}$ & $\begin{array}{l}\text { PTS } \\
\text { RCIC }\end{array}$ & $\begin{array}{l}\text { pressurized thermal shock } \\
\text { reactor core isolation cooling }\end{array}$ \\
\hline IFR & increasing failure rate & $\mathrm{RCM}$ & reliability centered maintenance \\
\hline INPO & Institute for Nuclear Power & RPV & reactor pressure vessel \\
\hline IPE & $\begin{array}{l}\text { Operations } \\
\text { individual plant evaluation (U.S.) }\end{array}$ & SALP & $\begin{array}{l}\text { systematic assessment of licensee } \\
\text { performance (U.S.) }\end{array}$ \\
\hline \multirow[t]{2}{*}{ IPSN } & Institut de Protection et de Sûreté & TVO & Teollisuuden Voima Oy (Finland) \\
\hline & Nucléaire (France) & UK & United Kingdom \\
\hline LER & licensee event report (U.S.) & U.S. & United States \\
\hline MECA & $\begin{array}{l}\text { maintenance effects and criticality } \\
\text { analysis }\end{array}$ & VTT & $\begin{array}{l}\text { Technical Research Centre of } \\
\text { Finland }\end{array}$ \\
\hline
\end{tabular}





\section{Evidence of Aging Effects on Certain Safety-Related Components}

\section{INTRODUCTION}

In response to the interest shown by member countries, Principal Working Group No. 1 (PWG-1) of the Committee on the Safety of Nuclear Installations (CSNI) decided in September 1993 to conduct a generic study on the effects of component aging in nuclear power plants. In particular, there would be an analysis of the potential for failure rates to become larger as plants age. Several countries decided to participate in this study: France, Sweden, Finland, Japan, United States (U.S.), and United Kingdom (UK).

\subsection{Progress of the Study}

After some preliminary work, there was further consideration at the September 1994 meeting of PWG-1. Work products had been received from France, Finland, and Japan. Progress reports were available from the U.S., UK, and Sweden.

The group considered the schedule and determined that it would be possible to complete this project by September 1995.

Following the September 1994 meeting, a draft report was prepared. The draft report summarized the work products provided for the September 1994 meeting by the participating countries, along with additional products provided later by Sweden, the U.S., and the UK. The draft report was reviewed by PWG-1 during their April 1995 meeting, and comments were provided. Additional work products were provided by Sweden, Finland, Japan, U.S., and UK after the April 1995 meeting. The draft report was revised to incorporate the comments of the working group from their April 1995 meeting and to incorporate the additional work products that were provided. The revised report was submitted to the working group for additional review. These comments are incorporated in this report.
Work products provided by the participating countries are, in some cases, relatively brief reports written specifically for this study. In other cases, the work products are rather extensive reports of aging related studies that had been produced as part of the contributing countries' ongoing aging and maintenance research. The reports cover the full spectrum of considerations of aging effects. Some (Sweden, Finland, U.S., and UK) provided general descriptions of some of the aging related activities in their countries; some (Japan, U.S.) provided an evaluation of overall plant performance as a function of age as an indication of the effect of aging; some (U.S., UK) included evaluations of the effect of aging on the reliability of safety systems; and some (France, Sweden, Finland, Japan, U.S., UK) evaluated the effects of aging on the failure rates for specific failure modes and specific components and subcomponents.

The general descriptions of ongoing aging research should not be considered comprehensive, but should be considered as representative examples of the country's activities. However, references are provided that will lead the interested reader to more extensive descriptions of the activities.

This report, an NRC republication of Volume 1 of the original PWG-1 report (CSNI 1995a), presents summaries of the reports provided by the participating countries. The full texts of the reports provided by the participating countries were compiled in Volume 2 of the PWG-1 study (CSNI 1995b); ${ }^{\text {a Volume } 2}$ was published as a proprietary document.

a. See Section 11 of this report for bibliographic information. 


\subsection{Definition of Aging}

For the purposes of this study, it is helpful to discuss the possible meanings of the word aging and approach a working definition. The Japanese paper (Safety Information Center 1994) a provides their understanding of the definition intended for this study as "functional degradation after the passing [of a] period of time." The Finnish report (Simola 1992) provides the definition recommended by the International Atomic Energy Agency (IAEA 1990), "the continuous timedependent degradation of materials due to normal service conditions, which include normal operation and transient conditions. Postulated accidents and post-accident conditions are excluded." The definition recommended by the U.S. Electric Power Research Institute (EPRI 1992) is the "general process in which characteristics of a system, structure, or component gradually changes with time or use." This more general definition encompasses all the uses of the term aging in the documents summarized in this report, and thus may be the most appropriate for use for this study.

Associated with the definition of aging is the time of service or the amount of use to be considered in the evaluations. The appropriate time or use will be established by the evaluation being performed, the availability of the data, and the sorting capabilities. For example, if the evaluation is for the effect of aging on overall nuclear plant performance, the appropriate time might be the hours of power operation. If the evaluation is for the failure rate of a component in a standby safety system, the appropriate use may be the number of demands to start. Often records of replacements or maintenance of components are not available, or capabilities to sort the data are not available to obtain the most appropriate time or use. In these cases, valuable insights of performance can still be obtained by using substitute times or uses. For example, the age of a component might be taken as the time since first power operation without regard for replacement or repair. In the summaries provided in this report, the times or uses used in the evaluations were reported if they could be determined from the documents provided.

The term failure is used frequently in the reports provided by the participating countries. However, it is usually used without an explanation of what is considered a failure. Often the term failure is used to describe a condition that leads to a maintenance activity (for example, a leaking seal), or a case where a component did not meet a surveillance requirement, rather than the failure of the component to perform its intended safety function. Some studies use the term event rather than failure, and we have attempted to make that distinction in our summaries.

In principle, if no preventive maintenance or repair occurred, the failure rate over time would follow the classic bathtub curve, shown in Figure 1-1. The bathtub curve describes three stages in the failure rate. The high failure rate early in life is due mostly to manufacturing defects and installation errors. The term infant mortality is sometimes used to describe these early failures. This is followed by the second stage, a period of time during which the failure rate is low and the failures random. This, in turn, is followed by an increasing failure rate in the third stage, as the equipment ages and begins to wear out. An increasing failure rate indicates that the population of components may be getting near its end of life. A goal of maintenance is to prevent this third stage from occurring. Aging studies based on failure occurrences examine the failure modes and failure times for evidence that the failure rate for a given failure mode is increasing or high, indicating that the population of components is in the third stage.

An increasing failure rate may have aging as a major contributing cause. Failure data give evidence of an increasing failure rate if the failures occur more frequently at the end of the study period than at the beginning. Figure 1-2, adapted from Ascher and Feingold (1984), demonstrates this concept by showing the times of failures for three hypothetical data sets. In the first case (with the happy face), the failures occur less frequently late 


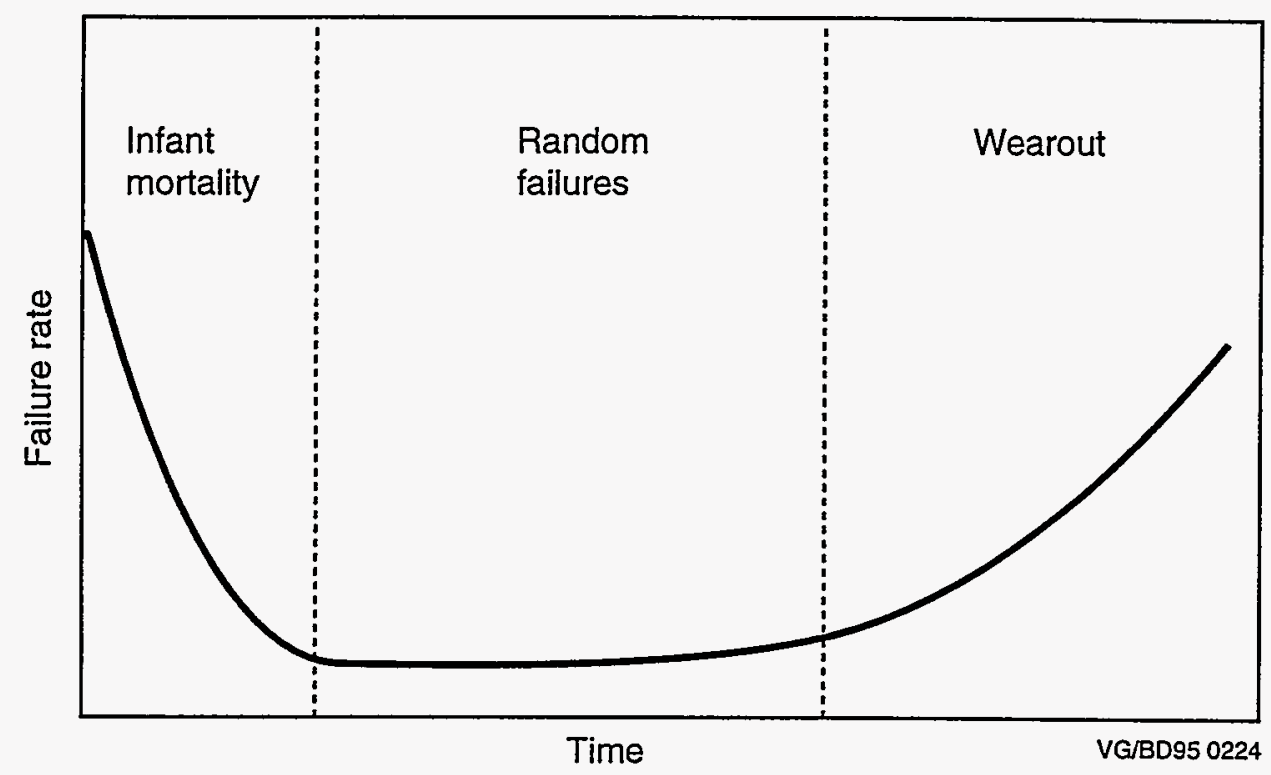

Figure 1-1. Classic bathtub curve, showing a high initial failure rate, a low, constant failure rate in midlife, and an increasing failure rate late in life as the components age.
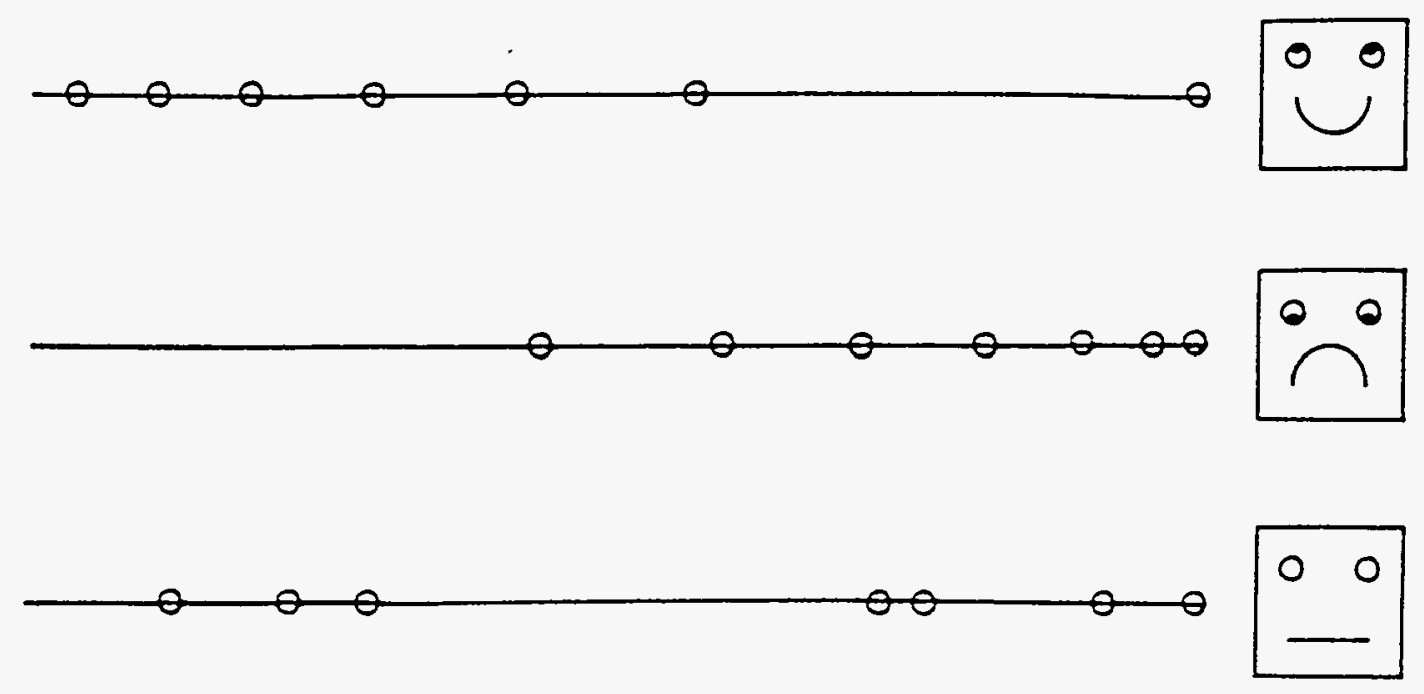

Figure 1-2. Three sets of failure occurrence times, giving evidence for decreasing, increasing, and constant failure rates. 
than early, indicating an improving system and a decreasingfailure rate. In the second case (with the sad face), the situation is reversed, indicating an increasing failure rate, possibly as a result of aging. The third case (with the neutral face) shows evidence of an apparently constant failure rate. A constant failure rate may or may not be associated with component aging, depending on whether the rate is high or low. A simple test for the presence of a trend in the failure rate, based on whether the failures tend to occur early or late, is the Laplace test, explained in Section 8 of this report.
The following sections of this report consist of summaries of the reports submitted by the participating countries, in the following order: France, Sweden, Finland, Japan, the United States, and the United Kingdom. Section 8 presents an evaluation and comparison of the various statistical analysis methods used in the studies. Section 9 presents conclusions. Section 10 lists references, and Section 11 lists other relevant documents.

Addendum 1 presents a critique of this PWG-1 study. The critique was prepared by a consultant for the Nuclear Energy Agency (NEA). 


\section{FRANCE}

The French contribution to this aging study focused on observation of failure rates of certain electrical equipment to determine if the failure rates increased with time, indicating aging. The components investigated were circuit breakers and relays. France provided a preliminary report describing their study. The report included extensive appendixes of the failure data. The following discussion summarizes their report and presents an example of the data.

\subsection{Aging of Circuit Breakers and Relays}

The French study concerning $6.6 \mathrm{kV}$ circuit breakers and electrical relays is reported in a preliminary report, IPSN/DES/SEREP, Study of the Ageing of EDF Equipment: The Cases of The $6.6 \mathrm{kV}$ Circuit Breakers and The Electrical Relays, (Maupou 1994). a The study included performance of the equipment over the time period 1977-1993.

The focus of the study was to determine, through analysis of failure data, whether there is evidence that aging is occurring in $6.6-\mathrm{kV}$ circuit breakers and electrical relays. The study assumes that failure rates of circuit breakers and relays should follow the traditional "bath-tub" curve (see Figure 1-1). This term is used to describe the behavior where a high failure rate early in life is followed by a relative long period of nearly constant low failure rate, then an increase in the failure rate later in life, as the equipment wears out. The relatively high failure rate early in life is assumed to have occurred before the beginning of commercial operation and, therefore, the study focuses on observations to determine if the failure rate is increasing later in life, indicating aging. The approach of this study is to focus on the evaluation of failures rather than making an initial assessment or analysis of aging, including the

a. See Section 11 of this report for bibliographic information. identification of aging causes, mechanisms, and effects.

Circuit breakers have been the subject of numerous incidents reported in several documents identified in the French report. For the study performed, the data used was that available to the Safety Assessment Department (DES) and included: the DES file of incidents significant for safety, the events of safety implications from the Electricité de France (EDF) file, an EDF memorandum, and two DES reports with specific information on the circuit breakers. From the reports, a total of 144 failures were identified for the $6.6-\mathrm{kV}$ circuit breakers, of which only 99 occurred after commercial operation began. In the case of the electrical relays, there was a total of 178 failures, 147 of which occurred after commercial operation began. The number of failures is relatively small, since the total number of circuit breakers is approximately 1674 and the number of relays was assumed to be 448,000 .

From the data, the estimate for the average failure parameter lambda was given by:

$\lambda=$ (failure count in interval delta $t) /$ (population $\mathrm{x}$ delta $\mathrm{t}$ )

The analysis procedure for the relays was much the same as for the circuit breakers.

For circuit breakers, data showed the following:

- No failures occurred at four sites

- Forty-nine failures (approximately 50\%) occurred at one site (Bugey). The manufacturer of the circuit breakers at this site was different from the other sites

- The small numbers of failures at other sites precludes exact statistical analysis

- For the Bugey site, lambda varied from about $5 \times 10^{-7} \mathrm{~h}^{-1}$ to $9 \times 10^{-7} \mathrm{~h}^{-1}$ for the first eight years of operation, rising to a peak of $6 \times 10^{-6} \mathrm{~h}^{-1}$ and an average of 
$4.5 \times 10^{-6} \mathrm{~h}^{-1}$ for the period between the ninth and thirteen year, and returned to the initial eight year level after the thirteenth year. This failure history is shown in the table and histogram in Figure 2-1.

These three zones of failure rates for the breakers at the Bugey site are shown in Figure 2-2. Zone $A$ is the initial period of normally low failure rate. The beginning of Zone $B$ is the transition period from low to high failure rate. This increase of failure rate was recognized, and during the tenth and eleventh years of operation a modification of the return springs was performed. This action did not remedy the problem. The failure rate remained high, as shown by the middle portion of Zone B. During the twelfth and thirteenth years of operation, a maintenance of replacing rollers, roller shafts, and ratchets was performed. This maintenance activity did not fully remedy the problem. During the end of the thirteenth year an additional modification to the original return spring was done, and an improved maintenance program was initiated. The failure rate was lowered, as shown in Zone $\mathrm{C}$, indicating the maintenance activity was successful.

For relays, data showed the following:

- The variation in lambda was not so significant, with a weighted mean of $2.6 \times 10^{-9} \mathrm{~h}^{-1}$ for units with 1 to 5 years of service and $5.1 \times 10^{-9} \mathrm{~h}^{-1}$ for units with 6 to 10 years of service

- The Bugey site showed lambda going up by a factor of approximately 5 in the first 10 years

- More work to verify this undesirable trend is forecast by the French.

The report also states that the number of relay failures does not appear to be very large. The average failure rate for all the plants combined is $5.2 \times 10^{-9} \mathrm{~h}^{-1}$, whereas the values adopted by the Institut de Protection et de Sûreté Nucléaire (IPSN) for their probabilistic safety studies was $3 \times 10^{-7} \mathrm{~h}^{-1}$. However, the report cautions that because of the large number of relays installed, many of which do not have a critical safety function, it is possible that not all the failures were reported.

The report recommended that for future failures, more care should be taken to record information that would make more precise analysis of the failure data possible. These analyses would allow more effective improvements in the maintenance programs. The information recommended to be recorded is

- The date the equipment entered service

- Modifications, preventative maintenance, and corrective maintenance

- Identification of the component that failed

- The function of the equipment degraded by the failure of the component.

Some main conclusions reached in the French study are:

- For one site (Bugey) there was evidence of aging of $6.6-\mathrm{kV}$ circuit breakers; the problem was recognized and corrective maintenance performed. After the corrective maintenance, the failure rate returned to the average failure rate of the circuit breakers for the sites included in the study.

- For the other sites the failure rate remained low with only a random variation indicating there was no evidence of aging of $6.6-\mathrm{kV}$ circuit breakers for these sites.

- For the electrical relays at Bugey the data showed an increase in average failure rate of a factor of 5 in ten years. This variation, if confirmed, could be evidence that the relays are experiencing some aging.

- For the other sites the failure rate of the electrical relays is essentially the same order of magnitude over the entire period of the investigation; therefore, there was no evidence of aging.

- For a more precise analysis of aging in the future, the study recommended better and more detailed failure reporting, particularly for complex equipment. 


\begin{tabular}{|c|c|c|c|c|c|c|c|c|c|c|c|}
\hline \multirow[b]{2}{*}{$\begin{array}{l}\text { Years of } \\
\text { operation }\end{array}$} & \multicolumn{2}{|c|}{$\begin{array}{c}\text { Bugey } 2 \\
(03 / 1979) \\
\end{array}$} & \multicolumn{2}{|c|}{$\begin{array}{c}\text { Bugey } 3 \\
(03 / 1979)\end{array}$} & \multicolumn{2}{|c|}{$\begin{array}{c}\text { Bugey } 4 \\
(07 / 1979) \\
\end{array}$} & \multicolumn{2}{|c|}{$\begin{array}{l}\text { Bugey } 5 \\
(01 / 1980) \\
\end{array}$} & \multicolumn{3}{|c|}{ Total } \\
\hline & $\begin{array}{c}\text { Number of } \\
\text { failures }\end{array}$ & $\begin{array}{l}\text { Number of } \\
\text { components }\end{array}$ & $\begin{array}{c}\text { Number of } \\
\text { failures }\end{array}$ & $\begin{array}{l}\text { Number of } \\
\text { components }\end{array}$ & $\begin{array}{c}\text { Number o } \\
\text { failures }\end{array}$ & $\begin{array}{l}\text { Number of } \\
\text { components }\end{array}$ & $\begin{array}{l}\text { Number of } \\
\text { failures }\end{array}$ & $\begin{array}{l}\text { Number of } \\
\text { components }\end{array}$ & $\begin{array}{l}\text { Number of } \\
\text { failures }\end{array}$ & $\begin{array}{l}\text { Number of } \\
\text { components }\end{array}$ & $\begin{array}{l}\text { Component } \\
\text { failure rate } \\
\text { per hour }\end{array}$ \\
\hline 1 & 0 & 60 & 1 & 60 & 1 & 60 & 0 & 60 & 2 & 240 & $9.51 E-07$ \\
\hline 2 & 0 & 60 & 0 & 60 & 0 & 60 & 0 & 60 & 0 & 240 & $0.00 \mathrm{E}+00$ \\
\hline 3 & 0 & 60 & 0 & 60 & 1 & 60 & 0 & 60 & 1 & 240 & 4.76E-07 \\
\hline 4 & 0 & 60 & 0 & 60 & 0 & 60 & 0 & 60 & 0 & 240 & $0.00 \mathrm{E}+00$ \\
\hline 5 & 0 & 60 & 0 & 60 & 0 & 60 & 0 & 60 & 0 & 240 & $0.00 \mathrm{E}+00$ \\
\hline 6 & 0 & 60 & 0 & 60 & 0 & 60 & 1 & 60 & 1 & 240 & 4.76E-07 \\
\hline 7 & 0 & 60 & 0 & 60 & 1 & 60 & 1 & 60 & 2 & 240 & $9.51 \mathrm{E}-07$ \\
\hline 8 & 0 & 60 & 0 & 60 & 1 & 60 & 1 & 60 & 2 & 240 & 9.51E-07 \\
\hline 9 & 5 & 60 & 1 & 60 & 0 & 60 & 1 & 60 & 7 & 240 & 3.33E-06 \\
\hline 10 & 7 & 60 & 4 & 60 & 1 & 60 & 1 & 60 & 13 & 240 & $6.18 \mathrm{E}-06$ \\
\hline 11 & 0 & 60 & 2 & 60 & 5 & 60 & 1 & 60 & 8 & 240 & $3.81 \mathrm{E}-06$ \\
\hline 12 & 4 & 60 & 6 & 60 & 0 & 60 & 0 & 60 & 10 & 240 & $4.76 \mathrm{E}-06$ \\
\hline 13 & 2 & 60 & 0 & 60 & 0 & 60 & 0 & 60 & 2 & 240 & 9.541E-07 \\
\hline 14 & 0 & 60 & 1 & 60 & 0 & 60 & 0 & 0 & 1 & 180 & $6.34 \mathrm{E}-07$ \\
\hline 15 & 0 & 0 & 0 & 0 & 0 & 0 & 0 & 0 & 0 & 0 & $0.00 \mathrm{E}+00$ \\
\hline 16 & 0 & 0 & 0 & 0 & 0 & 0 & 0 & 0 & 0 & 0 & $0.00 \mathrm{E}+00$ \\
\hline 17 & 0 & 0 & 0 & 0 & 0 & 0 & 0 & 0 & 0 & 0 & $0.00 \mathrm{E}+00$ \\
\hline
\end{tabular}

Histogram of failure rates.

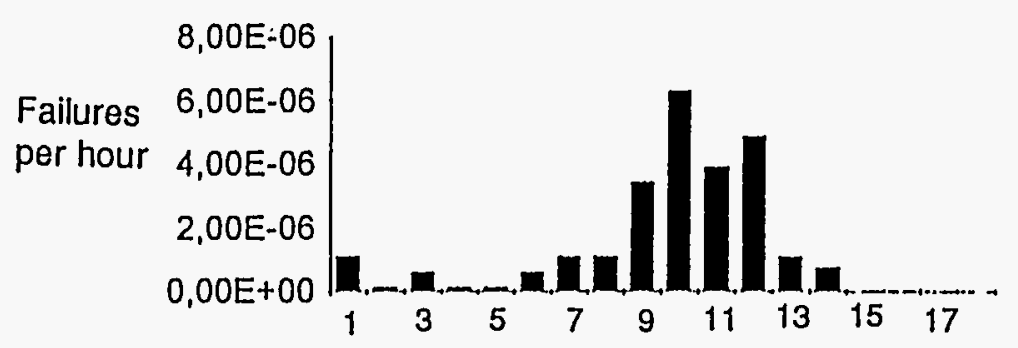

Years of operation

Figure 2-1. Failure rates of $6.6-\mathrm{kV}$ breakers for Bugey site. 


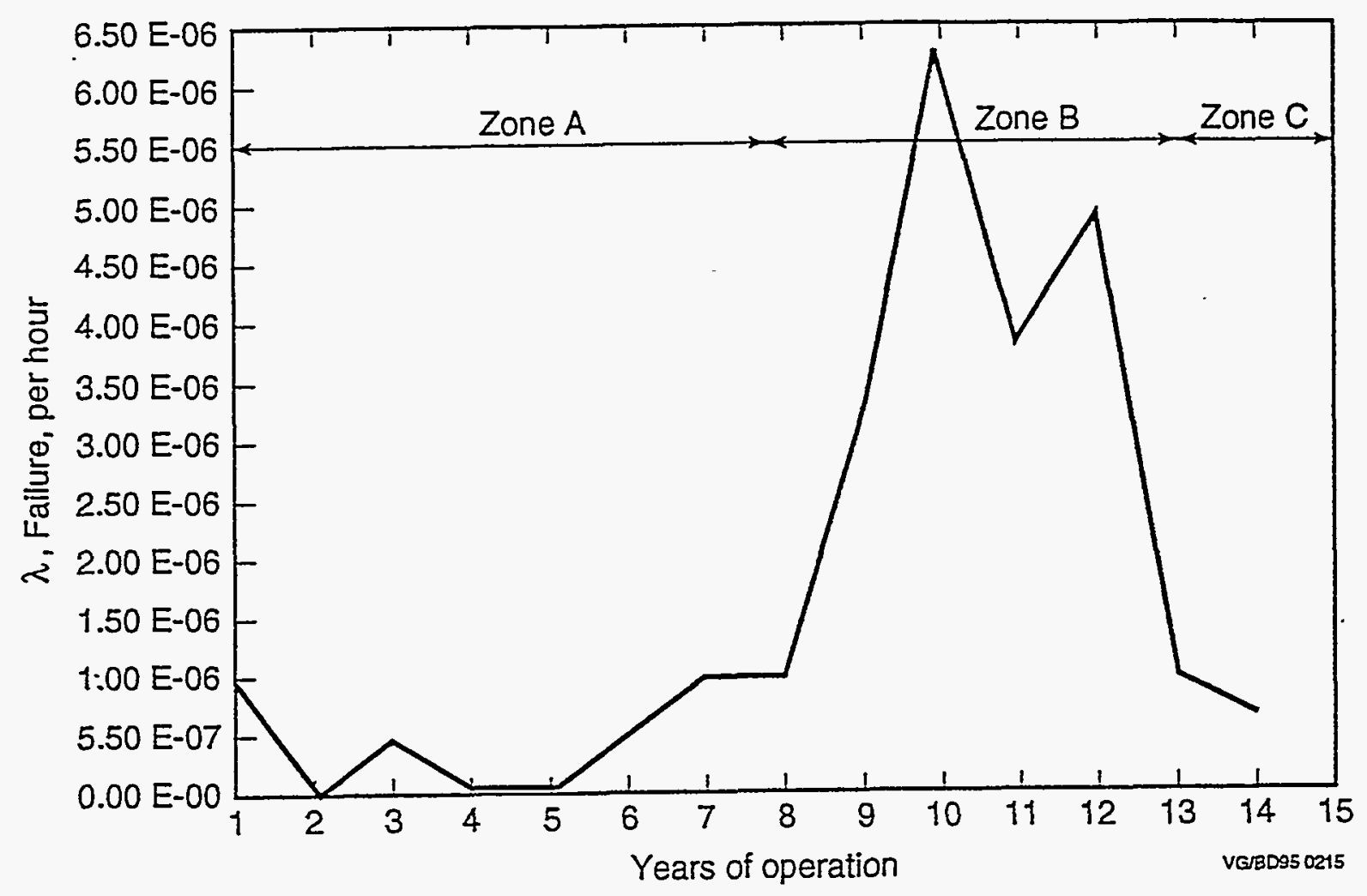

Figure 2-2. Failure history of $6.6-\mathrm{kV}$ breakers at the Bugey plant. 


\section{SWEDEN}

The Swedish contribution to this study included a description of work underway in Sweden to determine if aging of equipment is being indicated by an increase in the failure rate. They reported results of a survey of their database and results of a survey of plant maintenance personnel. They also provided a detailed description of statistical methods for analyzing failure data for aging trends, and they provided an example application for centrifugal pumps in containment spray systems. The description of this work was provided in two reports and a set of presentation slides. The following discussion is a summary of those documents.

\subsection{Description and Status of an Ongoing Aging Study}

Sweden is currently conducting a study (Shen and Nyman 1994) ${ }^{\mathrm{a}}$ whose purpose is to screen the Swedish Reliability Database to determine if increases in failure rates are occurring, which would indicate that aging and abnormal wear are present. The study, which is in an early stage, is considering only components in safety-related systems and is considering only two units that are 15 to 20 years of age, Oskarshamn 1 and Ringhals 1 . The initial steps have been completed: (a) to survey the Swedish database to identify available information relevant to aging, and (b) to use a questionnaire to obtain the opinions of maintenance personnel regarding whether aging is occurring, what components and parts are aging, and what are the causes.

The survey of the Swedish database indicated that most maintenance work was related to leaks that developed from failures of packings and seals for components such as valves, pumps, heat exchangers, etc. The responses of the mechanical maintenance personnel to the questionnaire

a. See Section 11 of this report for bibliographic information. confirmed these results. The mechanical maintenance personnel identified the causes of aging as material fatigue, load variations, warm and cold surfaces, wrong materials, manufacturing faults, and erosion.

The response of electrical maintenance personnel to the questionnaire indicated that contactors, relays, breakers, cables, transmitters, motors, generators, and condensers are affected by aging. They identified material fatigue, high temperature environment, manufacturing faults, lack of spare parts and technical support, assembling faults, and vibration as the causes of aging.

The maintenance personnel suggested better materials, design changes, improved maintenance, improved operating environment, new equipment, improved quality and trend measurements as measures to be taken to solve aging problems.

The next step of the Swedish study is to collect data for the affected components and statistically treat them by means of Bayesian trend analysis. A small test study was done on critical failures of centrifugal pumps. One of the findings of the test study was that the trend analysis tools used in the study need to be modified to consider the time between failures instead of the numbers of failures of the different age groups of the components. The Swedish researchers found it may also be necessary to include non-critical faults in the trend analyses to more clearly identify the aging phenomena. Another important step they plan is to establish routines for effectively merging and grouping age related data sources for later meaningful statistical treatment.

Numerical results were not reported and apparently are not available at this time. Also, the information provided did not tie the components to specific systems, except for a statement that only safety-related systems were considered. 


\subsection{Development of a Trendmodel for Aging Analysis}

Sweden also provided a summary of the study documented in the SKI Report 94:31. The summary, "Pilot Study - Further development of a trendmodel for aging analysis" (Pörn 1995), a briefly describes the extension of the Bayesian trend analysis model, that has been used for the computation of initiating event intensities in the Swedish I-Book, to allow trend analysis of times between events, and also of several sequences of times between events. The summary also describes the test of the modified model using data from the Swedish Reliability Data Book (T-Book) for centrifugal pumps in the containment spray system for two units. For the model, the events, such as failures, are assumed to arise from a Poisson process with nonconstant intensity (failure rate) of the form

$\lambda(t)=C \cdot \lambda_{1} \cdot t^{C-1}+\lambda_{0}$,

where $C, \lambda_{1}$, and $\lambda_{0}$ are unknown parameters. This failure rate is a generalized Weibull function, or generalized power-law function, with the generalization consisting of the addition of $\lambda_{0}$. If $0<$ $C<1$, the failure rate decreases, corresponding to fewer failures as time passes. If $C=1$ it is constant. If $C>1$, it increases, corresponding to more failures as time passes.

The Jeffreys noninformative prior distributions are found for the three parameters, and updated with the data in the usual Bayesian way, to yield the posterior joint distribution for the three parameters. The distribution for $\lambda(t)$ is then found at each time $t$.

Three applications were performed to test the model. The data from the T-Book for the three applications were:

a. See Section 11 of this report for bibliographic information.
A. All failures for centrifugal pumps in the containment spray system of Unit B1

B. All failures for centrifugal pumps in the containment spray system of Unit B2

C. Spurious stops for centrifugal pumps in the containment spray system of Units B1 and B2.

For each application, the distribution of the parameter $C$ was determined as an indication of whether the failure intensity is decreasing, remaining constant, or increasing, and the validity of the assumed functional form for $\lambda(t)$ was checked by comparing the observed cumulative frequency and fitted cumulative intensity.

For example $A$, the entire distribution of the $C$ parameter is less than 1 , indicating a decreasing trend of the failure intensity. The comparison of the observed cumulative frequency and the fitted cumulative intensity is shown in Figure 3-1. Although no formal hypothesis is mentioned, the curves appear visually to agree.

For example B, the Power Law Poisson Process seems to be a questionable model. The conformity between the observed cumulative frequency and the cumulative intensity is poor. The observed cumulative frequency seems to be a mixture of various intensities in different epochs. Such behavior cannot be described by the homogeneous Power Law Process.

For example $\mathrm{C}$, the comparison of the observed cumulative frequency and the fitted cumulative intensity is shown in Figure 3-2. The discrepancy between the two curves is evident. The authors of the summary suspect that the data are influenced by the behavior of an outlier pump. This single pump (one of 17 pumps in the group) experienced ten of the total of 19 reported failures. 


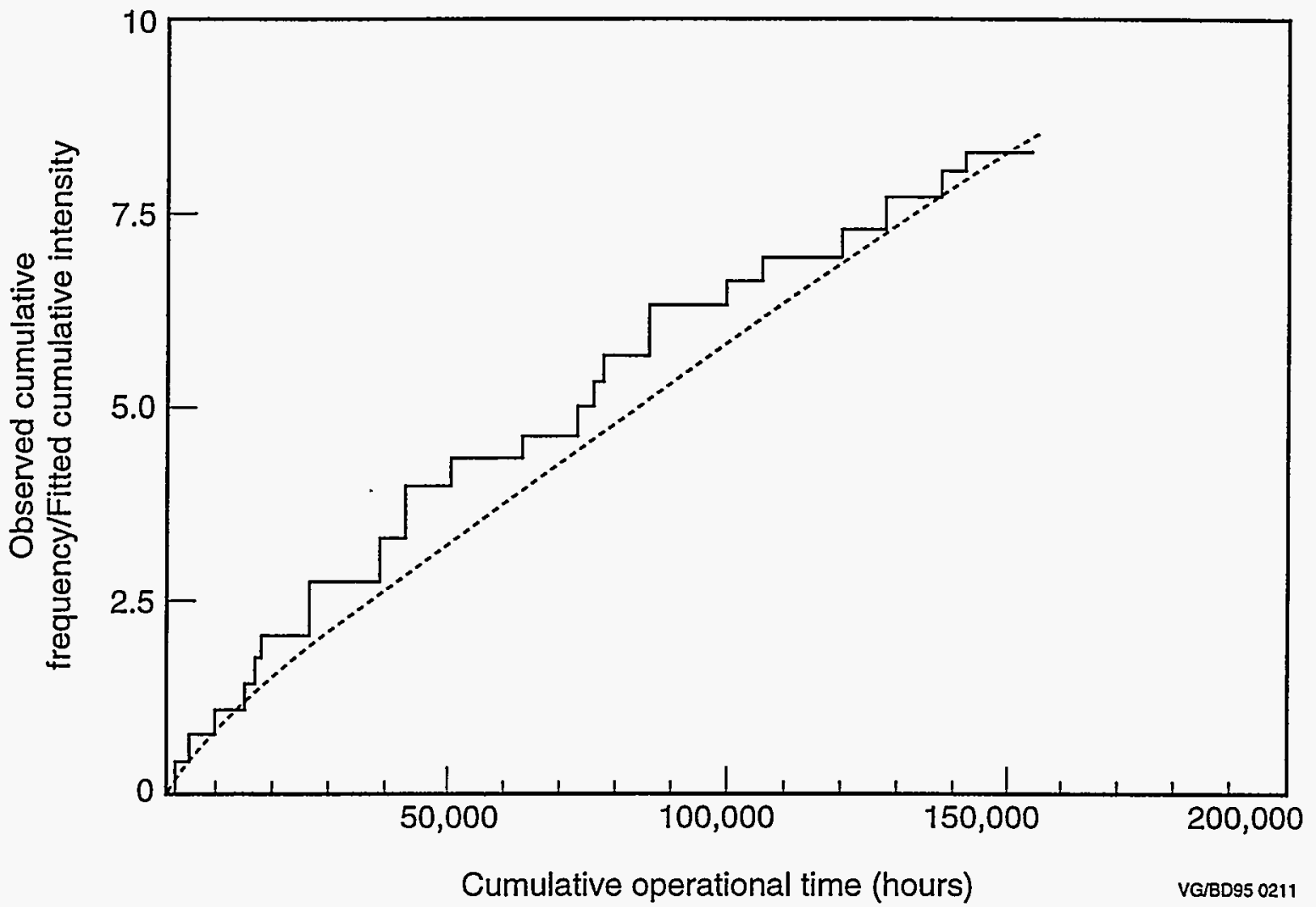

Figure 3-1. Results of trend analysis for failures of centrifugal pumps in containment spray system of plant B1.

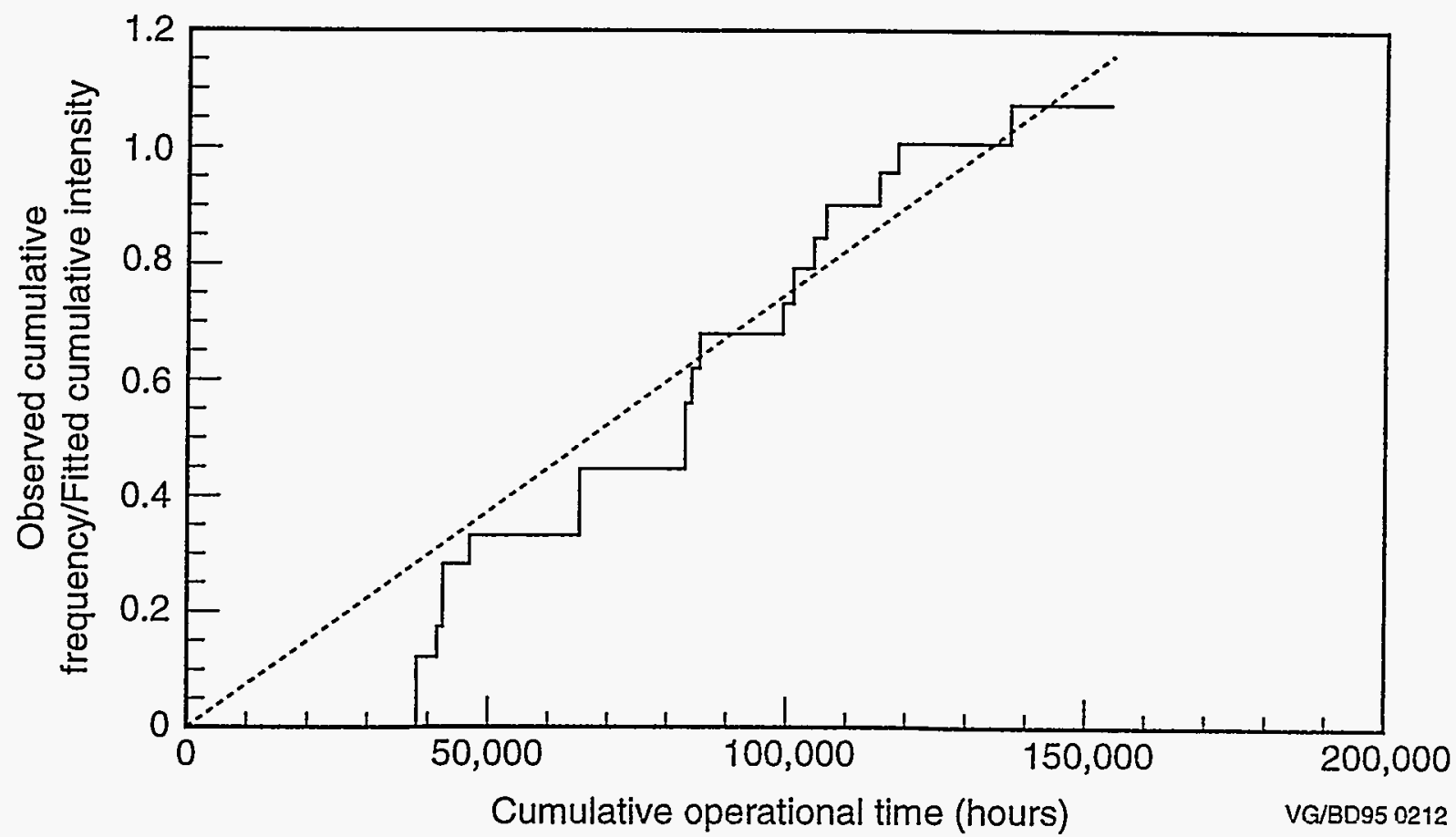

Figure 3-2. Results of trend analysis for spurious stops of centrifugal pumps in containment spray systems of plants B1 and B2. 
The summary comments on several aspects of the study, as follows:

- The assumption of a Poisson process requires that repairs be minimal, restoring the component to its state just before the failure ("as bad as old"). The authors believe that many repairs make the component better than old but not as good as new. Such repairs are much more difficult to model than either good-as-old or goodas-new. A "Trend Renewal Process" model is proposed, but the summary gives no details.

- The Swedish TUD-data base treats a component as a location or socket, not as an individual piece of hardware. Therefore, the age of the particular piece of hardware in the location is not available from the data base.

- It is inherently difficult to estimate the failure rate when preventive maintenance prevents true failures from occurring.

- There is a conflict between obtaining a homogeneous data set (which gives meaningful conclusions that are straightforward to interpret) and a large data set (in which evidence for trends is not dominated by random variability). For example, the study finds a relatively clear decreasing failure rate for containment spray pumps at one plant when all categories of failures are considered, but not when only critical failures are considered. 


\section{FINLAND}

The Finnish research and development work related to the PWG-1 aging study is summarized in this section. The objective of the Finnish work has been to apply reliability engineering methods to the different aspects of nuclear power plant aging management. Much of the effort focused on development of reliability based models for identifying and quantifying dominate failure and aging mechanisms and for evaluating various aging mitigation techniques on active components. Statistical methods for evaluating failure data trends are also discussed, and an example of application to motor-operated valves is provided. These methods are used to complement other safety and reliability evaluations of both plant components and structures. In addition, methods for probabilistic analysis of crack growth in structural components are discussed, including an example of crack growth in BWR shutdown cooling system piping. Finland provided four reports, summarized in the following discussions.

\subsection{Experience Based Reliability Centered Maintenance}

Finland provided two reports that address the reliability centered maintenance (RCM) concept. One was a letter report (Laakso et al. 1994) ${ }^{\mathrm{a}}$ from the Technical Research Centre of Finland (VTT) that provides a summary of aging research activities in Finland and includes a discussion of RCM. The other was a comprehensive report, entitled Experience Based Reliability Centered Maintenance, an Application on Motor Operated Valve Drives (Hänninen and Laakso 1993), that presents a case study of a "living maintenance" program based around the RCM concept. The report focuses primarily on the application of RCM to motor operated valves (MOVs) with actuators manufactured by AUMA in Germany.

a. See Section 11 of this report for bibliographic information.
The data collection evaluated MOV failures at the Teollisuuden Voima Oy (TVO) BWR Units I and II and the Loviisa PWR Units I and II. The TVO data collection evaluated 81 technical specification related MOVs (at each unit) and 127 nonsafety-related MOVs (at each unit) from 1981 to 1992. The Loviisa site data collection evaluated 44 technical specifications related MOVs at Unit I and 95 technical specifications related MOVs at Unit II over the years of 1989 to 1992 . A total of 957 faults were recorded for both of the plant sites during the evaluated years.

For the failures that were recorded, detailed failure modes and effects analysis and corrective maintenance and effect worksheets were filled out. This initial data collection and evaluation was very time consuming. It was noted that a significant time savings could be realized by performing a detailed analysis of only the most recent 4 to 8 years of maintenance data, and only a rough analysis of data from the earlier years. Also, aging studies using maintenance data would be expedited if data analysis efforts were more interactive with data recording efforts.

Failure trend analysis was performed in order to augment the RCM approach. It was stated that the Finnish application of RCM does not yet include any methods for determining optimal task intervals. The Weibull model used for the trending analysis in the report attempts to indicate whether the probability of failures decreases with time, increases with time, or remains constant. The results of the trending analysis for the MOVs indicated that the components' failure rates were almost constant or slightly decreasing with time. This does not demonstrate the absence of aging effects, since an evaluation of the data for an individual failure mechanism or failure mode might still show a high occurrence rate or an increase with time. (This analysis did not consider the internal leaks discussed in Section 4.3 of this report; those internal leaks did show a slight increase in the occurrence rate.)

In the evaluation of the MOVs at the four plants, it was found that the dominant failure 
modes were: (a) packing and deposit problems causing high forces for stem movement, and (b) torque switch trip problems. Even though MOV aging was not indicated by an increase in the failure rate, age-related failures were noted, including dirty contacts, oxidation of contacts, loosening of spring pack, and grease hardening. Human factor issues and design issues entered into potential failure modes via incorrect or improper setting of limit and torque switches.

The RCM approach documented in the Finnish report deviated slightly from traditional U.S. RCM programs in one respect. Typical U.S. RCM programs have an application philosophy of "... focus first on functions, functional failures, and the importance associated with these functional failures" (Los Alamos Technical Associates 1985). Typically, the application of preventive maintenance in the U.S. will be selected by using a logic based (i.e., yes/no questions) flow diagram. Although this logic diagram will vary slightly depending on the particular organization implementing the RCM program, the logic diagram will estimate the criticality of the functional failures. The Finnish logic diagram focuses more on the failure detection method and the failure characteristic, even if the failure is a critical failure. Conversely, the Finnish RCM method does question whether the result of a failure has a higher cost than performing preventive maintenance tasks. This costbenefit question is not addressed directly by some U.S. RCM approaches.

In conclusion, the Finnish report suggests some effective preventive maintenance tasks to reduce the failure rate for some failure modes for MOVs, as determined by their application of RCM. These preventive maintenance tasks include: measurement and fingerprint monitoring of motor power, valve movement time, and torque switch tripping, and the recording of stem forces during function testing in applicable cases. The report points out that the RCM study was time consuming, but computerization and experience helped to speed up the RCM process.

\subsection{Probabilistic Methods in Nuclear Power Plant Component Ageing Analysis}

Finland provided a report (Simola 1992) that summarizes methods for analyzing aging. The references list Finnish and Swedish reports through 1991, and reports from other parts of the world through 1989 . Chapter 2 very briefly describes programs on aging and/or life extension in the U.S., France, Canada, and Japan. Chapters 3 and 4 give a cursory review of some simple graphical methods for detecting trends in failure occurrences, some standard terms used in aging analysis [increasing failure rate (IFR), etc.], some standard replacement and repair models, and use of accelerated testing. Short-term aging models include renewal processes, non-homogeneous Poisson processes, and more complicated processes; the data consist of failure and maintenance descriptions. Long-term aging models include random crack growth models, strengthstrength-time models, and Markov modeling for cumulative damage; the data consist of monitoring of conditions.

Chapter 5 presents two Finnish case studies. The first study examined 9 years of data from 104 motor-operated closing valves at 2 sister plants. (Another analysis of the same data is summarized in Section 4.3 of this report.) The data were taken from maintenance work orders, and include incipient as well as critical failures. The data were studied qualitatively by failure mode effects analysis (FMEA) and similar methods. For example, about half the failures had an aging-related cause (including normal wear). Two statistical analyses were performed. For the first analysis, the failures were assumed to follow a Weibull process (one kind of nonhomogeneous Poisson process), and the Weibull parameters were estimated; the failure rate was estimated to be nearly constant, or perhaps slightly decreasing. As a methodological exercise, the study included a modification of the analysis that measured time from the beginning of plant operation rather than 
the beginning of the observation period. This modification showed a clearly increasing failure rate; note, however, that it treated the period between start of plant operation and start of data collection as having no failures, so the results of this exercise may have been somewhat distorted. The second analysis considered failures on demand (valve leaks during annual tests) rather than events in time. A Bayesian analysis was performed. The distribution of the failure probability $q$ at year $i+1$ was assumed to be related to $q$ at year $i$ by a Markov transition matrix. The prior distribution and the form of the matrix were all assumed, with one parameter of the matrix, $\alpha$, allowed to vary. The posterior likelihood was maximized when $a=0.7$, indicating a decreasing failure probability. This model gave a better fit to the data than when the distribution of the failure probability $q$ was assumed to be constant over time (corresponding to $\alpha=1$ ). The analysis does not appear to be a standard Bayesian analysis, because the prior and posterior distributions of $a$ are not mentioned.

The second case study in the Finnish report was an application of the PRAISE computer program to intergranular stress corrosion. (Although this case study is outside the scope of this aging study, a brief discussion is provided here for information.) Both the crack initiation probability and the crack growth characteristics depended on various factors. The study estimated the probability of leak. (The simulated cracks typically resulted in leak, not rupture.) The estimated time-dependent leak probabilities were much higher than has been actually experienced in Finnish reactors, and the computer-simulated final crack shapes differed significantly from those detected in removed piping, being shorter and deeper than those actually found. The reasons were investigated and are discussed. The study reported that such information is valuable for improving the reliability of the probabilistic models for better prediction of crack growth.

\subsection{Analysis of Failure and Maintenance Experiences of Motor Operated Valves in a Finnish Nuclear Power Plant}

Finland provided another report specifically addressing motor-operated valves (Simola and Laakso 1992). This study demonstrated the use of reliability engineering methods for qualitative analyses of component failures and maintenance actions. Specifically, the study gathered data from the failure reports of motor-operated valves at two BWR plants in Finland, TVO I and TVO II, and evaluated the data using failure mode and effects analysis (FMEA) and maintenance effects and criticality analysis (MECA). Altogether, the study addressed 104 valves operating over a period of nine years (1981 to 1989) at the two plants. The FMEA method used qualitative analyses to examine the failures, and the repair actions were systematically studied by MECA.

For the purpose of statistical analysis, valve failures were attributed to one or more of eleven valve subcomponents:

- Stem

- Stem and bonnet packing

- $\quad$ Slide and sealing surfaces

- Leakage pipe

- Gear box

- Torque switch

- $\quad$ Limit switches

- Switchgear equipment

- Circuit board

- Electric motor

- Indicators and push buttons.

The first four of these subcomponents were designated mechanical items; the other seven were designated electromechanical items. 
The first four of these subcomponents were designated mechanical items; the other seven were designated electromechanical items.

Of the reported failures, $65 \%$ were detected during the various periodic tests (leakage tests, monthly tests, and tests during refueling outages). Five failures occurred during demand situations.

Failures were categorized according to criticality. Failures directly preventing valve function were called critical. Failures that prevent valve function only during repair were called repair critical. Non-critical failures were those that were detected and repaired without any effect on valve operability.

Of the 104 valves addressed by the study, 67 experienced 181 reported failures during the nine operating years. Of the 181 reported events, 46 were critical failures; 23 involved failure to open, and 23 involved failure to close. It was estimated that the 104 valves had been operated nearly 20,000 times during the observation period. Thus, the probability of a critical failure is $1.2 \times 10^{-3}$ for closing and $1.2 \times 10^{-3}$ for opening.

Most of the critical failures were of one of three groups. Nine of the critical failures were due to excessive friction in the stem (for example, lack of cleanup and lubrication); these include instances of premature torque switch trip where no adjustment of the torque switch was needed. Eighteen were due to incorrect operation of limit and torque switches. Eleven involved electrical switchgear faults, including several contactor failures due to oxidation.

Among the 104 valves included in this study, 32 are valves whose test conditions are significantly lower than their design-basis accident conditions. For some modes and subcomponents, the probability of a critical failure is more sensitive for these valves in accident situations, where the operating temperature or the differential pressure across the slide is much higher than in the periodic tests. Among the 32 valves specified above, 11 critical failures were reported. In three cases, the fault was in the gearbox; two limit switch and three torque switch adjustments were necessary; three failures were due to excessive friction (stem or slide).

Trend analyses were conducted for some subcomponents and failure modes. According to the Weibull process model used in these trend analyses, the failure intensity is a function of time:

$\lambda(t)=\alpha \beta t^{\beta-1}$.

The expected cumulative number of failures occurring in time $(0, t)$ is

$N(t)=\alpha t^{\beta}$.

The parameter $\alpha$ is the scale parameter, and $\beta$ is the shape parameter. The shape parameter $\beta$ describes the possible trend in the failure rate: if $\beta>1$, the trend is increasing, and if $\beta<1$, the trend is decreasing. With $\beta=1$, the model reduces to the homogeneous Poisson process with a constant failure rate.

In the results of these trend analyses, the failure rate of electromechanical components was nearly constant, with a slight decrease during the observation period. This result is shown in Figure 4-1. The failure rate for mechanical components was nearly constant. Torque switch maloperations and contactor voltage cut-off (failure modes of particular interest because they contribute significantly to the critical failures) showed a nearly constant failure rate.

The annual number of internal leakages showed an increasing trend. The study includes a description of a model for predicting the number of internal leakages on the basis of results from previous years. The number of failures for a given year is modeled with a binomial distribution $\operatorname{Bin}(\mathrm{n}, \mathrm{q})$. The expected increase of failure probability in the subsequent year is taken into account by modifying the parameter $q$ to have an increasing trend. A prior distribution is used to describe the uncertainty of the failure probability, and as observations are made, this distribution is updated with Bayes equation to produce the posterior distribution. Figure 4-2 shows the results. The figure shows the observed number of internal leakages (indicated with dots) and the predicted distribution of the number of failures for MOVs in TVO I and TVO II for a nine year time period. 


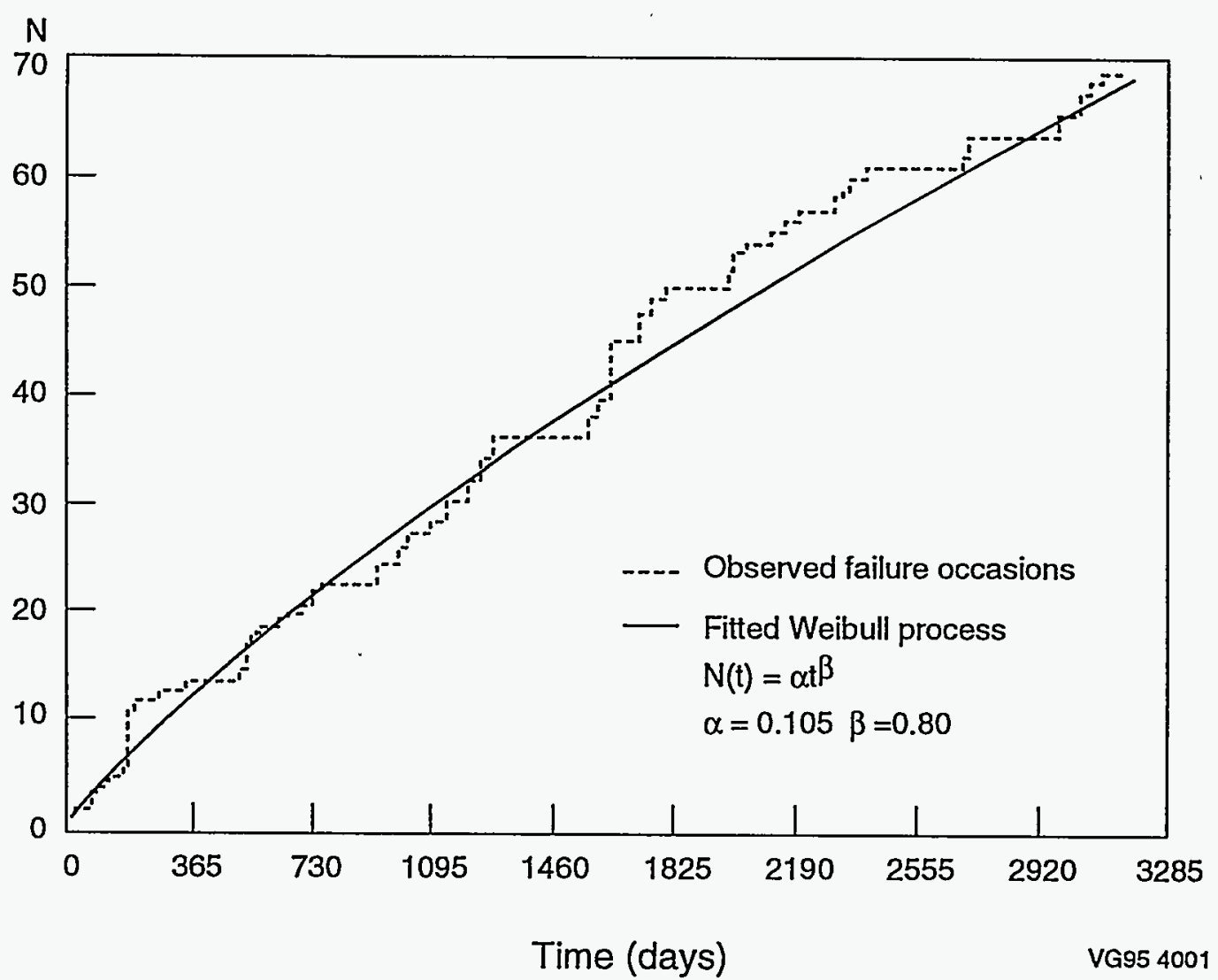

Figure 4-1. Failure trend of electromechanical subcomponents (TVO I and TVO 2).

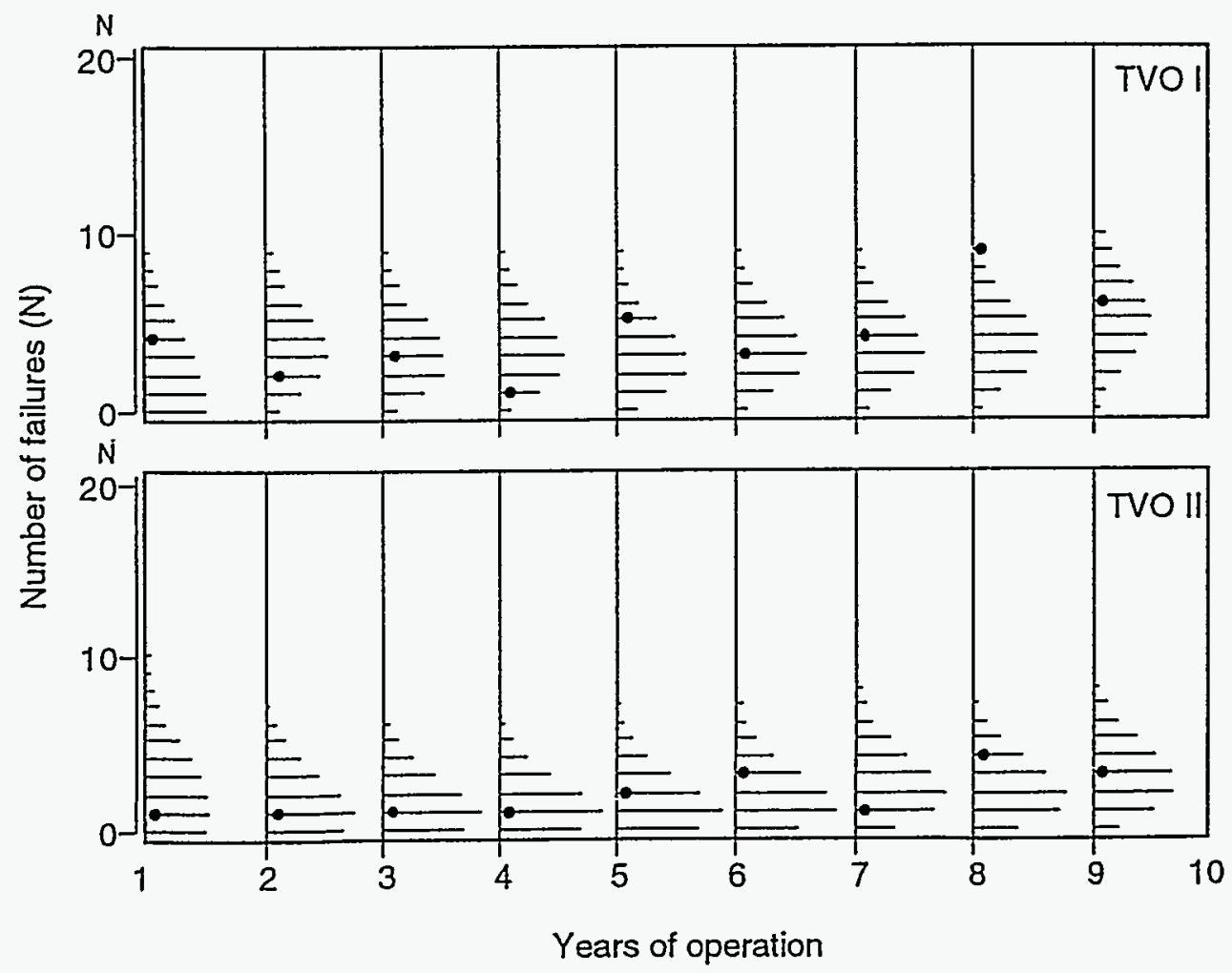

Figure 4-2. Observed number of internal leakages and predicted distribution of number of failures in TVO I and TVO 2 MOVs. 
Repair times were significantly shorter than the repair times allowed by technical specifications (generally 720 hours for failure of a single component where there are four redundant systems). Average repair time was 45 hours for critical failures (valve was unavailable for operation before and during repair), and 13 hours for repair-critical failures (valve was unavailable for operation only during the repair). The study produced Weibull distributions of repair time data. (See Figure 4-3.)

Many of the valves' failures to change position indicated a complex interaction among mechanical and electrical failures, involving functions maintained by mechanical and electrical maintenance groups. Several causes of these failure combinations, leading to premature torque switch trip of the valve actuator, were very complicated to identify afterwards.

One major problem is the effectiveness of testing and the coverage of test results. In accident and transient situations, a number of valves are required to function in operational conditions that are much more severe than the periodic test conditions. Thus a valve that passes the periodic opening/closing test may fail to change position in an accident situation, for example, with a higher temperature or differential pressure over the slide.

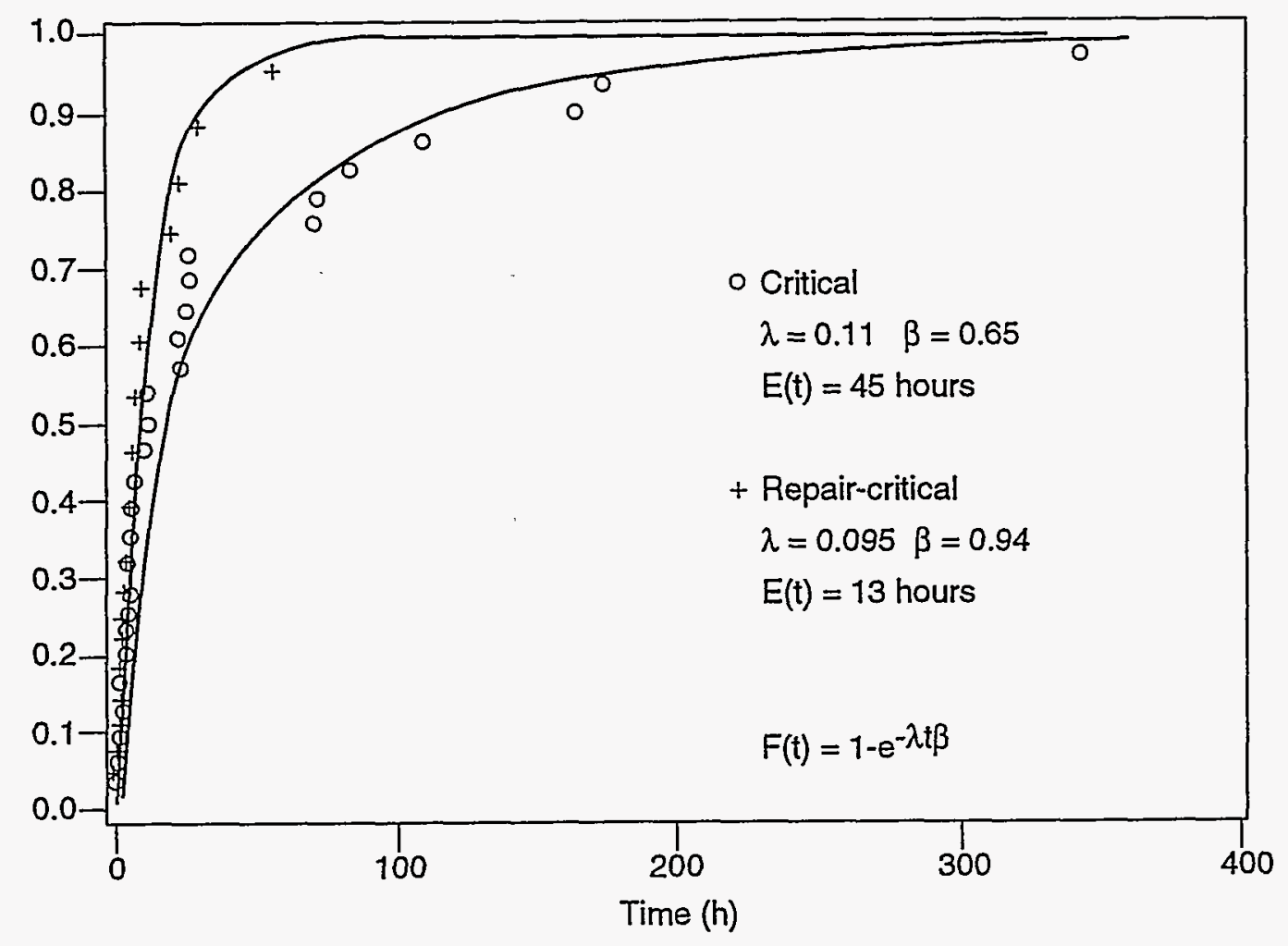

VG95 4003

Figure 4-3. Cumulative probability distributions of MOV unavailability times caused by repairs during plant operating period. 


\subsection{Probabilistic Safety and Aging Assessment of Structural Components}

The VTT letter report provided by Finland (Laakso et al. 1994), ${ }^{\mathrm{a}}$ which was a summary of aging research activities in their country, included a discussion of aging assessment of structural components. (Based on a strict interpretation, these components are outside the scope of the PWG-1 study; however, this Finnish work presents some important concepts for evaluating aging, so it is discussed briefly here for information.) These components require special consideration, because the gradual development of defects, such as crack growth, cannot usually be observed directly, but must be inferred from limited periodic non-destructive testing (NDT) data or other indirect measurements. The NDT data are often noisy and difficult to interpret, the sample size may be limited, and the inspection methods may change with time. The inspections may be infrequent. However, accurate assessments of material condition are needed to determine operational strategies such as determination of residual operation time and scheduling of inspections, repairs, or replacements. Therefore, a probabilistic approach, one that accounts for the uncertainties in the NDT data and in the development of the fault, is needed to optimize the operational and maintenance activities. Probabilistic models and their solution techniques have been developed and published (Pulkkinen and Uryas'ev 1992; Pulkkinen 1994). A model to be

a. See Section 11 of this report for bibliographic information. developed for optimization of the residual operation time and inspection strategies of a gradually failing structure is illustrated in Figure 4-4 (Pulkkinen 1994).

A part of the model is being tested using steam generator collector weld NDT data on crack detections and thermal transient data from the Loviisa plants. The structural reliability assessment is based on randomization of the PairsErdogan model for determining the probability distribution of the crack size and its growth. The available NDT results at the given inspection times and the number of significant stress changes caused by the thermal transients can in relevant cases be used to update the crack size distribution. The approach is a straightforward application of stochastic filtering. The calculation algorithms are based on Monte Carlo simulation. The updated estimates are used to predict the future growth of the crack length and evaluate its safety. The computer program is ready for testing with a practical example to be published in 1995.

Finland also provided a survey of the literature on the use of probabilistic approaches in different component aging evaluations (Simola 1992). A case study in the literature on the applicability of the PRAISE computer code for the evaluation of environmentally assisted crack growth revealed large differences between observed and simulated crack growth (Marquis and Simola 1990). Results indicate that the code needs modification of either the residual stress model or the calculations of specific damage parameters. In addition, the codes OCA-P and VISA-II for probabilistic assessments of PTS loading cases of reactor pressure vessels were installed on a microcomputer and their operation was verified. 
Finland

\section{DEFECTS}

$N(t)=$ number of defects at time $t$

$C_{i}(t)=$ characteristics of defect $i$ at time $t$

MODEL: probability distribution of $\left(N(t), C(t)\right.$,i.e. $P_{t}(N(t), C(t))$

\section{DEVELOPMENT OF DEFECTS}

MODEL: stochastic process dynamics for $(\mathrm{N}(\mathrm{t}), \mathrm{C}(\mathrm{t}))$,i.e.,

$\mathrm{P}(\mathrm{N}(\mathrm{t}+\Delta \mathrm{t}), \mathrm{C}(\mathrm{t}+\Delta \mathrm{t}) \mid \mathrm{N}(\mathrm{t}), \mathrm{C}(\mathrm{t}))=\mathrm{g}(\mathrm{N}(\mathrm{t}), \mathrm{C}(\mathrm{t}))$, or

the conditional probability distribution of the defects .

\section{FAILURE CRITERION}

Component fails when $(N(t), C(t)) \in F$,

$\mathrm{F}=$ critical defect size and characteristics

\section{INSPECTIONS}

MODEL: stochastic model for detection

$\mathrm{P}(\mathrm{n}(\mathrm{t}), \mathrm{c}(\mathrm{t}) \mid \mathrm{N}(\mathrm{t}), \mathrm{C}(\mathrm{t}))=$ the conditional probability distribution of the measured defect characteristics $(n(t), c(t))$ given the true characteristic $(\mathrm{N}(\mathrm{t}), \mathrm{C}(\mathrm{t}))$

\section{COSTS}

MODEL: costs of inspections and failures

\section{OPTIMAL INSPECTION AND OPERATION LIFE STRATEGY}

Figure 4-4. A proposed model for optimization of residual operation time and inspection strategies of a gradually failing structure (Pulkkinen 1994). 


\section{JAPAN}

Japan's contribution to this aging study is a report summarizing an evaluation of the failures reported for their 45 commercial light water reactor power plants. The report categorizes the number of failures for the studied components by the type of aging mechanism. It also provided an evaluation of the number of failures by plant age. The following discussion presents a summary of the report.

\subsection{Evaluation of Aging Events}

The report provided by Japan was prepared by the Safety Information Research Center of the Nuclear Power Engineering Corporation (NUPEC). The report is entitled The Aging Phenomena in Commercial Nuclear Power Plants in Japan (Safety Information Center 1994). ${ }^{a}$ This study discusses and displays aging failure data from the 45 commercial light water reactor power plants in Japan (24 BWRs and 21 PWRs), including all the plant systems except the reactor pressure vessels, steam generators, control rods, and control rod drive mechanisms. The data were retrieved from a NUPEC database entitled "The Incident and Failure File." By law, or Japanese Ministry of International Trade and Industry (MITI) notification, the Japanese utilities must report plant incident and failure information to the MITI according to its reporting criteria, which then asks NUPEC, its affiliate organization, to file or further process if necessary.

The aging related cause codes used for this study were: mechanical fatigue, stress corrosion cracking, corrosion, thinning, natural deterioration, insulation deterioration, loosening, abrasion/fracture, thermal fatigue, and drifting. The mechanical fatigue included both low and high cycle fatigue caused by repeated stress loadings and vibration. Most of the corrosion was

a. See Section 11 of this report for bibliographic information. electrochemically induced due to loss of protective coatings. The thinning events were all caused by erosion-corrosion. Natural deterioration included failure of electrical components such as integrated circuit cards, fuses, resistors, switches, coils, and other consumable parts, as well as failures of packings, O-rings, gaskets, etc. due to a lack of appropriate preventative maintenance.

A total of 726 reported incidents and failures occurred in Japanese nuclear power plants from 1969 to 1993 . Of these, about half were identified as aging events. About half of these age-related events were included in this study. (Events related to steam generators, reactor pressure vessels, control rods, and control rod drive mechanisms were excluded from the study.) Figure 5-1 shows the data of failure events caused by aging retrieved from the NUPEC data base and arranged by cause code and general component type. The aging events in Japanese nuclear power plants are not a large number when compared to the experience, for example, in the U.S, especially considering the size of the Japanese nuclear program.

Figure 5-2 shows the fraction of the total aging events for each component. The aging events are relatively uniformly distributed among the components. Figure 5-3 shows the fraction of the total for each cause code. The largest fraction of aging events was caused by mechanical fatigue ( $31 \%$ of the total), followed by stress corrosion cracking (23\%), thinning (14\%), and natural deterioration (12\%).

Figure 5-4 shows the trend of the total number and the number per plant of the aging failure events with fiscal year. Improved and standardized plants have been introduced in Japan since fiscal year 1983 with the aim of increasing safety and reliability. Data for both conventional and improved plants are plotted. Note that the number of light water reactor plants in operation in Japan steadily increased from 3 in 1971 to 45 (23 conventional and 22 improved and standardized) in 


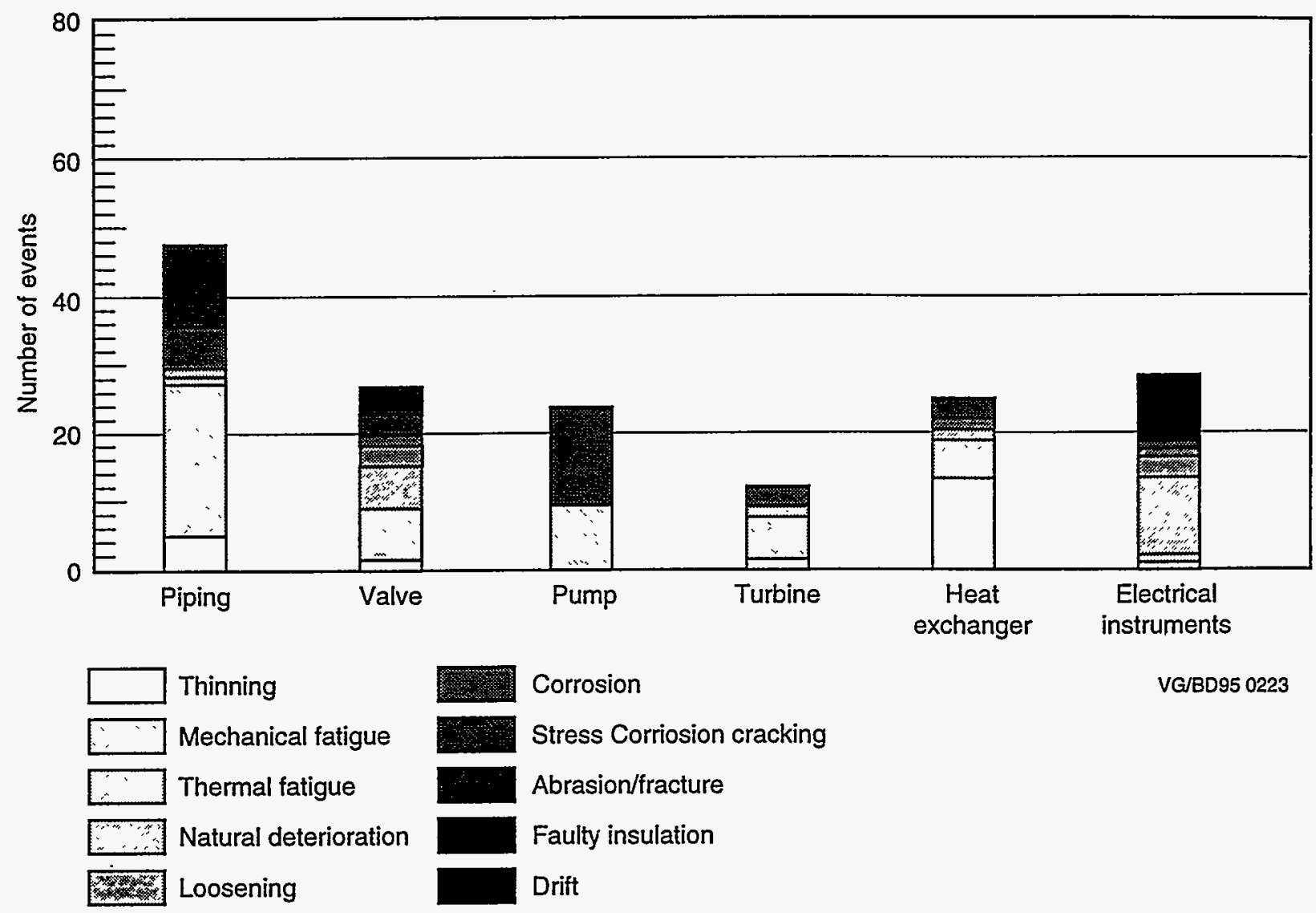

Figure 5-1. Summary of failure modes for failures caused by aging.

(Components identified are those included in the scope of this review)

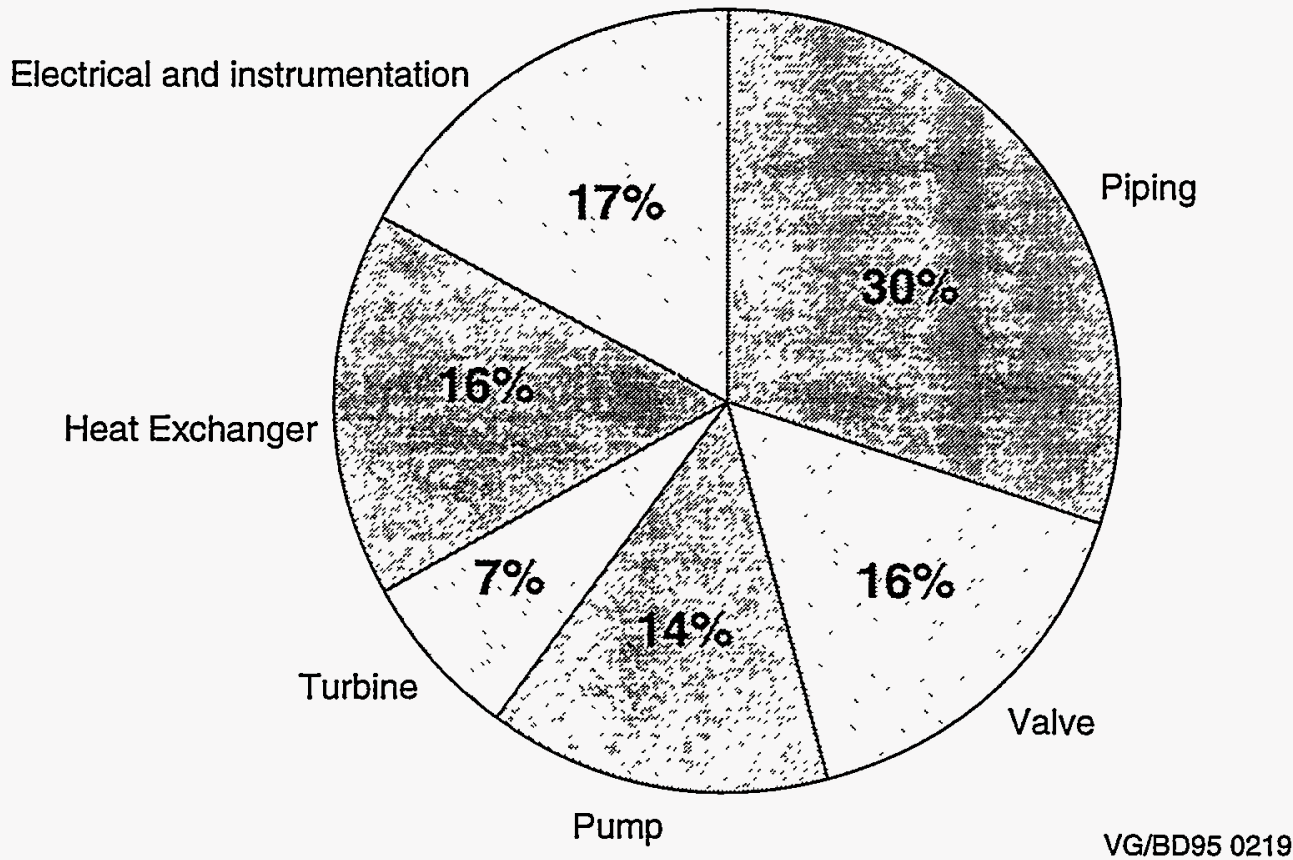

Figure 5-2. Percent of events for each component. 


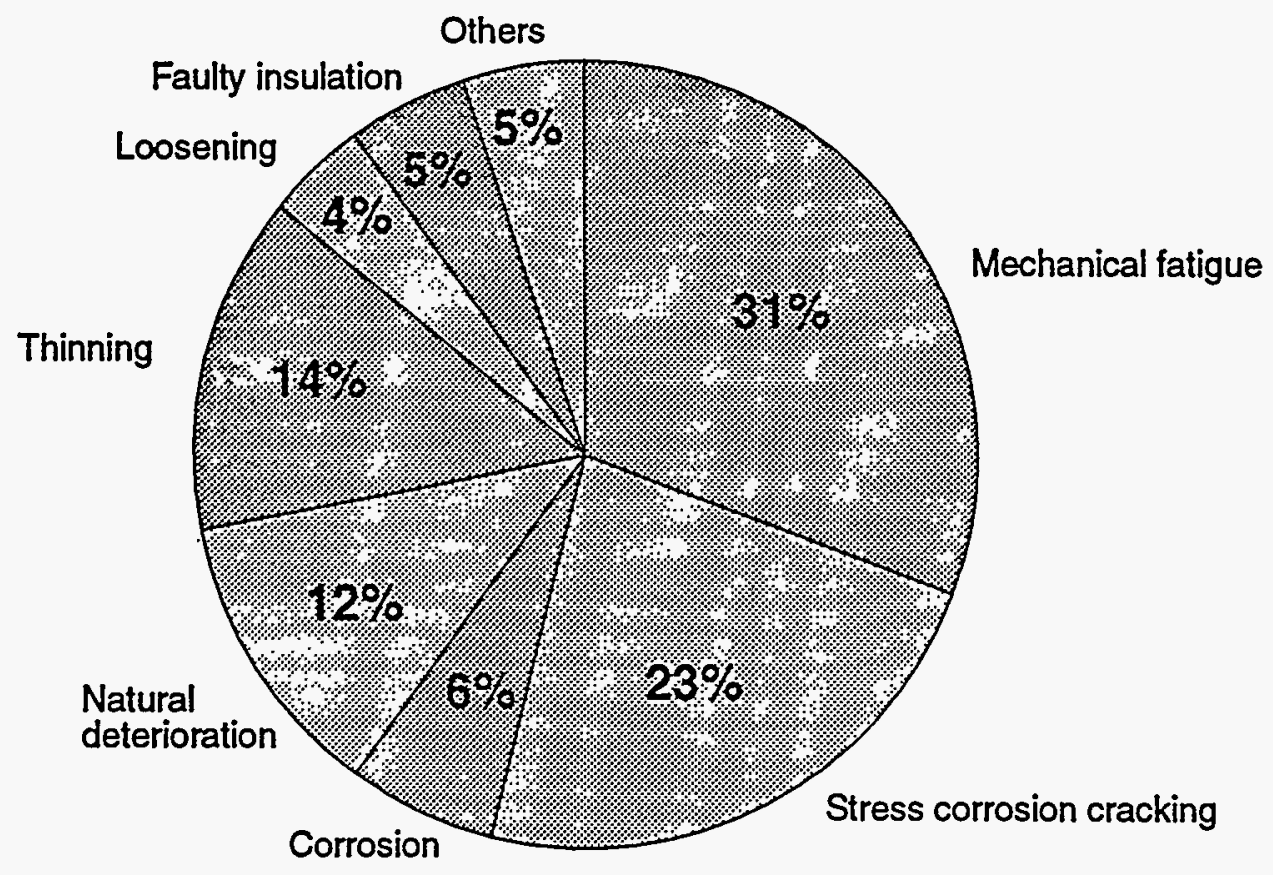

M96 0030

Figure 5-3. Percent of events for each failure mode.

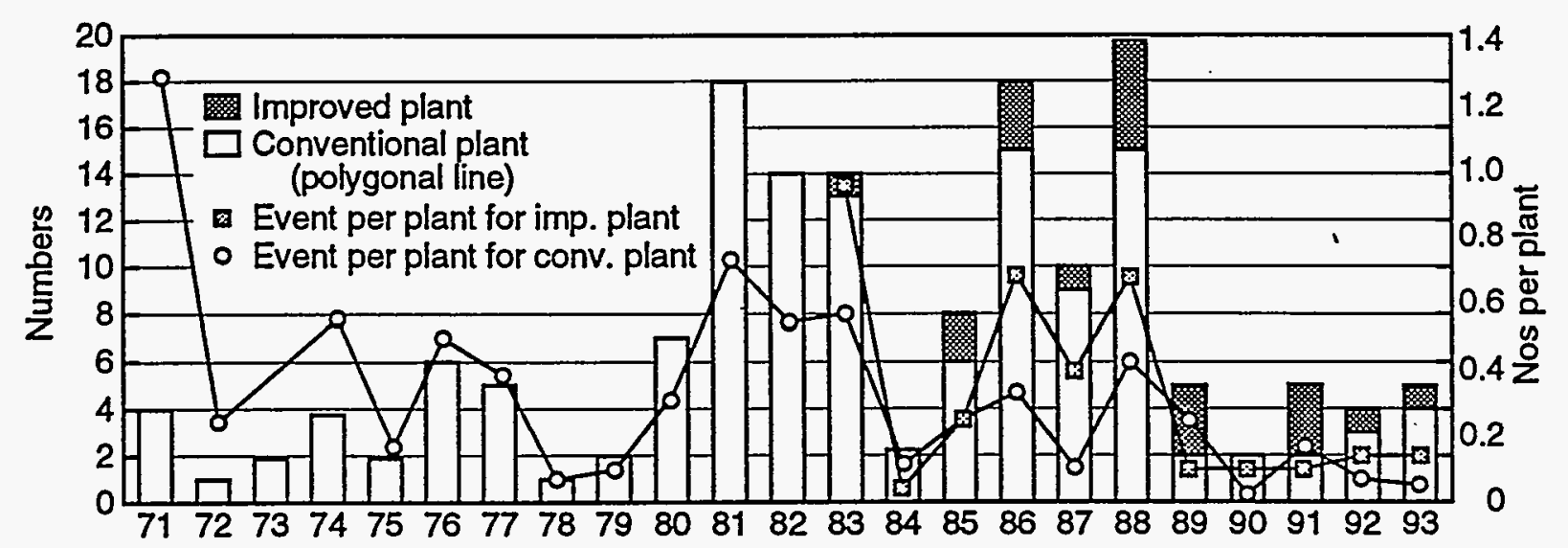

Note: Events related to steam generators, reactor pressure vessels, control rods, and control rod drive mechanisms are excluded from the number of events.

M95 0166

Figure 5-4. Number of events due to aging by fiscal year. 
1993. Also note that there was a change in the reporting criteria in 1981 , which caused an increase in the number of reported events in that year and subsequent years. The aging events per plant show an initial drop in the early 1970s, an increase in 1981, and then a drop in the late 1980s (1989 and 1990) to a relatively constant value of around 0.1 events per plant.

The number of failure events caused by aging is plotted versus operating years in Figure 5-5. The bar graph portion of the plot presents raw data in terms of total events per operating year for all plants, and the indicated decrease in events with plant age is caused partly by the lower number of plants operating at an advanced age. (As of 1993, 20 of the 45 Japanese plants had been operating for 10 years or less.) Even so, the top polygonal line (aging-related events per plant per year of operation) indicates that older plants generally experience fewer failures than newer plants. It is suggested that the older plants experience fewer aging failures because the preventative maintenance programs are continually improving and enhancing component performance in Japan (and presumably elsewhere). When failure occurs, similar components at the same plant and at similar plants are inspected and the preventative maintenance program is adjusted to prevent future failures. Also, periodic measurements of parameters such as wall thickness, insulation resistance, sensor drift, etc., are used to focus the preventative maintenance programs. Therefore, fewer aging failures are expected at the older plants where the preventative maintenance programs are mature and effective.

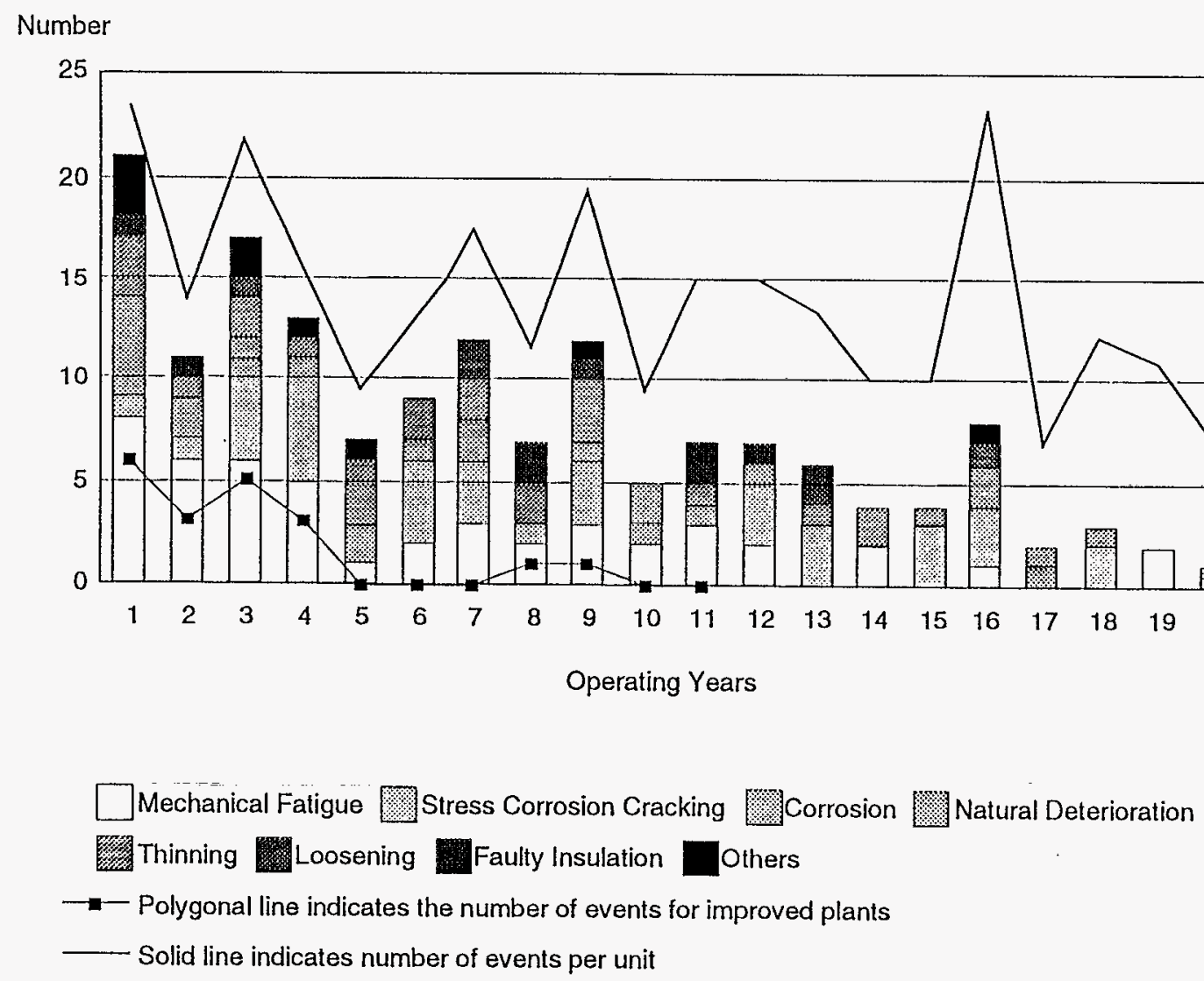

Figure 5-5. Number of events caused by aging versus years of operation. 


\section{UNITED STATES}

For their contribution to the current PWG-1 study, the U.S. contributed three reports. These reports are (1) a discussion of performance measures for aging of nuclear power plants, (2) an evaluation of BWR high pressure coolant injection (HPCI) system performance, and (3) a reliability study of safety-related steam turbinedriven pumps. The following discussion first presents a brief description of the U.S approach to aging as it relates to license renewal, followed by summaries of the three reports. Additional details on the three topics are given in the full reports, listed in the reference section of this report.

The U.S nuclear power industry has ongoing programs for considering the effect of aging on nuclear power plant safety. These programs include activities by the nuclear utilities, the Electric Power Research Institute (EPRI), the Department of Energy (DOE), and the Nuclear Regulatory Commission (NRC). The programs have been underway since the early 1980s. Much of the work is being done to support extending the life of the nuclear power plants beyond their licensing term. The work is also important for identifying aging issues that need consideration during the current license term.

On December 13, 1991, the NRC issued a license renewal rule establishing the procedures, criteria, and standards governing the renewal of nuclear power plant operating licenses. Later, the NRC proposed a revision to the license renewal rule (Federal Register, September 9, 1994), reflecting the conclusion that greater reliance could be placed on the maintenance rule (Code of Federal Regulations 10:50.65, Requirements for Monitoring the Effectiveness of Maintenance at Nuclear Power Plants) for managing the effects of aging during the license renewal term. This revision went into effect June 7, 1995 (Federal Register, May 8, 1995).

The maintenance rule requires that U.S. commercial nuclear power licensees monitor the performance or condition of plant systems, structures, and components against licensee-established goals in a manner sufficient to provide reasonable assurance that these systems, structures, and components are capable of fulfilling their intended function. Anticipating the implementation of the maintenance rule in 1996, the NRC has determined that for the license renewal process, the current licensee programs and activities, along with the regulatory process, will be adequate to manage the effects of aging for the active components, as well as components subject to replacement based on qualified life or specified time period. For license renewal, components subject to an aging management review are limited to those passive components that must remain functional during and following the design-basis events.

By definition, passive components are those that perform their intended function without moving parts or without a change in configuration or properties. These include pressure retaining boundaries, component supports, reactor coolant pressure boundaries, the reactor vessel, core support structure, containment, seismic Category I structures, electrical cables and connections, and electrical penetrations. Excluded are pumps (except for casings), valves (except for bodies), motors, batteries, relays, breakers, and transistors. However, all components subject to a time-limited aging analyses would be subject to a license renewal evaluation. (Time-limited aging analyses are those analyses, such as embrittlement, fatigue or qualified life, that are based on an assumed service life defined by the license term, for example 40 years.)

In contrast to the emphasis of the U.S. NRC's revised license renewal rule, the focus of this aging study of the CSNI Working Group PWG-1 is on active components. This focus is appropriate, since the activities of the CSNI working group, like the U.S. NRC maintenance rule, are directed toward assuring that aging of the active components is not leading to unacceptable degradation of plant safety. 
The NRC's License Renewal and Environmental Review Project Directorate is currently performing a project that might be of interest to the PWG-1 working group. The project includes a systematic critical review of the reports generated over the years by the several organizations involved in nuclear plant aging research, and a review of the recent operating experience related to aging issues. The major contributor of reports has been the NRC's Nuclear Plant Aging Research (NPAR) program. One hundred fiftynine NPAR reports have been reviewed under the project, along with 9 NUMARC Industry reports and 5 Department of Energy reports. The recent operating history review included 31 NRC Generic Letters, 265 NRC Information Notices, 82 NRC Licensee Event Reports, and 5 NRC Bulletins. The first phase of the project is to summarize in a tabular format the age-related degradation mechanisms, their effects, and any recommendations reported in the documents. This work has resulted in the development of Generic Aging Lessons Learned (GALL) tables. The information in the GALL tables is being entered into a data base so that it can be conveniently searched. This phase of the work is nearly completed. The next phase of the project will be an assessment of the aging issues identified during the initial phase.

\subsection{Performance Measures for Aging of Nuclear Power Plants}

A logical concern for extending the life of nuclear power plants is whether plants age in such a way as to be significantly less safe as they get older. There is also the question of how to measure a diminution in plant safety if it is occurring. The following discussion is a summary of a conference paper (Ross 1993), provided by the U.S., that describes a study investigating the use of overall reactor plant performance as a way of measuring the effect of plant aging. In using this measure, the study recognizes that the performance is not only a result of possible aging of plant active and passive components but also reflects physical improvements in plants and the ability of the operating crew to cope with operational challenges. Nonetheless, overall plant performance is an indication of safety as they age, with the exception of a hitherto unrecognized failure mode which would appear without warning.

Because some of the results of the study are presented as events per year it is necessary to define the size of the population to evaluate if the rate per plant is increasing. Currently there are 109 operating reactors in the United States, with the age distribution as shown in Figure 6-1.

The study used the results from four NRC data management programs as measures of plant performance. The study briefly describes the four programs and examines the results as a function of age. The four programs are:

- $\quad$ NRC Performance Indicators

- NRC Event Analysis

- NRC Accident Sequence Precursors

- NRC Systematic Assessment of Licensee Performance (SALP).

The study did not examine every indicator for each of the programs, but select examples of important indicators. Summaries of the descriptions of the programs and findings follow.

Performance Indicators. The performance indicators are:

- Number of scrams while critical

- Number of selected safety system actuations

- Number of significant operating events

- Number of safety system failures

- Forced outage rates

- Number of equipment-forced outages

- Collective radiation exposure per plant. 


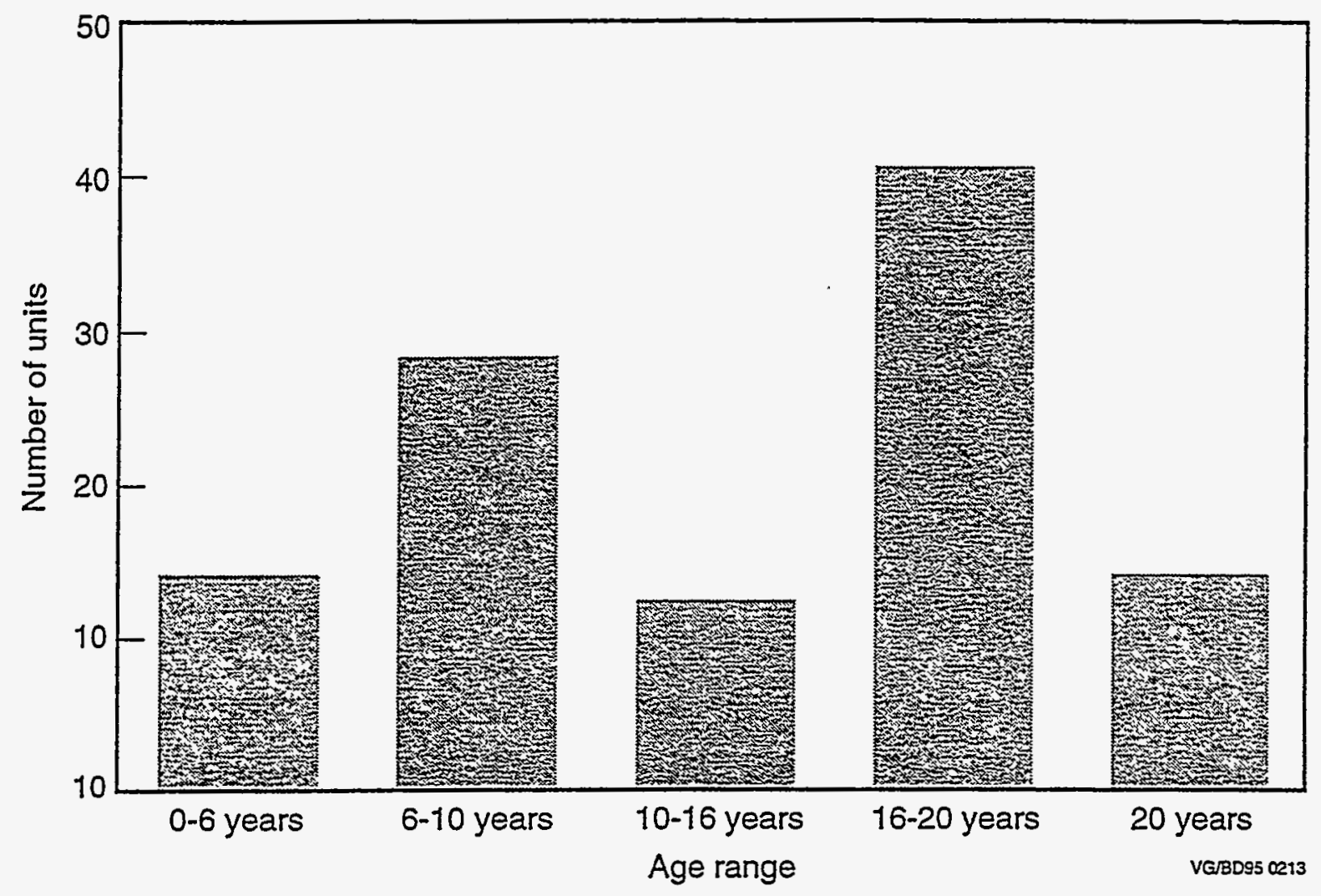

Figure 6-1. Age since commercial operation.

Three of the seven indicators were examined. The cumulative number of scrams for the period of 1987 to mid-1992 were plotted with calendar time for each of the age groups of the operating plants defined in Figure 6-1. The plot is shown in Figure 6-2.

The slopes of the curves represent the annual rate of scrams. Note the slopes are about the same, indicating no age effect. The higher initial rate for the 0-5 year age group is explained by the "bathtub" effect; that is, an early higher failure rate from initial defects, decreasing to a nearly constant random rate, followed by an increasing rate from wearout (see Figure 1-1). Similar plots are shown in the study for the significant operating events and the safety system failures. For the significant operating events plot, the curves for the younger and older plants show higher numbers of events while the mid-life plants are lower.
The study poses the question: Is this the bathtub effect at each end of the age groups? However, for all age groups the slopes level off and approach the same value near the end of the observation period, and the study concludes these somewhat conflicting results are difficult to interpret. The safety system failure plot is similar to the plot for the number of scrams in that the curves are grouped together, except the curve for the young plants is slightly higher. Again, the slopes are nearly the same, indicating no age effect.

Event Analyses. The NRC requires nuclear power plants to submit written descriptions of events regarding plant operation. The NRC receives in excess of 2,000 such reports annually. The more important events are selected using about 20 criteria such as unexpected performance, or personnel overexposure, or on-demand failure of a safety system. For the period from 


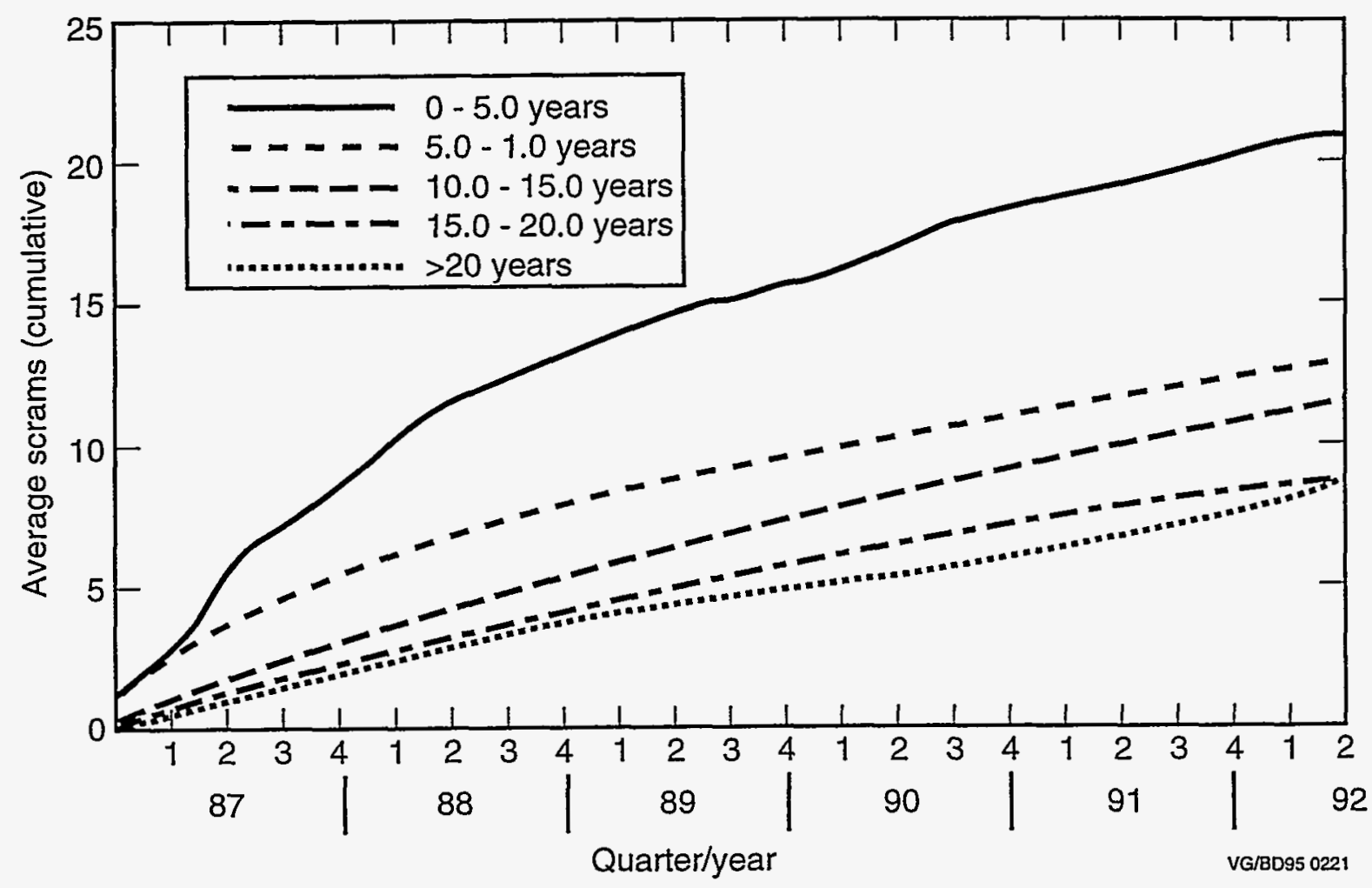

Figure 6-2. Automatic scrams while critical.

1988 to mid-1992, there have been 1,331 events selected as important. The study shows a figure of the number of events versus age of the plants at the time of the events. The figure resembles Figure 6-1 in that the number of events track the density of plants in the age groups indicating there is no age effect.

Accident Sequence Precursors. This program evaluates operational occurrences such as plant problems, equipment failures, or other operational incidents that involve portions of postulated core damage sequences. It uses event tree models and probabilistic risk assessment techniques in evaluating actual failures that have occurred along with the probabilities for postulated additional failures that could occur. There were exactly 400 events quantified under the program since its inception over a decade ago. The study shows figures of PWR and BWR precursor occurrences versus the age of the plant at the time of the occurrence. The figures show more precursors early in life, which is explained as the bathtub effect. The precursors are essentially decreasing with age even though the plant population is not, indicating plant performance is improving rather than degrading with age.

Systematic Assessment of Licensee Performance (SALP). This program is an integrated effort to assess the plants' performances. The data used in the study were the SALP ratings for three functional areas: operations, engineering support, and maintenance. Each of the areas was given a numerical value from 1 to 3 during a SALP evaluation. The meaning of the numbers is:

- Category 1 , superior

- $\quad$ Category 2, good

- $\quad$ Category 3, acceptable. 
A statistical analysis was done to examine correlation with plant age. Of the three functional areas evaluated, the only one that correlated with plant age was operations. This correlation showed a clear improvement in the rating for older plants. The mean plant age for the functional area ratings for operations is shown in Figure 6-3.

Observations. As expected, with four widely varied quantifications, there are differences in the results. What can be said from the study is:

- The Performance Indicators show a trend as plants age, with an improvement from an early adverse performance and leveling off, indicating no further age effect; however, the trend is not uniform across all indicators.

- The important event analysis shows that the number of events track the density of plants in the age groups, indicating there is no age effect.

- The Accident Sequence Program shows a decrease in the number of precursors with age, even though the age density of the plants is not decreasing, which is an indication the plants are improving with age.

- Of the three SALP ratings selected for analysis, only the ratings for the operations

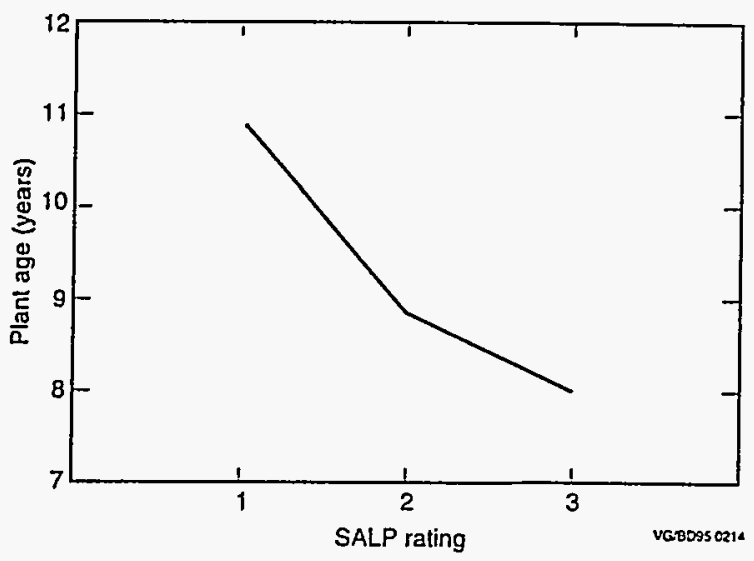

Figure 6-3. Mean plant age versus SALP rating. functional area showed a correlation with age, and it showed an improvement with age.

The overall plant performance ratings show no deleterious age effect. The Performance Indicators, the Accident Sequence Precursors, and one observation from the Systematic Assessment of Licensee Performance (SALP) indicate the plants get better with age. The important event analysis and two observations from the SALP seem to show no age effect. Several reasons could be suggested to explain the this conclusion. They are:

- An aging plateau exists, but has not yet materialized

- Maintenance is effective in combatting the effects of aging and in maintaining the reliability of the systems

- Design criteria and licensing standards produce an inherently rugged plant.

This study concluded that trending of indicators as enumerated in this study should help the plant owners and regulators measure performance as the plants inevitably age.

\subsection{Evaluation of High Pressure Coolant Injection (HPCl) System Performance}

This U.S. report (Grant et al. 1995) presents a performance evaluation of the HPCI system at 23 U.S. commercial BWRs. The study was based on the operating experience from 1987 through 1993, as reported in Licensee Event Reports (LERs) and monthly nuclear power plant operating reports.

Of the 303 events reported which involved the HPCI system during the evaluation period, 145 were classified as HPCI failures and 63 as HPCI actual unplanned demands occurring from a reactor pressure vessel (RPV) low-water level condition. A subset of the 145 failures were used to calculate the observed unreliabilities, namely, 
the failures for which a demand frequency could be counted or estimated.

The objectives of the study were as follows.

1. To estimate HPCI system unreliability based on operational data, and to compare the results with the assumptions, models, and data used in Probabilistic Risk Assessments/Individual Plant Evaluations (PRA) IPEs)

2. To provide an engineering analysis of the trends and patterns seen in the HPCI system operational data.

Operational data compared with PRA/IPE estimates. The HPCI system was modeled using standard PRA techniques, and the operational data were used to develop the basic event failure probabilities to allow quantification of the models. Between-plant comparisons were made on the basis of these models. The results, using the actual plant operational data, were then compared to the results from current PRA/IPEs. Selected results of that comparison are as follows.

- The observed industry-average unreliability of the HPCI system, taking credit for recovery actions, is 0.056 . The observed plantspecific unreliability on a single injection, taking credit for recovery actions, ranged from 0.050 to 0.067 . This variation is within the uncertainty range of the PRA/IPE predictions for the respective plants.

- If recovery is excluded from the calculation, as is appropriate for comparisons with PRA/ IPEs, the industry-average unreliability for a single injection is 0.14 . The observed plant-specific unreliabilities without recovery ranged from 0.11 to 0.30 . The plantspecific observed unreliabilities are consistent with the values used in 12 of 23 PRA/IPEs. Ten of the other eleven plants had observed unreliabilities greater than a factor of three higher than, and outside the uncertainty bounds of, the plant-specific PRA/IPE unreliabilities. The one remaining plant had insufficient information in the PRA/IPE to allow for a comparison. These results raise a question about the quantitative PRA/IPE results for these plants for the accident sequences that involve the HPCI system.

Engineering analysis of operational data. The engineering analysis included both an industrywide and a plant-specific examination. Investigation of trends and patterns in system failures and demands were based on operational time, lowpower license date, subsystem, cause, and method of discovery. Selected results of the engineering analysis are as follows.

- The overall nature of the failures experienced during actual demands and full flow tests differed somewhat from those discovered during monthly surveillance testing, engineering and design reviews, and routine inspections. This result indicates that the current testing and inspection activities may not be focusing on the dominant contributors to unreliability during actual demands, and that these activities may need to be modified to better factor in the conditions and experiences gained from actual system demands.

- No correlation was seen between the plant's low-power license date and either the unreliability per year, or the total number of failures per year, as shown in Figure 6-4. This result indicates that plant age does not affect the reliability of the HPCI system in these plants.

- The number of HPCI system unplanned demands and total failures per plant operational year decreased during the 7-year period. These trends are shown in Figure 6-5. (The unplanned demand rate, as shown in Figure 6-5, is defined as the total unplanned demands divided by the equivalent operating time for the plants in operation during the year. Likewise, the system failure rate is defined as the number of 


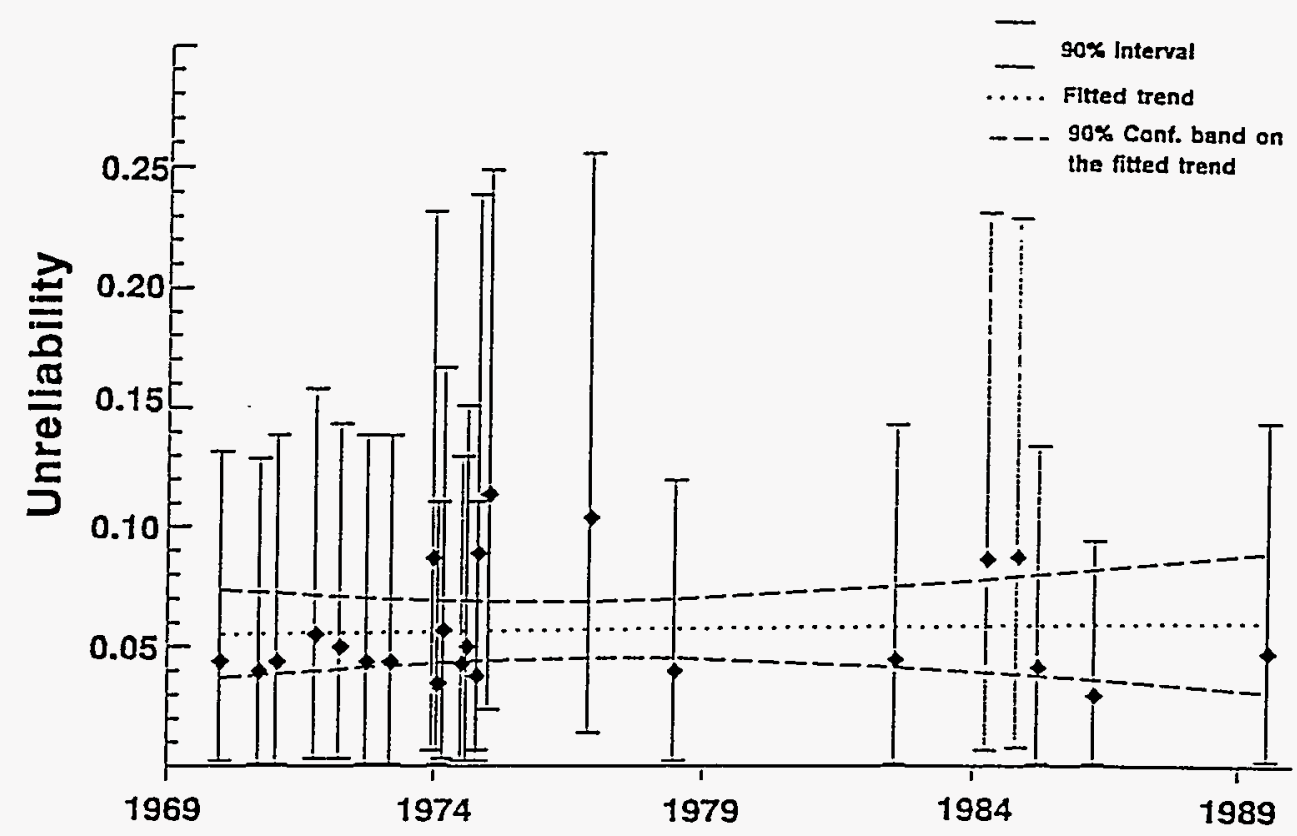

Low power license date

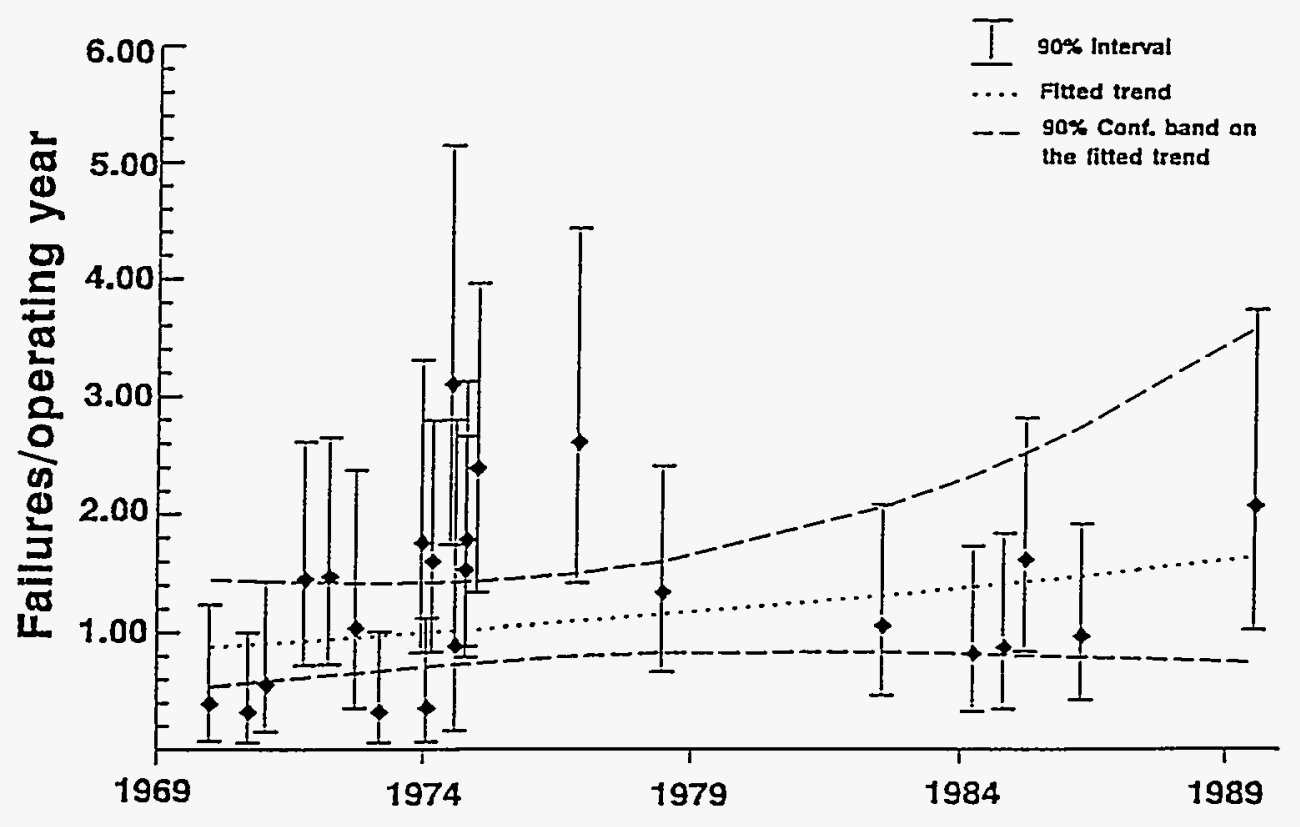

Low power license date

Figure 6-4. Plots of plant-specific HPCI system unreliabilities and failures per operating year plotted against plant-specific low power license date. (Failures per year are all failures divided by the equivalent operating years for the plant). 


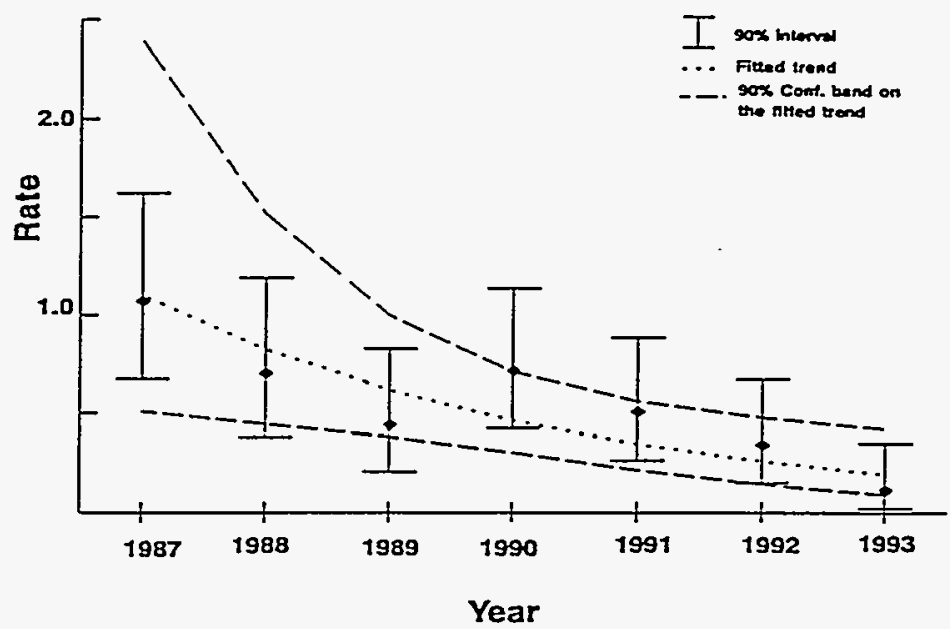

System unplanned demand rate

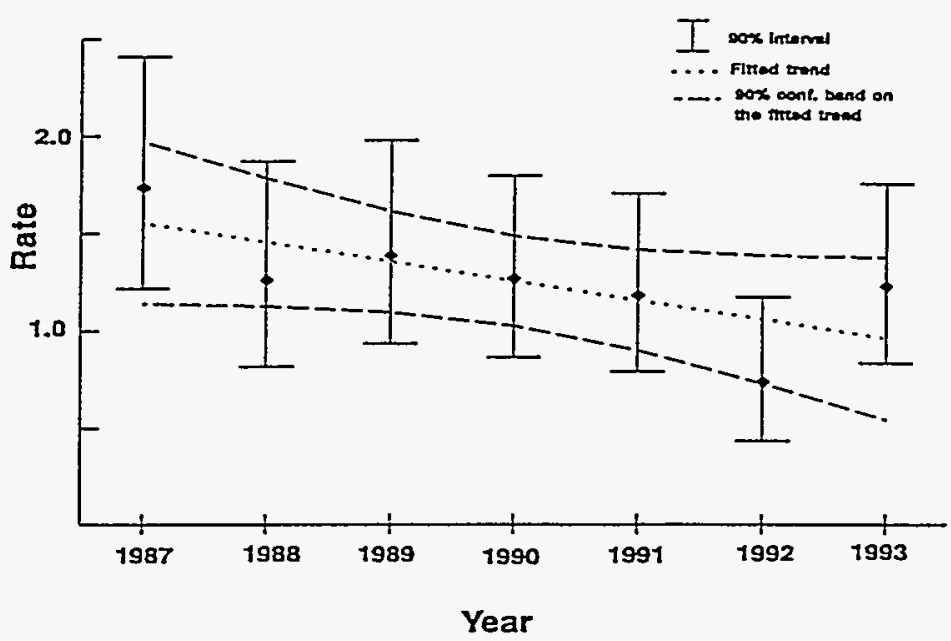

System failure rate

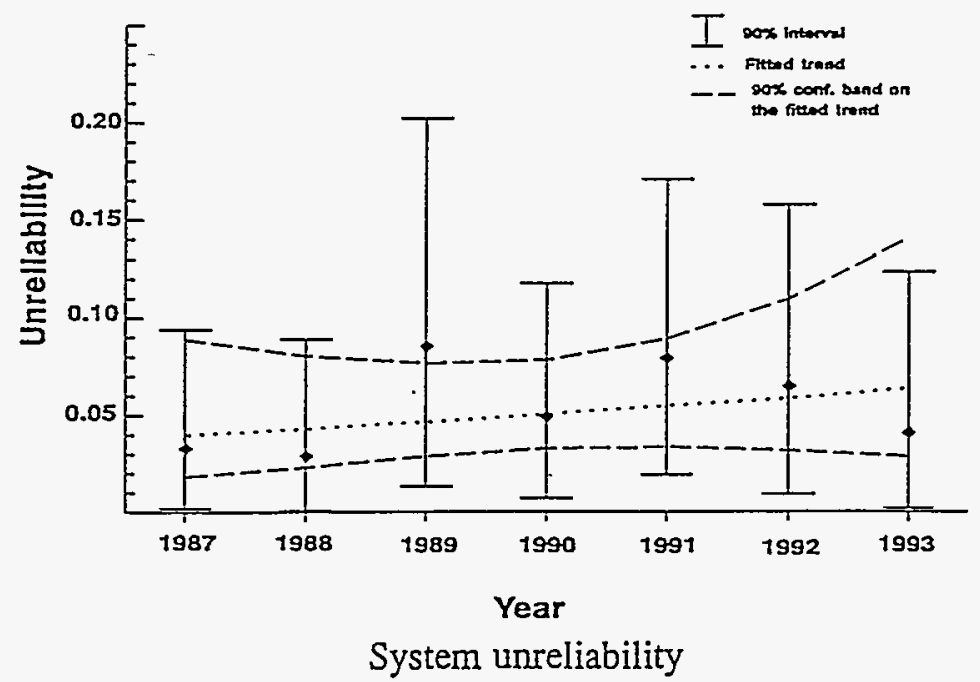

Figure 6-5. HPCI system unplanned demand rate, failure rate, and unreliability, per calendar year. 
system failures divided by the equivalent operating time for the plants in operation during the year.) The associated unreliability showed no significant trend. This result, too, indicates a lack of an aging influence, and it also indicates that system reliability cannot be trended based on demand or failure rate trends.

\subsection{A Reliability Study of Safety-Related Steam-Turbine-Driven Pumps}

This U.S. study (Boardman 1994) reviewed the operational history of auxiliary feedwater (AFW), HPCI, and reactor core isolation cooling (RCIC) system pump turbine assemblies. During the past 16 years, although there have been $71 \mathrm{NRC}$ and industry generic communications and studies which addressed problems with these standby turbines, there have been recurring problems with the reliability of these turbines.

The purpose of this particular study was to analyze available data on standby turbine-driven pump failures to identify failure mechanisms and corrective actions, and to update the reliability data on these pumps for use in reliability and risk-based studies. The findings and conclusions documented in this report are based on the following.

- A review of over 2,000 LERs for the period of 1974 through 1992, 660 NPRDS failure reports for 1985 through 1992, and generic communications and studies issued by the NRC and U.S. industry.

- Discussions held with appropriate personnel at selected plants to gain a better insight into specific failures that had been reported.

- Discussions held with the turbine and governor manufactures to gain a better understanding of the components involved.
This study, which was peer reviewed by the NRC staff and industry (including the Institute for Nuclear Power Operations (INPO), Dresser-Rand Terry-Turbodyne, the Woodward Governor Company, and the General Electric Company), confirmed the continuing validity of earlier NRC and U.S. industry studies. Significant turbine failures appear to result from: (a) governor control system failures, many of which were age related, such as the multiple failures of power supply voltage dropping resistors; (b) lack of maintenance necessary to compensate for site-specific, age-related degradation; (c) lack of design control; and (d) condensate in turbine steam supply lines. Recurring failures identified during this study were analyzed for root causes that had not been previously addressed in generic communications. Significant factors affecting standby turbine reliability identified during this study were maintenance which did not incorporate existing manufacturers' guidance (including specified periodicities), and the failure of subcomponents and piece-parts as a result of site-specific aging phenomena not considered in preventive maintenance programs.

In February 1993, investigation at a nuclear power plant in response to turbine-driven AFW pump overspeed events identified the following problems.

- The site was using a 1975 Terry Turbine manual which was not adequate for certain maintenance being performed by the utility, a concern addressed in NRC Generic Letter 83-28, Required Action Based on Generic Implications of Sàlem ATWS Events, August 8, 1983.

- The Unit I governor-valve to governorservomechanism mechanical linkage had been out of adjustment, which could result in turbine-driven AFW pump overspeed during quick-start.

- The condition of the turbine drain system permitted the accumulation of condensate, which was a primary cause of the overspeed events, a problem addressed in NRC Information Notice 86-14, Supplement 1, 
Overspeed Trips of AFW, HPCI and RCIC Turbines, December 17, 1986.

Failure detection for these standby pumps is sensitive to surveillance testing methodology, and certain surveillance test requirements may not replicate actual demands. Continuing reports of recurring failures, such as governor dropping resistors and overspeed trip ball tappets, are strong indications that additional effort is warranted.

The failure rates of these standby pump turbine-drivers remained essentially constant, though certain of these failures were repetitive. The lack of standardization of turbine assembly design, and site-specific differences in maintenance practices, tend to mask industry-wide trends. Considering the types of failures identified during this study, enhancement of standby pump turbine-driver reliability could be achieved by:

- Using existing Terry and Woodward maintenance instructions and obtaining additional manufacturer guidance for maintenance not adequately detailed

- More effective implementation of design control and dedication of commercial grade items used in standby turbine applications

- Enhanced use of guidance contained in previously issued NRC and industry generic communications applicable to turbine failures.

The results of this study indicate that failures of these pump turbines are not related to aging, but are mostly a result of maintenance deficiencies. 


\section{UNITED KINGDOM}

The UK provided a report entitled Review of UK Studies on Aging Effects on Nuclear Power Plants (Todd 1994) ${ }^{\mathrm{a}}$ which provides a summary of much of the work being done in the United Kingdom to investigate the aging of nuclear power plant equipment. They also provided a report, Review of UK Studies on Aging Effects on Nuclear Power Plants - Case Studies Draft A (Dunbar 1995), ${ }^{\mathrm{a}}$ which is an extension of the first report and provides more detail for two case studies. The following discussion presents summaries of the two reports.

\subsection{Review of Aging Studies}

The report, Review of UK Studies on Aging Effects on Nuclear Power Plants, was prepared by the Nuclear Safety Division of the UK Health and Safety Executive. This paper identified research programs and other studies of nuclear component aging and summarized their general findings. The main sources for the project were material made available by AEA Technology, the Health and Safety Executive, and Nuclear Electric (NE) (one of the nuclear utilities in the UK). The UK studies generally fell into two main categories: material degradation studies and analysis of maintenance data. A number of the key studies are described in the following paragraphs.

Derivation of Reliability Data for Aging Equipment (Dunbar 1994). ${ }^{\text {T The objectives of this }}$ project were to develop an aging classification system and establish relationships between component failure rates and various design and environmental factors. An aging classification database was developed for a range of components including valves, pumps, heat exchangers, blowers, electric motors, and non-rotating electrical power supplies. A limited examination of how relevant processes and design parameters influence the various aging failure modes was performed. An analysis of mechanical valve failure rate versus age (in two intervals, 5 to 8 and 16 to

a. See Section 11 of this report for bibliographic information.
18 years) using data from one Magnox and one advanced gas reactor was completed. It was concluded that there was some correlation between the increase in the failure rates of mechanical valves and their age. However, the study was based on the assumption that the age of the components and site age coincide. The study identified lack of detailed data as a major obstacle to more specific aging studies in the UK.

Continued Operation of a UK Magnox Reactor (Fendick et al. 1994). This study includes a qualitative aging review (identification of aging processes and an assessment of monitoring, repair, and replacement strategies) and the development of data collection systems for reliability monitoring of a variety of systems, including those used to trip the reactors and cool the reactors after a trip. The study was carried out by observing how a specific function is performed at an identified location over a period of time. Key observations included the fact that their graphite cores do not appear to have deteriorated with age; their vessel transition temperature changes may be greater than anticipated; and their pressure vessel welds are in excellent condition.

Reliability Data Collection and Engineering Trend Analysis to Support Continued Operation of a UK Magnox Reactor (Andre' 1994). The main achievements of this study were the development of computerized tools for (a) sorting and analysis of maintenance data to highlight trends on system reliability; (b) extracting information on mean failure rates, ratio of pro-active to reactive maintenance interventions, and the proportion of events which cause a loss of function; and (c) analyzing time between failures. When these computer tools were applied to the available data, no adverse trends were found; however, the data did suggest that an adjustment to the control rod maintenance schedule was appropriate.

Reliability and Data Collection Study of Heysham 1 Power Station (NE 1993). ${ }^{\text {a The }}$ purpose of this study was to use the computer tools discussed above to determine the reliability characteristics of a number of Heysham Unit 1 
systems over a 3 year period and thereby evaluate their maintenance and testing practices. Data from the following kinds of systems and components were analyzed: gas circulators; vessel cooling water; essential electrical supplies; $\mathrm{CO}_{2}$ supply route; vessel and boiler cooling valves, diesel engines and pumps; control rods, etc. For most components, no significant trends were found, i.e., component life expectancy was the same later as earlier in the period. However, the effectiveness of the approach was demonstrated by the detection and elimination of governor faults on the gas turbine systems. These components had shown an increase in defect events immediately prior to new governor installation.

First Periodic Functional Review of Ageing Monitoring Inspections at Calder Hall and Chapelcross Covering the Two Years up to June 1993, (Crosby 1993). a The main objective of the periodic functional ageing monitoring review adopted by British Nuclear Fuels Ltd. (BNFL) is to analyze any evidence of adverse trends, with particular emphasis on the monitoring of structural items subject to ageing through wear, creep and corrosion. The review includes the production of individual reports containing inspection results, analysis of specific findings, and the production of a summary report. The review concentrates on inspection of items which are difficult or impractical to replace or repair and whose failure would have significant impact on safety. The main findings of the project can be summarized as:

- Ageing monitoring inspections during the past two years have shown no changes due to ageing which constitute, at this time, a threat to safety in the operation of the Calder Hall and Chapelcross reactors.

- Some components have shown a definite change in their characteristics due to ageing. However, these components can be repaired, or their degradation does not prejudice the safety of site operation in the period up to the next ageing review.

a. See Section 11 of this report for bibliographic information.
The main conclusions drawn by the overall review are that no major phenomena of degradation due to aging have been observed at the UK nuclear power plants studied, and that degradation phenomena, when present, are of a minor nature and do not appear to affect the reliability performance of plant systems. The main limitation in the analysis of the active components is the lack of consistent component-specific data from installation to removal. A summary of the findings is presented in Table 7-1.

\subsection{Case Studies}

The report Review of UK Studies on Ageing Effects on Nuclear Power Plants - Case studies (Dunbar 1995)a reviews two UK case studies. One is part of the General Nuclear Safety Research Project PSA 21 (GNSR PSA 21) program and includes development of a system for classifying and evaluating failure data and applying the system using data from three plants of different designs and varying ages with component age ranges up to 13 years. The other is a study of data from the Heysham 1 plant covering three years.

The conclusion reached in the report is that the GNSR study appears to show evidence of aging but the Heysham 1 study finds no evidence of such a trend. Summaries of the information provided in the report for the case studies are provided below.

GNSR PSA 21 Study. This project comprises various phases addressing two main subjects: (a) the classification of failure data, and (b) the analysis of data to detect aging. The system classification classifies the failures based on environmental parameters, conditional influence, operating status at the time of failure, degradation type and location, failure mechanism, failure mode, and effects of the failure. For each of these classifications, alpha-numeric descriptors were assigned to describe the failures and provide for electronic sorting for evaluation. Components of valves, 
Table 7-1. Summary of findings in studies surveyed.

\begin{tabular}{|c|c|c|}
\hline Reference & Subject & Findings \\
\hline $\begin{array}{l}\text { Dunbar } \\
1994^{\mathrm{a}}\end{array}$ & $\begin{array}{l}\text { Derivation of reliability data } \\
\text { for aging equipment }\end{array}$ & $\begin{array}{l}\text { - } \begin{array}{l}\text { No strong correlations were observed between } \\
\text { selected operating parameters and failures } \\
\text { reported due to aging phenomena. }\end{array} \\
\text { - } \begin{array}{l}\text { Correlation between age and failure rate are not } \\
\text { dramatic for older components. }\end{array} \\
\text { - Components in stations of similar age exhibit } \\
\text { similar behavior. }\end{array}$ \\
\hline $\begin{array}{l}\text { Fendick } \\
\text { et al. } \\
1994\end{array}$ & $\begin{array}{l}\text { Continued operation safety } \\
\text { case for UK Magnox stations }\end{array}$ & 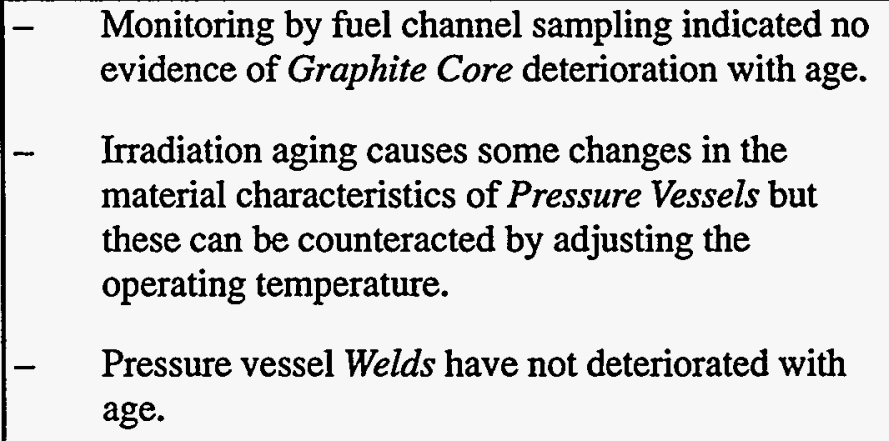 \\
\hline $\begin{array}{c}\text { Andre' } \\
1994\end{array}$ & $\begin{array}{l}\text { Data collection and analysis of } \\
\text { failure event data in Magnox } \\
\text { reactors }\end{array}$ & $\begin{array}{l}\text { No changes in the fundamental characteristics of } \\
\text { systems installed early in the life of the station and } \\
\text { studied in the report were detected. } \\
\text { - Component deterioration was observed in some } \\
\text { Rods but this problem was easily solved by } \\
\text { adjusting maintenance practices. }\end{array}$ \\
\hline $\begin{array}{c}\mathrm{NE} \\
1993^{\mathrm{a}}\end{array}$ & $\begin{array}{l}\text { Data analysis of safety related } \\
\text { systems at Heysham } 1\end{array}$ & 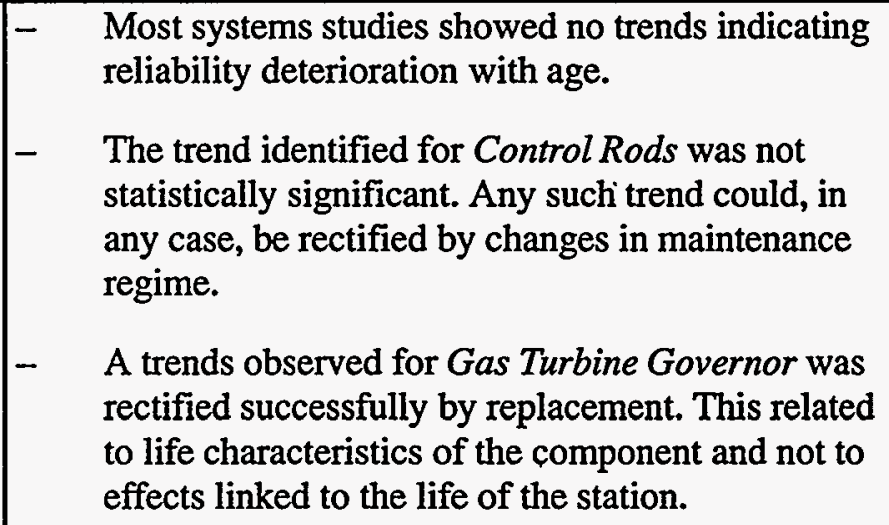 \\
\hline $\begin{array}{l}\text { Crosby } \\
1993^{\mathrm{a}}\end{array}$ & $\begin{array}{l}\text { Functional review of aging } \\
\text { monitoring at BNFL reactors }\end{array}$ & $\begin{array}{l}\text { - } \begin{array}{l}\text { No changes capable of threatening safety were } \\
\text { detected. }\end{array} \\
\text { - } \begin{array}{l}\text { Changes due to aging relate to life characteristics } \\
\text { of replaceable or repairable components and are } \\
\text { not linked to the age of the station. }\end{array}\end{array}$ \\
\hline
\end{tabular}

a. See Section 11 of this report for bibligraphic information 
pumps, motors, power supplies, heat exchangers, and blowers and fans were selected for evaluation based on the populations of data available in the AEA Technology databank. For these components the project also produced an inventory of the selected components for use in computing failure rates.

The data analyses were performed only for mechanical valves, because these were the only components with sufficient volume of data available to allow a meaningful statistical analysis. The data analysis was performed on two types of data: failure rates for groups of components defined in terms of design and operating characteristics, and failure rates on groups of components sorted by age.

For the first type of analysis, results are presented showing the contribution of each descriptor for each of the classifications. For example, $76 \%$ of the failure modes, the classification, were found to be leakage, the descriptor. Results were also presented identifying possible links between the separate aging factors, that is, the descriptors. For example, internal failures were found to be responsible for $70 \%$ of the instances of blockage.

Failure rates were related to pressure, temperature, and valve diameter. Trends were evaluated using scatter plots that plotted failures per calendar year against these parameters. The analyses were made more quantitative by fitting a regression model of the form:

$\mathrm{y}=\alpha+\beta_{1} \mathrm{x}_{1}+\beta_{2} \mathrm{x}_{2}+\beta_{3} \mathrm{x}_{3}$

where $y$ is the failure rate, $\alpha$ is a constant and the $\beta$ 's are the regression coefficients associated with pressure, temperature, and diameter. The $\alpha$ 's and $\beta$ 's were reported for six valve groupings starting with the group of all valves progressing to the more specific group of gate valves with the leakage failure mode and the service media recorded. In all cases the correlation coefficients were small, pointing to weak correlations.

The final phase of the analysis studied groups of components sorted by their presumed age. The analyses were made using failure data for valves collected from three plants started at different times. The plants were:

- A Magnox plant, which started operation in 1968

- An advanced gas reactor (AGR) plant, which started operation in 1978

- The prototype fast reactor plant, which started operation in 1976.

The analyses assumed that the age of the component was the same as the age of the plant, and that there were strong similarities between the AGR and Magnox valves. As in the initial phases of the study, analyses were made of the percentage of failures associated with specific failure modes and failure causes to check that the results were compatible between the two approaches.

The failure causes and failure modes percentages were found to vary considerably with age across the plants, but the ranges obtained for each mode and cause encompass the values obtained in the previous phases. This result was taken as an indication that the data derived in the previous phases were representative of average behavior of components of mixed ages. The comparison of component groups of the same age (8 years) for different plants showed that failure mode and cause percentages are roughly the same. This result was taken to indicate that age may be a stronger influence in determining the distribution of failure mode and causes than operating conditions.

For two plants, the estimated failure rates were plotted against the presumed age of the valves, as shown in Figure 7-1. An increase in failure rates with valve age is apparent both within and across the plants. The rates span about one order of magnitude between the lowest and highest age categories. There is some overlap between the range of the failure rates for the $A G R$ and Magnox plants, suggesting that the magnitude of the effect of age on the failure rate may be smaller 


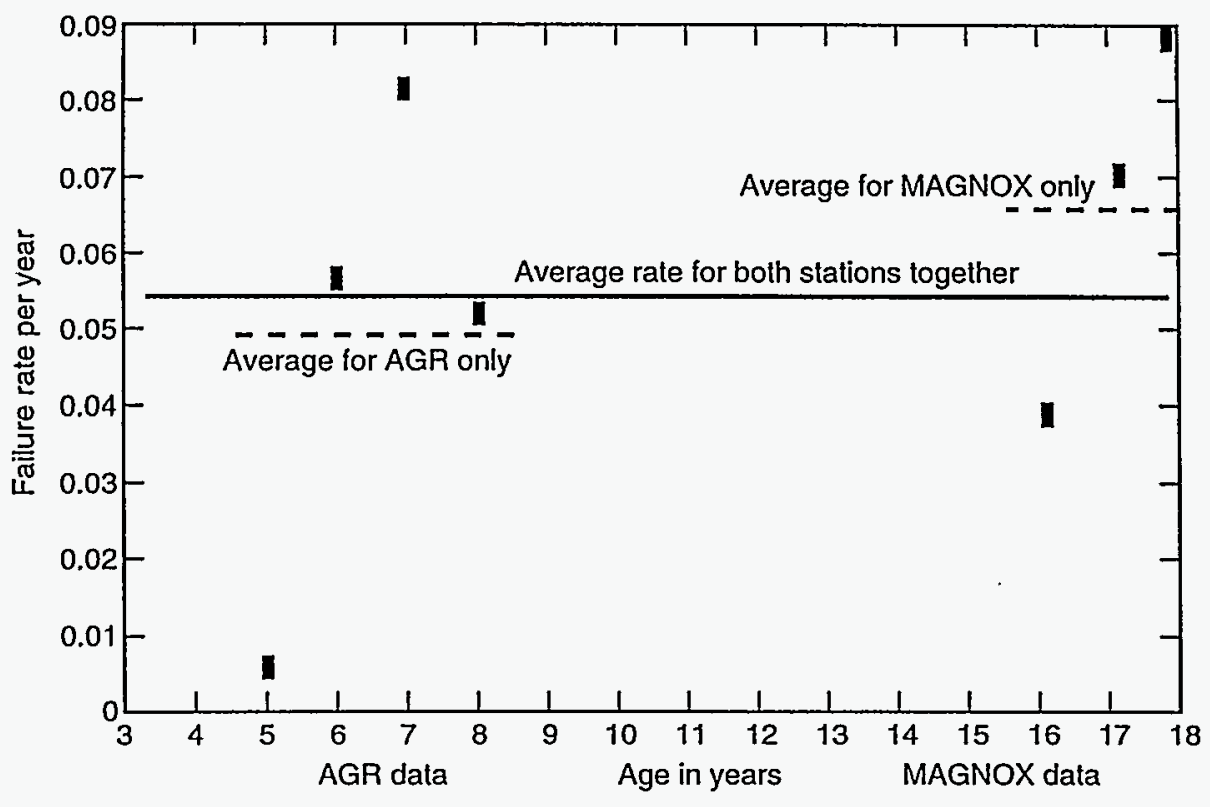

vGrBD95 0222

Figure 7-1. Failure rates for AGR and Magnox valves.

than is suggested by the variations observed within the same plant. The GNSR study attempts to comment on the statistical significance of the variations shown in Figure 7-1 However, the approximation made in the study to calculate the statistical uncertainty intervals (not shown in Figure 7-1) is not robust. This must be taken into account when assessing the apparent trends in Figure 7-1.

A series of assumption was made on the age of the valves and on similarities of design and operation across the stations, which is likely to affect further the interpretation of the results in Figure 7-1. These assumptions were necessary because of deficiencies in the data, but they preclude a proper quantitative study of the statistical significance of the results. Poor data quality was identified as one of the main limitations of the study. The uncertainty introduced by the assumptions means that the conclusions from the study are essentially qualitative rather than quantitative. The study does not attempt to quantify either the rate of increase in the failure rate with age, nor the statistical uncertainty associated with the average failure rates calculated for each plant irrespective of valve age.
The general conclusion from the analysis of the valve data is that some positive correlation between age and failure rate is likely, but it is not possible, from the available data, to establish a quantitative relationship for predicting the failure rate with age.

Heysham I Study. This study examined the corrective maintenance records of the Heysham 1 plant. It included review of the records for 14 sub-systems and covered the last three years that the records were held in the plant Maintenance Record system, the beginning of 1990 up to the end of 1992. A computerized data base was developed by importing the data of interest and organizing them into appropriate computer files. Summary statistics were developed for the components of the subsystem that showed the ratio of planned and unplanned maintenance events, mean corrective maintenance event rate, and percentage of corrective maintenance events that caused loss of function of the components and loss of function of the system. Graphical analysis was carried out showing the relative contribution to the total corrective maintenance events of the component, cause of fault and nature of corrective action. This technique was used to assess the 
dominant characteristics of the failure mechanisms.

Maintenance event trend analyses were made using calendar time plots. The plots used were:

- Standard control charts plotting monthly event rates

- Moving averages using a period long enough to smooth out seasonal averages

- Rate to date using increasingly longer periods ending with the overall surveillance period

- CUSUM plots using the cumulative difference with respect to the mean.

As an example, a standard control chart for safety circuits is shown in Figure 7-2. As a further evaluation of trends, the times to failure were fit to a Weibull distribution function, with a shape factor of one indicating a constant event rate and values greater and less than one indicating increasing and decreasing failure rates, respectively.

In most of the cases, the corrective maintenance event rate, which was assumed to be directly proportional to the component failure rate, appears to decrease. In some cases, the rate peaks and then decreases. Figure 7-2 shows an example of this behavior. These cases often coincide with periods of particular problems with the rate decreasing after the problem is resolved. For the particular case of the safety circuits shown in Figure 7-2, the peak is explained as most likely due to opportunistic maintenance to repair non critical defects during a reactor refuelling rather than a result of increased defect rate. The example illustrates that care is required when interpreting charts of this type. The shape factor for Weibull distribution of the corrective maintenance events for the safety circuit is essentially one indicating a constant failure rate.

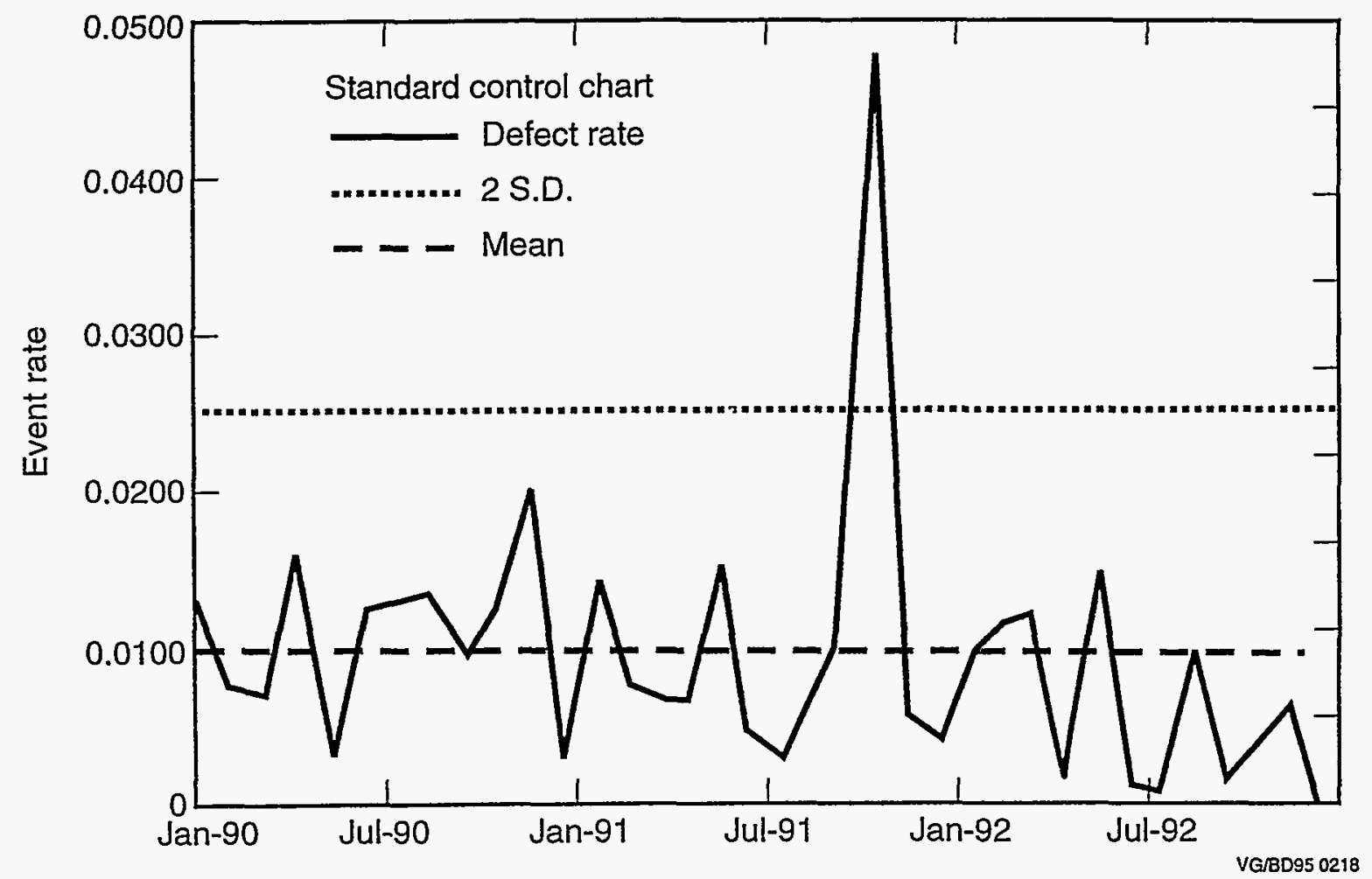

Figure 7-2. Trend charts for safety circuit data (monthly event rate). 
Trend plots for the control rod and control and interlock data suggest an increase in failure rate over the three year period. The study attributes the trend to an increasing number of defects for static contactors, a component of the sub-system. However the Weibull analysis for this component shows a tendency for early failures, and that there is no evidence of a wearout mechanism that would have shown an increase in the failure rate later in component life. The apparent contradiction is explained by recognizing that the static contactors are replaced when they fail, and because they are subject to infant mortality their failure rate will be initially higher, resulting in increased maintenance events for the system. This example illustrates the difference between deterioration in reliability applicable to repairable systems and that applicable to components normally replaced after failure. The system is shown as having an increase in maintenance events with time, implying reliability deterioration at the system level, yet the cause cannot be attributed to component aging, because the Weibull analysis shows that the static contactors are subject to early failures rather than late failures as would be the case if the failures were due to mechanisms normally associated with aging, such as fatigue or wearout. 


\section{STATISTICAL ANALYSIS}

This section compares the methods of statistical analysis used, both in the reports officially submitted and in other work of which we are aware. The conclusions of the analyses are also compared to some extent. Subsections 8.1 through 8.3 deal with reported failures of active components. Subsection 8.4 addresses passive components. The final subsection lists some overall conclusions.

\subsection{Examination of Failure Causes}

Of the reports provided by the participants, several investigated whether the causes of failures were related to aging. For example, the British GNSR study reviewed by Dunbar (1995) looks for instances of wear, and for environmental stresses such as pressure and temperature. The Japanese report (Safety Information Center 1994) a gives a similar tabulation of causes such as mechanical fatigue, corrosion, and natural deterioration. (See Figures 5-1 and 5-3 of this report.) The Swedish report by Shen and Nyman (1994) ${ }^{a}$ describes a similar investigation. The Finish report by Simola (1992) discusses studying data by FMEA and similar methods; for example, about half the failures had an aging-related cause (including normal wear). Such a tabulation of the data is a natural first step in studying aging; therefore, it has been performed in many countries.

The individual studies are not easy to compare. Only results for mechanical valves are reported for the British GNSR study, and many entries are "unknown." Results for six kinds of components are reported by the Japanese, of which 25 valve failures involved age-related causes. The Swedish report presents summary conclusions in terms of electrical components and mechanical components, and does not give the immediate failure causes. The Finnish report by Simola reports results only for motor-operated valves,

a. See Section 11 of this report for bibliographic information. and says that about half had causes related to aging. In summary, aging is found as a contributor to many reported failures, but the details are difficult to compare between countries.

\subsection{Direct Estimates from Binned Failure Data}

The approach considered here collects the data into bins, such as all the components of age $i$, where $i$ identifies a time interval, such as a year. A natural nonparametric estimate of the failure rate or failure probability for the $i$ th bin is simply the number of observed failures divided by the total exposure time for the bin or the number of demands for the bin. A plot of the estimated failure rate or probability versus $i$ may show the presence or absence of a trend. This method is used by the British GNSR study (Dunbar 1995) a and by the French study (Maupou 1994) ${ }^{\mathrm{a}}$; in both of these cases failure rates by age are found and plotted.

Versions of this approach are also used in the U.S. HPCI study by Grant et al. (1995), with other ways of binning. In some cases, the data were binned by calendar year (ignoring differences between plants). The unplanned demand rate, failure rate, and system unreliability were each found, based on the data for the calendar year, and examined for evidence of a trend (Figure 6-5 of this report). In other cases, the data were binned by plant. Each plant had about seven calendar years of data, from which a plant-specific HPCI system unreliability or failure rate was calculated. The plant low power license dates covered a span of about 20 years. The unreliabilities and failure rates were plotted against the low power license dates, and showed no trends corresponding to age of the plant (Figure 6-4 of this report).

The results of the three studies differ. The qualitative analysis presented in the GNSR study shows an increasing failure rate for mechanical valves at each of two plants over time spans of three and four years, respectively; however, the older plant is only slightly worse on average than 
the much younger plant. The French study of circuit breakers found too few failures at most plants to show a trend. At one plant the failure rate rose during a five-year period, until a problem was correctly identified and fixed, after which the failure rate returned to its original low value. The U.S. study found no trends that indicated aging.

\subsection{Modeling Trends in Failure Rates or Probabilities}

One of the purposes of modeling trends in failure rates or failure probabilities is to determine the presence and magnitude of any overall trend. Failures in time and failures on demand are modeled somewhat differently, and so are discussed separately below.

\subsubsection{Failures in Time}

All the reviewed reports model trends by assuming that failures in time arise from a nonhomogeneous Poisson process. This is a simple generalization of the usual model in probabilistic risk assessment (PRA), in which failures occur at random with a constant failure rate, $\lambda$. The generalization consists of allowing the failure rate, $\lambda(t)$, to vary in a deterministic way over time. The failure rate is called the Poisson intensity function in some of the literature.

Although all the reviewed reports use a nonhomogeneous Poisson process, the Swedish summary by Pörn (1995) ${ }^{\mathrm{a}}$ questions this model. It suggests a more complex model, a "Trend Renewal Process," that would allow for repairs that restore the component to a condition between its new state and its state just before the failure.

Test for Presence of a Trend. A recent report by Sanzo et al. (1994) gives an extensive review of much of the aging work in the U.S. This report and, to a lesser extent, the Finnish report by Simola (1992) review standard tests for several hypotheses, such as increasing failure rate (IFR) and "new better than used." A U.S. report by

a. See Section 11 of this report for bibliographic information.
Wolford et al. (1992) uses the Laplace test to test whether a trend is present. When all the data sources (plants, components, etc.) report data for the same time interval, this test is based simply on comparing the mean of the observed failure times with the midpoint of the study period. More precisely, suppose that the process is observed from time 0 to time $\tau$, and that $n$ failures are observed; denote the failure times by $T_{1}, T_{2}, \ldots, T_{n}$. The average of the failure times is $\sum T_{i} / n$, denoted $\bar{T}$. If the failure rate is constant, $\bar{T}$ should be near $\tau / 2$, the middle of the observation period, not at either end of the observation period. The theoretical standard deviation of $T$ is $\tau /(12 n)^{1 / 2}$, which is denoted by $S$ here. The Laplace test rejects the hypothesis of a constant $\lambda$ if $|T-\tau| / 2 \mid / S$ is larger than some cutoff value.

This can be illustrated with the data sets in Figure 1-2. The test requires slight modification, because the sampling in Figure 1-2 was not for a fixed time period, $\tau$, but until a prespecified number of failures was observed; each time line ends with a failure. Nevertheless, the first (happy) data set has the mean time of the observed failures far to the left of the midpoint of the time interval, and the Laplace test would therefore conclude that the failure rate is decreasing. With the second (sad) data set, the Laplace test would conclude that the failure rate is increasing, because the mean of the observed failure times is far to the right of the midpoint. The Laplace test would conclude that the third data set is consistent with the assumption of a constant failure rate, because the mean of the failure times is near the midpoint of the time interval.

Estimation of the Failure Rate. Wolford et al. (1992) and the closely related paper by Atwood (1992) consider three forms of the failure rate $\lambda(\mathrm{t}):$

$$
\lambda(t)=\lambda_{0} \exp \left[\beta\left(t-t_{0}\right)\right] \quad \begin{aligned}
& \text { exponential failure } \\
& \text { rate }
\end{aligned}
$$

$\lambda(t)=\lambda_{0}\left[1+\beta\left(t-t_{0}\right] \quad\right.$ linear failure rate

$\lambda(t)=\lambda_{0}\left(t / t_{0}\right)^{\beta} \quad$ power law or Weibull failure rate. 
The nonstandard form of the Weibull exponent allows the same interpretation of $\beta$ in all three cases, with $\beta=0$ corresponding to a constant failure rate.

In each case, the number $t_{0}$ is chosen for convenience by the analyst. Each such function has two unknown parameters, $\beta$ and $\lambda_{0}$. Maximum likelihood estimates (MLEs) are found for the parameters, typically using numerical iteration. (The usual algebraic formulas for the MLEs of the Weibull parameters are deemphasized, because they are valid only when the data reporting begins at time zero.) Using the asymptotic normality of the MLEs for $\beta$ and $\log \lambda_{0}$, the failure rate $\lambda(t)$ at any fixed time $t$ has an approximate confidence interval based on the lognormal distribution. For use in PRA, this lognormal distribution is recommended as the Bayes distribution for $\lambda(t)$. Wolford et al. (1992) applied the method to components in the auxiliary feedwater system at a pair of plants at one station. Little evidence of aging was found, and it had a negligible effect on risk to the plant.

The Swedish report summarized by Pörn $(1995)^{\mathrm{a}}$ is very similar. It assumes that the failure rate has a Weibull form plus an unknown constant:

$\lambda(t)=C \cdot \lambda_{1} \cdot t^{C-1}+\lambda_{0}$,

This generalized Weibull model has three unknown parameters. The report takes a Bayesian approach from the start. It finds noninformative prior distributions for the three unknown parameters, updates them with the data, and obtains posterior distributions, which are combined to yield a posterior distribution for $\lambda(t)$.

The Finnish study reported by Simola and Laakso (1992) examined nine years of data from 104 motor-operated closing valves at two sister units. One statistical analysis assumed a Weibull failure rate, and estimated the parameters; the failure rate was estimated to be nearly constant, or

a. See Section 11 of this report for bibliographic information. perhaps slightly decreasing, for both sets of valve components (mechanical and electromechanical). However, an analysis specifically looking at leakage failures found an increasing failure rate.

Bier et al. (1990) follow a Bayesian approach which relies much less on a parametric form. They model the prior belief about the failure rate as a finite collection of possible failure rate functions, each with a corresponding probability. They express the data in terms of counts per time period, such as per year. The prior mixture of failure rates corresponds to a mixture of failure probabilities for each time period. This mixture is updated by the data, yielding a posterior distribution for the failure probability in each year. Note that separate updates are not performed for the different years; instead, the entire data set is used to update the prior distribution once, yielding a posterior distribution for the probability of a failure for each year.

Diagnostic Checks of the Assumptions. The reports by Wolford et al. (1992) and Atwood (1992) investigate the validity of the assumed failure rate function by comparing the observed cumulative failure count with the fitted cumulative failure rate based on the assumed model. The graph is called a Q-Q plot in statistical literature. The corresponding Kolmogorov-Smirnov tests are performed. The reports also investigate the validity of the asymptotic normality, by visually comparing the confidence ellipse based on asymptotic normality with a confidence region calculated from more fundamental considerations.

The Swedish report summarized by Pörn also investigates the validity of the assumed failure rate function by comparing the observed cumulative failure count with the fitted cumulative failure rate (a $Q-Q$ plot). Only the graphical comparison is mentioned in the summary. For three analyses of centrifugal pumps in the containment spray system, the study finds good agreement with the Weibull assumptions in one case and questionable agreement in the other two cases.

The other reports that model trends do not consider diagnostic checks, although Bier et al. 
briefly mention the usual Bayesian problem of choosing an appropriate prior distribution.

Comparisons. The reports described here all use a Poisson process with failure rate $\lambda(t)$, but they differ to some extent in the form of $\lambda(t)$. They also differ in the details of the analysis, but would probably reach similar conclusions if they were all analyzing the same data set.

In fact different data sets were used, and the studies agreed in finding little evidence for aging. The Wolford and Bier studies found evidence for aging only for a few components in the systems they analyzed, typically because very few failures were reported for most types of components. The Swedish study of three data sets for centrifugal pumps found one decreasing failure rate and two constant failure rates, although the assumptions of the Weibull process were questioned in the latter two cases. The Finnish study of motoroperated valves found a slightly decreasing failure rate, when the model measured time from the start of the data reporting period.

\subsubsection{Failures on Demand}

The Finnish report by Simola (1992) describes an analysis of failures on demand (valve leaks during annual tests). A Bayesian analysis was performed. For simplicity, the distribution of the failure probability $q$ at any time was made discrete on 1000 points, and $q$ at year $i+1$ was assumed to be related to $q$ at year $i$ by a Markov transition matrix (with dimension $1,000 \times 1,000$ ). The prior distribution and the form of the matrix were all assumed, with one parameter of the matrix, $\alpha$, allowed to vary. The posterior likelihood was maximized when $a=0.7$, and this model gave a better fit to the data than when $q$ was assumed to be constant over time (corresponding to $\alpha=1$ ). The analysis does not appear to be a standard Bayesian analysis, because the prior and posterior distributions of $\alpha$ are not mentioned.

A standard statistical method for analyzing the same data set is logistic regression; this method is being investigated for use in the U.S. (see Atwood 1995). This method uses the logit function, defined as $\operatorname{logit}(p)=\log [p /(1-p)]$. In applications, $p$ is the probability of failure. To analyze the Finnish valve data, we modeled the logit of the failure probability with three parameters: an overall constant, a plant effect, and a slope parameter for the time trend. When the Finnish data set was analyzed with this method, the failure probabilities were estimated as shown in Figure 8-1; trend lines and $90 \%$ confidence bands for the lines are shown.

Both analysis methods conclude that the failure probability increases with time. The logistic regression method is standard, and therefore is available in commercial software packages, accompanied by tests for goodness of fit and for statistical significance of the parameters. The logistic regression analysis of this data set shows that both the parameter for plant effect and the parameter for time trend differ from zero by a statistically significant amount, and that no significant lack of fit was evident. The method in the Finnish report appears to have been invented for this analysis, and so does not have such refinements. For example, the analysis does not show whether the difference between $\alpha=0.7$ and $\alpha=1.0$ is statistically significant or whether the data show lack of fit to the model.

\subsection{Passive Components}

Passive components are of concern because they may be weakening, and yet the deterioration may not be recognized until a catastrophic failure occurs. Most passive components do not provide adequate numbers of failures to analyze statistically. The relevant data for statistical analysis would, instead, consist of condition monitoring (a term used by Simola 1992). That is, the condition of the component, such as thickness, presence of cracks, or surface smoothness, would be observed or measured, continuously or periodically. Sanzo et al. (1994) argue strongly and at length that the physics of aging should be central to any investigation of aging. This would lead to more detailed data for active components (for example, not only that a component failed but its physical state at the time of failure) and to relevant in-situ measurements for passive components. It should 

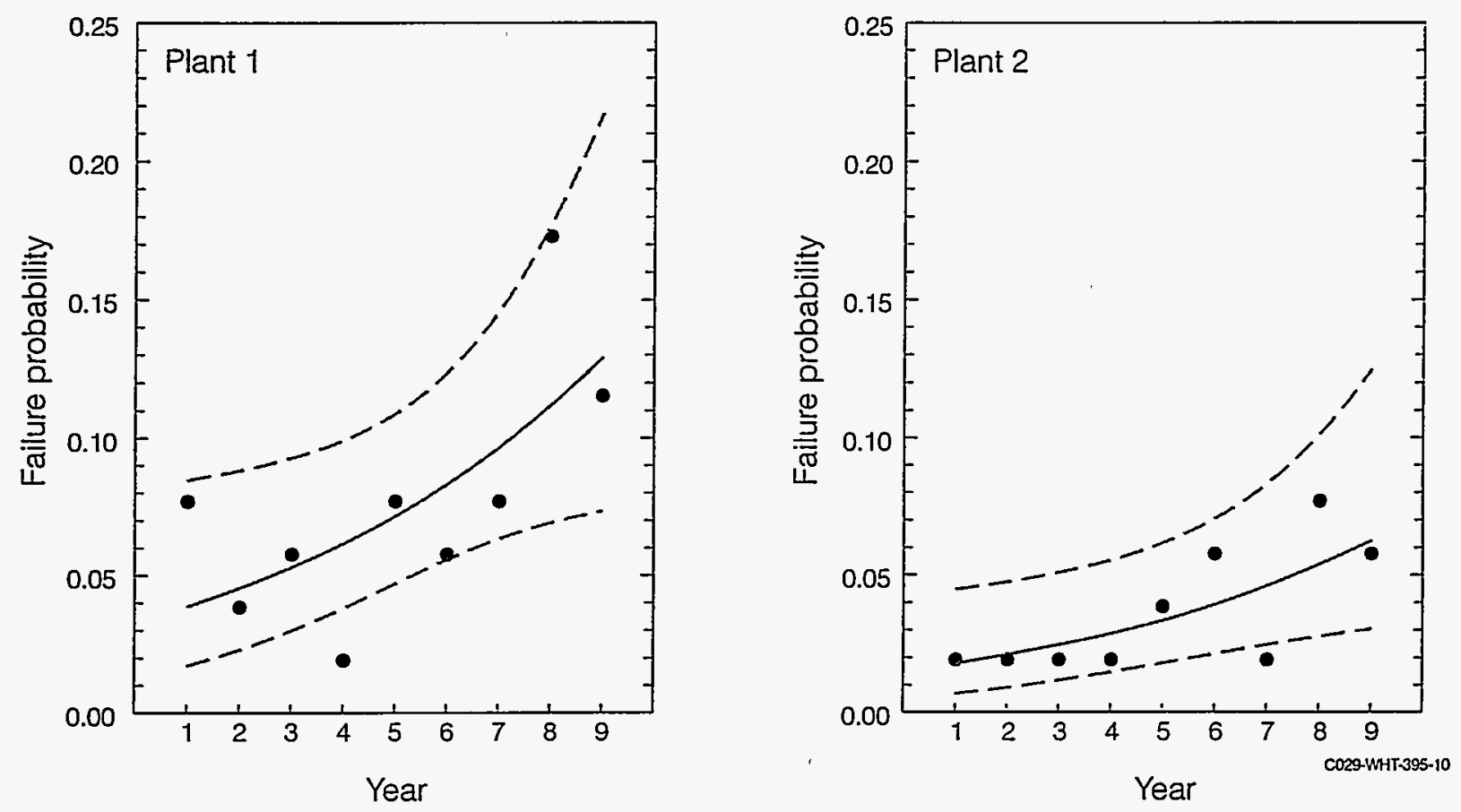

Figure 8-1. Fitted trend lines for the failure probability and simultaneous confidence bands on the fitted lines at the two Finnish plants.

be noted, however, that the collection of such data (ultrasonic measurements for example) can be very costly.

Because of a lack of data, passive components are sometimes studied by simulations. The Finnish report by Simola (1992) describes a simulation of intergranular stress corrosion. The simulated cracks typically resulted in leak, not rupture. However, the simulated cracks differed significantly in size and shape from actual cracks in removed pipe sections. U.S. authors Phillips et al. (1994) performed a similar simulation of crack growth from fatigue resulting from thermal cycles. They also found a strong tendency for leak before rupture, especially later in life, but did not compare the simulations to actual measurements.

\subsection{Conclusions}

For active components:

- Aging is found as a qualitative contributor to many failures, but the details are difficult to compare from country to country.
- Significant trends of increasing failure rates or failure probabilities have not been found. Possible exceptions are (a) the U.K. GNSR report on mechanical valves, where the results are tentative because of limited data; (b) the French study of 6.6-kV circuit breakers at the Bugey plant, where the increase was mitigated and the failure rate dropped after a problem was identified and fixed; (c) the French study of electrical relays at the Bugey plant, where the failure rate increased about fivefold in ten years; and (d) the Finnish data on valve leaks, where the failure rate increased about threefold in nine years. More commonly, the trends in failure rates have been flat or slightly decreasing. We suggest a possible reason for this lack of evident aging: maintenance work on active components corrects problems before they become very serious, preventing failure rates from increasing enough to be clearly visible in failure data. 
- Analysts in various countries use similar methodological approaches. It is common to classify observed failures by causes, including causes related to aging. Use of estimates from binned data is natural. For modeling trends of failures in time, the nonhomogeneous Poisson process has been used most heavily, although some analysts wish to make the model more realistic.

- It is easy to misapply the methods. For example, Simola (1992) mentions two analyses of a data set that yield contradictory conclusions about the trend in failure rate. In this example, the difference is explained by the fact that one of the analyses, conducted as an exercise, treated a period of missing data as having no failures. As a second example, Dunbar (1995) ${ }^{\mathrm{a}}$ mentions

a. See Section 11 of this report for bibliographic information. two analyses of one data set, one showing an increasing failure rate and one a decreasing failure rate. The apparent contradiction is resolved by noting that the first is based on times of failure measured from a single time zero and the second on times measured from the component installations, and that neither of the trends is statistically significant. As a final example, Dunbar also cites analyses from two studies of similar equipment at different plants, one showing a strong increasing failure rate and one showing a slightly decreasing failure rate. It is not clear whether the difference is real.

Aging of passive components is more difficult to assess, and is not considered in most of the submitted reports. Simulation is sometimes used to study the issue. Only one report mentioned actual data on aging of passive components. 


\section{CONCLUSIONS}

All participating countries have reported ongoing activities in their countries related to investigating nuclear power plant aging, indicating they recognize the importance of understanding and managing aging. The Japanese report, however, makes clear their position that, for their plants, there are few events attributable to aging, because deteriorated or malfunctioning components or parts are replaced when they are discovered during periodic inspection or are replaced as a result of preventative maintenance, often in response to problems experienced at other plants.

The information provided by the participants indicates that for most cases, the overall maintenance and surveillance programs serve to produce relatively constant failure rates for the active components. In addition, information provided on the evaluation of plant performance and safety system reliability confirm that aging of active components is being adequately managed at the plant and system level, in that degradation of plant performance or reduced reliability have not been observed.

In a few cases, the failure rates increased with age, indicating a time-dependent contributor to the failure parameter. This is true particularly of the case of the $6.6-\mathrm{kV}$ circuit breakers for the French Bugey plants, where the increase was significant. The problem was recognized, and then corrected by modifying the aging part and implementing an improved maintenance program. In the other cases, the indications of an increasing trend of the failure was in the incipient stage and required qualitative and statistical analyses to infer the trend, or the increases were not great enough to produce a noticeable effect on the performance of the system.

Several of the participating countries reported developments of statistical methods for evaluating failure data to provide early detection of increasing failure rates. The countries use similar statistical approaches. Use of estimates from binned data is natural. For modeling trends of failures in time, the nonhomogeneous Poisson process has been used most heavily, although some analysts wish to make the model more realistic. Finland developed analytic methods for qualitative analysis of failure modes at the item level and used statistical methods to identify the recurrence of failure modes.

The various statistical methods were shown to have the potential for monitoring the effectiveness of maintenance and surveillance programs; however, use of the methods does require extra attention to the mathematical detail. The researchers in one case reported that trend analysis tools need to be capable of considering the times between failures instead of the number of failures of different age groups. They also reported that an important step for the evaluation of aging is to establish routines for merging and grouping age-related data sources and failure modes for later meaningful statistical treatment.

Several reports indicated that accurate calculations of equipment failure rates are difficult because of problems inherent in failure data. The problems identified include:

- Difficulty in establishing the population or the total number of demands that serves as the base from which to calculate the failure rates. (Although the failures are reported, the number of pieces of equipment or the number of demands without failures are mostly not reported.)

- Difficulty in establishing the time in service or the number of demands at failure. (Often the maintenance records are for an equipment function or location and do not provide data on time of installation or replacement.)

- Difficulty choosing between obtaining a set of data that is fairly homogeneous but represents only a few failures, and obtaining a larger set of data that is less dominated by random variability but is more difficult to interpret because of differences in hardware 
characteristics, operating conditions, failure modes, etc.

- Difficulty in determining accurately the instances when preventative maintenance prevents failures from occurring.

- Use of periodic tests for determining the failure rate when the conditions for the safety function are much more severe than for the test. (Particularly for valves, the periodic tests may not be a good indication of their ability to open or close as required during an accident condition with higher differential pressure and temperature.)

Several of the reports identified lack of component-specific data from installation to removal as the major obstacle to more specific aging and maintenance studies. Aging studies and maintenance programs could be more effective if failure reports included:

- The cause of the failure

- The date the equipment entered service or was replaced

- Modifications, preventative maintenance, and corrective maintenance

- Identification of the component that failed

- The function of the equipment degraded by the failure of the component.

One report, HPCI System Performance, compared system unreliabilities observed from experience with the corresponding unreliability estimates from the plant probabilistic risk assessments (PRAs). For a single injection without recovery, the observed unreliabilities for about half the plants were in reasonable agreement with those determined from the PRAs, but for the others the observed unreliabilities were greater than three times higher than those from the PRAs. If recovery is included, all observed unreliabilities are in good agreement with those from the PRAs.

The report for the aging assessment of circuit breakers and relays reported that the observed overall failure rate for relays in the French plants was $5.2 \times 10^{-9} \mathrm{~h}^{-1}$, whereas the value adopted for the IPSN probabilistic safety studies was $3 \times 10^{-7} \mathrm{~h}^{-1}$. However, the report cautions that because the consequences of failures of relays is often not large, it is possible that not all the failures were reported.

Evaluation of the failure data indicated that in some cases the current testing and inspection may not be focusing on the dominant contribution to unreliability of the equipment. Also, in some cases there are recurring problems with reliability, in particular with steam-turbine-driven pumps and motor-operated valves, where additional effort for correction is warranted.

The study indicates that detailed qualitative and statistical analyses of failure modes and maintenance dates can identify potential aging problems in active components, and can provide a basis for preventive actions to manage those problems when adequate failure data are available and when the data are used for systematic analysis. 
$\mid$ 


\section{REFERENCES}

Andre', P. D. (1994), "Reliability Data Collection and Engineering Trend Analysis to Support Continued Operation of a UK Magnox Reactor,” PLEX ‘94, Zurich, p 504.

Ascher, Harold, and Harry Feingold (1984), Repairable Systems Reliability, New York and Basel: Marcel Dekker, Inc., pp. v-vi.

Atwood, Corwin L. (1995), Modeling Patterns in Count Data Using Loglinear and Related Models, INEL-95/0121, December.

Atwood, Corwin L. (1992), "Parametric estimation of time-dependent failure rates for probabilistic risk assessment," Reliability Engineering and System Safety, 37, pp. 181-194.

Bier, Vicki M. et al. (1990), Development and Demonstration of Methods for Nuclear Power Plant Aging Risk Analysis: Bayesian Data Analysis, EGG-SSRE-8890, April.

Boardman, John R. (1994), Special Study - Reliability of Safety-Related Steam Turbine-Driven Standby Pumps, AEOD/S94-01, October.

CSNI (1995a), Evidence of Aging Effects on Certain Safety-Related Components-Volume 1: Summary and Analysis, Committee on the Safety of Nuclear Installations, Vol. 1 of NEA/CSNI/R(95) 9, September.

EPRI (1992), Nuclear Power Plant Common Aging Terminology, Electric Power Research Institute Report TR-100844, November.

Fendick, R. C. et al. (1994), “Continued Operation of a UK Magnox Reactor,” PLEX '94 Zurich, p 217.

Grant, G. M. et al. (1995), High Pressure Coolant Injection (HPCI) System Performance, 1987-1993 Final, INEL-94/0158, February.

Hänninen, Seppo and Kari Laakso (1993), Experience Based Reliability Centered Maintenance - An Application on Motor Operated Valve Drives, STUK-YTO-TR 45, March.

IAEA (1990), Safety Aspects of Nuclear Power Plant Ageing, Vienna, International Atomic Energy Agency, IAEA-TECDOC-540.

Los Alamos Technical Associates, Inc. (1985), Application of Reliability-Centered Maintenance to Component Cooling-Water System at Turkey Point Units 3 and 4, EPRI NP-4271, October.

Marquis, G. and K. Simola (1990), "PRAISE simulation of SCC in aging BWR power plants," Proceedings of the IAEA Specialist Meeting on Nuclear Power Plant Lifetime Assurance, Swedish Nuclear Power Inspectorate, Stockholm.

Phillips, J. H., et al. (1994), "Interpretation of Probabilistic Structural Analysis of an Aging Passive Component," Journal of Pressure Vessel Technology, 116, pp. 295-301.

Pulkkinen, U. (1994), Statistical Models for Expert Judgement and Wear Prediction, 1994. Doctor's thesis, VTT Publication 181, Espoo.

Pulkkinen, U. and S. Uryas'ev (1992), "Optional Operational Strategies for an Inspected Component," European Safety and Reliability Conference '92, Copenhagen, 10-12 June 1992, p. 13, Work Report VTT/SAH 1/92. 
Ross, Denwood F., Jr. (1993) Performance Measures for Aging of Nuclear Power Plants, American Society of Mechanical Engineers Pressure Vessel and Piping Conference, PVP-Vol. 252.

Sanzo, D., et al. (1994), Survey and Evaluation of Aging Risk Assessment Methods and Applications, NUREG/CR-6157, LA-12715-MS, November.

Simola, Kaisa (1992), Probabilistic Methods in Nuclear Power Plant Component Ageing Analysis, VTT Publication 94, Espoo.

Simola, Kaisa and Kari Laakso (1992), Analysis of Failure Maintenance Experiences of Motor Operated Valves in a Finnish Nuclear Power Plant, Technical Research Center of Finland, VTT Research Notes 1322.

Wolford, A. J., C. L. Atwood, and W. S. Roesener (1992), Aging Data Analysis and Risk AssessmentDevelopment and Demonstration Study, NUREG/CR-5378, EGG-2567, August. 


\section{OTHER DOCUMENTS MENTIONED}

These are the titles of reports that, though mentioned in this report, are not formally listed as references, because they are proprietary or otherwise not publicly available.

CSNI (1995b), Evidence of Aging Effects on Certain Safety-Related Components-Volume 2: Contributions of Participating Countries, Committee on the Safety of Nuclear Installations, restricted foreign proprietary report, Vol. 2 of NEA/CSNI/R(95) 9, September.

Crosby, P. M. (1993), First Periodic Functional Review of Aging Monitoring Inspections at Calder Hall and Chapelcross Covering the Two Years up to June 1993, BNFL Internal Report RDNSC(93)P249, July.

Dunbar, L. C. (1994), "Derivation of Reliability Data for Aging Equipment" - Failure Event Data Analysis for Aging Components, June.

Dunbar, L. C. (1995), Review of UK Studies on Aging Effects on Nuclear Power Plants - Case Studies Draft A, AEA Technology Consulting Services, February.

Laakso, Kari, Kaisa Simola, and Urho Pulkkinen (1994), Reliability Assessment of Ageing and Maintenance of Components in Finnish NPPs, letter Kari Laakso to Dr. D. F. Ross, October 14.

Maupou, Michael and Jean-Michel Gama (1994), Study of the Ageing of EDT Equipment: The Case of the 6.6kV Circuit Breakers and the Electrical Relays, IPSN/DES/SERER Issue B, July 29.

NE (1993), Heysham 1, Power Station Reliability Data Collection-Phase 3, Nuclear Electric Report DD6023, Issue 1, December.

Pörn, Kurt (1995), Pilot Study - Further Development of a Trendmodel for Aging Analysis, Summary of SKI Report 94:31, Pörn Consulting, April.

Safety Information Center (1994), The Ageing Phenomena in Commercial Nuclear Power Plants in Japan, September.

Shen, Kecheng, and Ralph Nyman (1994), Inventory and Statistical Treating of Ageing Phenomena in a Swedish Nuclear Power Plant, SKI/RA Report 012/94.

Todd, Iain (1994), "Review of UK Studies on Ageing Effects on Nuclear Power Plants," presented to the CSNI/PWGI Meeting in Paris, September. 
Addendum 1

A Critique of the Generic Study of PWG1-June 1995 


\title{
Addendum 1
}

\section{A Critique of the Generic Study of PWG1-June 1995}

\author{
by H. J. Teague (Consultant to NEA)
}

\section{SCOPE OF STUDY}

Inevitably the scope of a study like this is determined by what is available to the compilers. In this instance contributors from six countries, Finland, France, Japan, Sweden, United Kingdom and United States, have provided data obtained in the course of operating commercial nuclear plants. The investigation could not, in the nature of things, be designed as an ideal scientific experiment and is rather a matter of making the best of what happens to present itself. Fortunately there has always been a keen awareness in the nuclear industry of the need to preserve plant data. A great amount of information is available around the world but making use of such data is expensive in time and money. This generic study is a notable contribution to the process.

\section{WHAT IS MEANT BY AGEING?}

As often happens in studies of this kind, a degree of confusion, or at least ambiguity, may be detected. Much of the discussion is in terms of event statistics such as failures of components but there is often an implicit recognition that ageing sometimes occurs without being revealed in changes apparent from the sort of measurements that are recorded in plant records.

A particular instance of this is found in relation to the influence of maintenance procedures. For example, the Japanese contribution makes explicit reference to progress in preventive maintenance as a possible explanation for falling failure rates as time goes on. It seems desirable to agree on whether records used to assess ageing should at least clarify whether failures are confined to those occurring in a plant run and maintained as the design and operating rules assume. As the Japanese example suggests, changes in operating practice can have a significant influence on failure rates which may not reflect a real change in the plant itself.

It is natural to pay attention to ageing effects which are reflected in statistical records, and the present study does so. However, it is more difficult to take into account ageing which may be detectable (by an experience maintenance engineer, for example) but may not have produced a reportable incident which will find its way to the statistics. This study seems to contain very little in this regard, although it may be the best hope of early warning of ageing.

\section{STATISTICAL ANALYSIS}

In view of the great difficulty of extracting the influence of age on plant behavior, which depends on a multiplicity of influences, it is perhaps not surprising that statistical manipulation and processing forms so much of the report of this study. The techniques employed are essentially to look for trends in recorded data.

Accepting the quality of the data for the moment, all the methods used rely on making the trends more visible in some way and assessing the significance of the results. The methods may be regarded as falling into two main groups-graphical, and numerical. Both are, essentially, equivalent so it is largely a matter of personal preference.

A typical application is to examine the incidence of failures in time with a view to deciding whether a change has taken place; time is brought in as a rate, or possibly, as a sequence of times between failures. Graphically a simple plot will show (as clearly as the quality of the data permits) any trends, or changes in trends (e.g., Figure 6-2). This study contains many examples of fitting data to modified Poisson distributions, usually to derive a number to characterize the way in which a rate varies with time. Essentially, none of the 
methods can create information not already in the data, but they often make the characteristics more easily seen.

A vital part of any such analysis is to assess how significant the results are, statistically. In this study most results show, at most, weak trends, of doubtful significance. It is usually clear from the graphical representation that this is so and more sophisticated statistical analyses lend to do little more than confirm the message of the graphs. The graphical presentation in addition to bringing out the trends that may be discerned also shows up limitations, such as scatter in data and possible inconsistencies.

A more serous concern is that whatever method of analysis is used, there is normally an unstated underlying assumption that the data may validly be considered a homogeneous population; that is no condemnation of this or any similar study. In the real world there are so many potential factors of influence that data have to be grouped, or "binned." The main weakness is the largely unavoidable one that the skill and judgment on the part of the analyst and data-collectors may not be sufficiently explicit.

Nevertheless, analysis of the kind reported in the study is vital to the testing of monitoring processes. In fact the study abounds with examples which demonstrate an awareness of the problems. One such is emphasized in Chapter 7, Figures 7-1 and 7-2, though the explanations offered do not seem entirely convincing. In the case of Figure 7-1 the data do not seem to bear out the existence of two populations with sharply differing ageing ratios. On the evidence cited, the data for both plants cannot be differentiated and any conclusions on trends would be unjustified. In contrast, the explanations offered for the behavior shown in Figure 7-2 do seem convincing and underline the difficulties created for analysts when significant changes are made in the middle of a program.

\section{THE BEST USE OF DATA}

The contributors to this study have shown themselves well aware of the limitations imposed by the inevitable paucity of data and this may account to some extent for the-perhaps disproportionately large-effort devoted to devising statistical models and analyzing them. In the course of this work Bayesian conditioning has been used widely, usually to update current estimates of, for example, the intensity factor for an assumed Poisson distribution in the light of more recently acquired statistical data. Has a corresponding effort gone into maximizing the raw data available? It is inevitable that data which are, strictly, not part of the same population have to be combined as though they were. The implication, in such cases, is that an expert judgment has been made that for the purposes of the analysis such blending of data can be justified. Although very full accounts have been presented for the analytical work, there seems to be no comparable discussion of the basis on which data were chosen, particularly what formal treatment was used to justify the use of expert judgment to include data obtained from distinctly different plants or operating conditions, etc.

From one point of view this could be seen as a weakness; more positively it might be explored as a way to increase the data available for analysis.

\section{PASSIVE COMPONENTS}

It seems odd that little is presented on so-called passive components. Those presumably include RPVs, steam generators, containment structures and pipework, all of which have long been seen as at least potentially of some concern on account of ageing. Possibly the CSNI/PWG structure is in danger of allowing this important matter to get lost by falling between PWG1 and PWG3. That would be unfortunate because there is much common ground in the data and analytical techniques likely to be needed.

\section{CONCLUSION}

1. PWG1 have rendered a notable service in assembling their Generic Study on Ageing, 
which draws on a range of experience and expertise in several countries

2. The material drawn upon stems from longstanding practice in plant assessment and monitoring, illuminated by the knowledge and experience of the individual contributors

3. Inevitably, difficulties in obtaining data relevant to ageing impose limitations on what can be achieved but this Generic Study contains much that will be of value to those concerned with plant assessment

4. Despite the diverse origins of the material, the resulting report emerges as a coherent and accurate summary typifying current activities on ageing

5. Attention has been drawn to possible scope for enhancing the amount of available data, perhaps by a formal procedure for incorporating expert knowledge

6. It is also noted that the Generic Study seems to exclude consideration of so-called passive components, which presumably rules out consideration of RPVs, steam generators, containments and pipework, all of which seem to be vulnerable to ageing. 
Evidence of Aging Effects on Certain Safety-Related Components

8. PERFORMING ORGANIZATION - NAME AND ADDRESS IIf NRC, provide Division, Office or Region, U.S. Nuclear Regulatory Commission, and mailing address; if contractor, provide name snd mailling address.)

Idaho National Engineering Laboratory

Lockheed Idaho Technologies Company

Idaho Falls, ID 84315

9. SPONSORING ORGANIZATION - NAME AND ADDRESS IIf NRC, type "Same as above"; if contractor, provide NRC Division, Office or Region, U.S Nuclear Regulatory Commission, and maillng address,

Safety Programs Division

Office for Analysis and Evaluation of Operational Data

U.S. Nuclear Regulatory Commission

Washington, DC 20555-0001

10. SUPPLEMENTARY NOTES

11. ABSTRACT (200 words or less)

In response to interest shown by the Nuclear Energy Agency (NEA), Principal Working Group 1 (PWG-1) of the Committee on the Safety of Nuclear Installations (CSNI) conducted a generic study on the effects of aging of active components in nuclear power plants. (This focus on active components is consistent with PWG-1's mandate; passive components are primarily within the mandate of PWG-3.) Representatives from France, Sweden, Finland, Japan, the United States, and the United Kingdom participated in the study by submitting reports documenting aging studies performed in their countries. This report consists of summaries of those reports, along with a comparison of the various statistical analysis methods used in the studies. The studies indicate that with some exceptions, active components generally do not present a significant aging problem in nuclear power plants. Design criteria and effective preventative maintenance programs, including timely replacement of components, are effective in mitigating potential aging problems. However, aging studies (such as qualitative and statistical analyses of failure modes and maintenance data) are an important part of efforts to identify and solve potential aging problems. Solving these problems typically includes such strategies as replacing suspect components with improved components, and implementing improved maintenance programs.

Nuclear plant aging, failure rates, statistical analyses, maintenance, plant reliability, active components (valves, turbines, relays, circuit breakers)

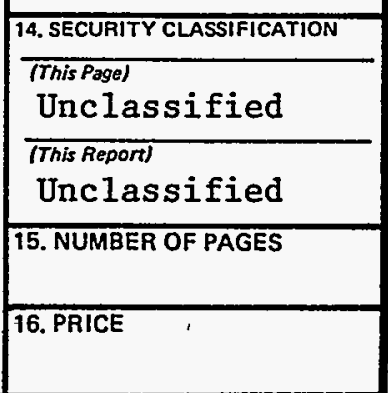



x

- 
$\hat{\theta}$ 


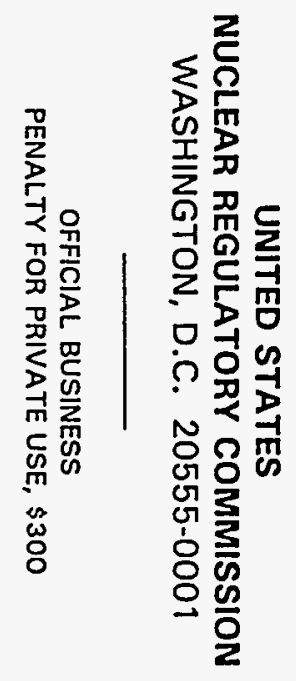

